Pontifícia Universidade C Católica

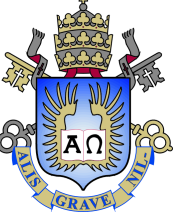

Patrícia de Sousa Oliveira

Otimização da Agenda de Manutenção das

Turbinas de uma Usina Hidrelétrica

Dissertação de Mestrado

Dissertação apresentada como requisito parcial para obtenção do grau de Mestre pelo Programa de Pós-graduação em Engenharia de Produção, do Departamento de Engenharia Industrial da PUCRio.

Orientador : Prof. Fernando Luiz Cyrino Oliveira Coorientador: Prof. André Luís Marques Marcato 


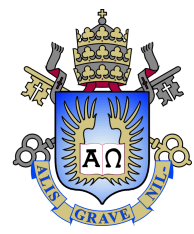

Patrícia de Sousa Oliveira

\title{
Otimização da Agenda de Manutenção das Turbinas de uma Usina Hidrelétrica
}

Dissertação apresentada como requisito parcial para obtenção do grau de Mestre pelo Programa de Pós-graduação em Engenharia de Produção da PUC-Rio. Aprovada pela Comissão Examinadora abaixo:

\author{
Prof. Fernando Luiz Cyrino Oliveira \\ Orientador \\ Departamento de Engenharia Industrial - PUC-Rio
}

Prof. André Luís Marques Marcato

Coorientador

Universidade Federal de Juiz de Fora - UFJF

Prof. Reinaldo Castro Souza

Departamento de Engenharia Industrial - PUC-Rio

Prof. João Alberto Passos Filho

Universidade Federal de Juiz de Fora - UFJF

Rio de Janeiro, 25 de março de 2021 
Todos os direitos reservados. A reprodução, total ou parcial do trabalho, é proibida sem a autorização da universidade, do autor e do orientador.

\section{Patrícia de Sousa Oliveira}

Graduou-se em Engenharia de Produção pela Faculdade Machado Sobrinho (Juiz de Fora, Minas Gerais). Pesquisadora do P\&D Fator de Disponibilidade de UHEs: Sistema de Apuração e Simulação Através de Técnicas Inteligentes com Foco na Análise de Risco contrato pela Usina Hidrelétrica Santo Antônio Energia. Projeto executado através da Universidade Federal de Juiz de Fora (UFJF).

Ficha Catalográfica

Oliveira, Patrícia de Sousa

Otimização da Agenda de Manutenção das Turbinas de uma Usina Hidrelétrica / Patrícia de Sousa Oliveira; orientador: Fernando Luiz Cyrino Oliveira; coorientador: André Luís Marques Marcato. - 2021.

79 f: il. color. ; $30 \mathrm{~cm}$

Dissertação (mestrado) - Pontifícia Universidade Católica do Rio de Janeiro, Departamento de Engenharia Industrial, 2021.

Inclui bibliografia

1. Engenharia Industrial - Teses. 2. Fator de Disponibilidade. 3. Otimização. 4. Análise Hierárquica do Processo. 5. Agenda. 6. Manutenção.

I. Oliveira, Fernando Luiz Cyrino. II. Marcato, André Luís Marques. III. Pontifícia Universidade Católica do Rio de Janeiro. Departamento de Engenharia Industrial. IV. Título.

CDD: 658.5 


\section{Agradecimentos}

Agradeço primeiramente à Deus, pois é Ele que me dá forças e guia-me para o melhor caminho todos os dias.

Agradeço aos meus pais, Jair e Lucimar, por sempre me incentivaram à estudar. Dizendo ser o maior bem a qual poderiam me deixar. Além de tudo, por toda paciência, carinho e compreensão neste anos de estudo.

Em especial, ao meu noivo Wilian, por estar sempre ao meu lado, me apoiando e principalmente incentivando a seguir esta carreira acadêmica. Obrigada também por me ouvir, entender e aconselhar. Além disso por me amar e fazer parte da minha vida.

Aos meus irmãos Josias e Carlos Eduardo, por tornarem minha vida mais divertida e alegre, principalmente nos finais de semana de relaxamento na nossa casa na roça.

Ao professor Fernando Cyrino, pela orientação e pela iniciativa do MINTER, ter a oportunidade de fazer parte dessa turma, foi um diferencial enorme na minha vida.

Agradeço ao professor André Marcato, pela coorientação, conselhos, dedicação e por ter apostado no meu trabalho, oferecendo a oportunidade de trabalharmos juntos no P\&D executado na Universidade Federal de Juiz de Fora (UFJF). Este último ano, pude obter uma imersão de conhecimento, a qual não tenho palavras para agradecer.

Aos amigos que pude fazer na turma de Mestrado, em especial ao Guilherme, Ramon e Hugo, que me ajudaram em alguns momentos difíceis dessa jornada, além de torcerem para o meu sucesso profissional e pessoal.

Aos amigos que também fiz no Projeto, em especial, à Elisa, Marcos e Lucas, que colaboraram imensamente na elaboração deste trabalho.

A minha amiga Híngred, por compreender as dificuldades do Mestrado e portanto estar sempre me dando forças para continuar seguindo em frente.

Agradeço especialmente ao Giovani Junqueira, pelo êxito na coordenação do projeto de $\mathrm{P} \& \mathrm{D}$, orientando as pesquisas e tornando possível o desenvolvimento deste trabalho.

À Universidade Federal de Juiz de Fora e a Usina Hidrelétrica Santo Antônio Energia, através do P\&D ANEEL N ${ }^{\circ}$ CT.PD.318.2019, pelo apoio financeiro para realização deste trabalho.

Por último, mas não menos importante, gostaria de agradecer à PUC-Rio pela bolsa de isenção de mensalidades do mestrado.

O presente trabalho foi realizado com apoio da Coordenação de Aperfeiçoamento de Pessoal de Nível Superior - Brasil (CAPES) - Código de Financiamento 001 . 


\section{Resumo}

Oliveira, Patrícia de Sousa; Oliveira, Fernando Luiz Cyrino; Marcato, André Luís Marques. Otimização da Agenda de Manutenção das Turbinas de uma Usina Hidrelétrica. Rio de Janeiro, 2021. 79p. Dissertação de Mestrado - Departamento de Engenharia Industrial, Pontifícia Universidade Católica do Rio de Janeiro.

O planejamento do cronograma de manutenção de unidades geradoras de usinas hidrelétricas é assunto de grande interesse para diversos agentes do setor de energia brasileiro. Uma abordagem correta para este problema, pode prevenir a degradação dos ativos físicos e minimizar a probabilidade de desligamentos forçados de seus equipamentos. Logo, as estratégias operacionais dos agentes são também influenciadas pelo cronograma de manutenção das turbinas. Porém, o sistema brasileiro possui algumas particularidades, a qual os grupos econômicos que vencem o leilão para a construção de novas usinas hidrelétricas, atendam a uma série de especificações técnicas, dentre elas, o Fator de Disponibilidade (FID). O FID é diretamente influenciado pelas horas de manutenção realizadas na usina e, em caso de desempenho abaixo do estipulado nos contratos de concessão, pode acarretar em perdas financeiras aplicadas pela o agente regulador. Com essa motivação em mente, o presente trabalho propõe uma metodologia para Programação da Agenda da Manutenção de Geradores de uma usina hidrelétrica, desenvolvendo um modelo matemático para determinar o momento ideal para realizar a manutenção, considerando restrições operacionais e aspectos regulatórios de usinas hidrelétricas. O trabalho propõe também, a obtenção de um ranking das turbinas com a utilização do método Analytic Hierarchy Process (AHP), com base nos indicadores de manutenção da usina hidrelétrica estudada. O objetivo da classificação gerada é fornecer subsídio para auxiliar o planejamento das manutenções, de forma a aumentar a disponibilidade dos equipamentos. A metodologia de otimização proposta para este problema é feita através de Programação Linear Inteira Mista (PLIM), onde as variáveis inteiras consistem no estado de operação e data de início da manutenção de cada unidade geradora. A representação do parque hidrotérmico é desafiadora, principalmente, devido à estocasticidade das vazões naturais afluentes. Ao final, para validar a modelagem proposta, é realizado um estudo de caso para uma planta real de grande porte do sistema brasileiro, a Usina Hidrelétrica Santo Antônio.

\section{Palavras-chave}

Fator de Disponibilidade; Otimização; Análise Hierárquica do Processo; Agenda; Manutenção; 


\section{Abstract}

Oliveira, Patrícia de Sousa; Oliveira, Fernando Luiz Cyrino (Advisor); Marcato, André Luís Marques (Co-Advisor). Optimization of the Maintenance Schedule for the Turbines of a Hydroelectric Plant. Rio de Janeiro, 2021. 79p. Dissertação de Mestrado - Departamento de Engenharia Industrial, Pontifícia Universidade Católica do Rio de Janeiro.

The planning of the maintenance schedule of hydroelectric power plant generating units is a matter of great interest to several agents in the Brazilian energy sector. A correct approach to this problem can prevent the degradation of physical assets and minimize the likelihood of forced shutdown of your equipment. Therefore, the agents' operational operations are also influenced by the turbine maintenance schedule. However, the Brazilian system has some particularities, which the economic groups that win the auction for the construction of new hydroelectric plants, meet a series of technical specifications, among them, the Availability Factor (AFA). The AFA is directly influenced by the hours of maintenance performed at the plant and, in case of performance below the stipulated in the concession contracts, it can result in financial losses applied by the regulatory agent. With this motivation in mind, the present work proposes a methodology for Programming the Maintenance Schedule of Generators of a hydroelectric plant, developing a mathematical model to determine the ideal moment to carry out the maintenance, considering operational restrictions and regulatory aspects of hydroelectric plants. The work also offers to obtain a ranking of the turbines using the Analytic Hierarchy Process (AHP) method, based on the maintenance indicators of the studied hydroelectric plant. The purpose of the generated classification is to provide subsidies to assist the planning of maintenance, in order to increase the availability of equipment. The optimization methodology proposed for this problem is done through Mixed Integer Linear Programming (MILP), where the entire variables consist of the state of operation and start data for the maintenance of each generating unit. The representation of the hydrothermal park is challenging, mainly due to the stochasticity of the affluent natural flows. At the end, to validate the proposed modeling, a case study is carried out for a real large plant in the Brazilian system, the Santo Antônio Hydroelectric Plant.

\section{Keywords}

Availability Factor; Optimization; Analytic Hierarchy Process; Schedule; Maintenance. 


\section{Sumário}

1 Introdução $\quad 14$

1.1 Contextualização do Tema e Problemática 14

$\begin{array}{lll}1.2 & \text { Descrição da Usina Hidrelétrica Estudada } & 17\end{array}$

$\begin{array}{lll}1.3 & \text { Objetivos da Pesquisa } & 19\end{array}$

$\begin{array}{lll}1.4 & \text { Justificativa } & 20\end{array}$

1.5 Estrutura da Dissertação 21

2 Referencial Teórico $\quad 22$

2.1 Sistema Elétrico Brasileiro 22

2.2 Fator de Disponibilidade (FID) 26

2.3 Manutenção Preventiva 30

2.4 Métodos Multicritério de Apoio à Decisão 31

2.5 Planejamento de Agenda da Manutenção 34

2.6 Considerações Finais 36

$3 \quad$ O Método de Análise Hierárquica do Processo (AHP) 37

$\begin{array}{lll}3.1 & \text { Contextualização } & 37\end{array}$

$\begin{array}{lll}3.2 & \text { Metodologia } & 38\end{array}$

3.3 Etapas do Método AHP 39

3.4 Aplicação do Método AHP na Usina Hidrelétrica 42

4 Modelagem Matemática Proposta $\quad 49$

4.1 Visão Geral do Modelo 49

4.2 Ordem de Prioridade para Realização da Manutenção Preventiva 51

4.3 Componentes do Sistema Hidrotérmico: Engolimento Máximo 52

4.4 Modelo Matemático Proposto para a Agenda da Manutenção 55

5 Estudo de Caso $\quad 60$

5.1 Informações Gerais 60

$\begin{array}{ll}5.2 \text { Dados Operacionais } & 61\end{array}$

5.3 Dados de Manutenção 63

5.4 Ordem de Prioridade para Realização da Manutenção Preventiva 64

6 Resultados e Discussões $\quad 65$

6.1 Resultados Obtidos com a Aplicação do Método AHP 65

6.2 Resultados Obtidos com a Modelagem Matemática Proposta 66

7 Conclusões e Sugestões de Trabalhos Futuros $\quad 71$

$\begin{array}{ll}\text { Referências bibliográficas } & 74\end{array}$

$\begin{array}{lll}\text { A Ofício } \mathbf{n}^{o} \text { 218/2011 - SRG/ANEEL } & 79\end{array}$ 


\section{Lista de figuras}

$\begin{array}{lll}\text { Figura 1.1 Exemplo de Impacto do FID } & 16\end{array}$

Figura 1.2 Composição Acionária da Santo Antônio Energia S.A. 18

Figura 2.1 Instituições do Setor Elétrico Brasileiro 23

Figura 2.2 Evolução da Capacidade Instalada e Contratada do SIN 24

Figura 2.3 Diagrama do SIN em Operação - Horizonte 2020

Figura 3.1 Estrutura Hierárquica Genérica 38

Figura 3.2 Hierarquia - Grupo de 4 pás 44

Figura 3.3 Hierarquia - Grupo de 5 pás 45

Figura 4.1 Visão Geral do Modelo 50

Figura 4.2 Fluxograma de Regras de Penalização para SAE 51

Figura 4.3 Etapas do AHP 52

Figura 4.4 Componentes de uma Usina Hidrelétrica 52

Figura 4.5 Curva Colina Genérica $\quad 54$

Figura 4.6 Fluxograma para ajuste pós-otimização 58

Figura 4.7 Fluxograma Geral da Metodologia Proposta 58

Figura 4.8 Fluxograma para ajuste pós-otimização Modificado $\quad 59$

Figura 5.1 FID da Santo Antônio Energia - 2012/2020 61

Figura 5.2 Vazão Afluente - Usina Hidrelétrica de Santo Antônio 61

Figura 5.3 Média do Indicador HDP 62

Figura 5.4 Vazão Turbinada Máxima por UG - 4 e 5 pás 63

Figura 6.1 HDF + HEDF - Grupo de 4 pás 66

Figura 6.2 TF - Grupo de 5 pás 66

Figura 6.3 Volume Turbinado e Vertido ao Longo do Ano 67

Figura 6.4 Vertimento e Número de UGs em Operação 68

Figura 6.5 Número de UGs em Operação, Manutenção e Paradas 68

Figura 6.6 UGs em Manutenção $\quad 69$

$\begin{array}{lll}\text { Figura 6.7 Calendário Final de Manutenção } & 70\end{array}$ 


\section{Lista de tabelas}

$\begin{array}{lll}\text { Tabela 3.1 } & \text { Escala de Saaty. } & 39\end{array}$

Tabela 3.2 Exemplo de uma Matriz de Critérios Genérica 40

Tabela 3.3 Índice Randômico (IR). 41

Tabela 3.4 Matriz Critérios SAE 45

Tabela 3.5 Peso de cada Critério SAE - autovetor 46

Tabela 3.6 Vetor com Autovalores e Estimativa de $\lambda \quad 46$

Tabela 3.7 Matriz Alternativas SAE - Grupo de 4 pás 47

Tabela 3.8 Matriz Alternativas SAE - Grupo de 5 pás 48

Tabela 3.9 Matriz Prioridade SAE - Grupo de 4 e 5 pás 48

Tabela 5.1 Duração da Manutenção em Dias 63

Tabela 5.2 Ordem de Prioridade Geral 64 


\section{Lista de Abreviaturas}

ANEEL - Agência Nacional de Energia Elétrica

AG - Algoritmos Genéticos

ACL - Ambiente de Contratação Livre

ACR - Ambiente de Contratação Regulada

AHP - Análise Hierárquica do Processo

AHP - Analytic Hierarchy Process

ANP - Analytic Network Process

ACO - Ant Colony Optimization

AFA - Availability Factor

BIO - Biomassa

CCEE - Câmara de Comercialização de Energia Elétrica

UFV - Centrais Geradoras Fotovoltaicas

CMSE - Comitê de Monitoramento do Setor Elétrico

CNPE - Conselho Nacional de Política Energética

MESA - Consórcio Madeira Energia S.A.

DICS - Discrete Integer Cuckoo Search

DM - Duração da Manutenção

ELECTRE - ELimination Et Choice Translation Reality

EPE - Empresa de Pesquisa Energética

FID - Fator de Disponibilidade

GF - Garantia Física

GFa - Garantia Física Apurada

GAMS - General Algebraic Modeling System

GMSP - Generator Maintenance Scheduling Problem

GA - Genetic Algorithm 
HDP - Horas de Desligamento Programado

IC - Índice de Consistência

IR - Índice Randômico

IP - Indisponibilidade Programada

MACBETH - Measuring Attractiveness by a Categorical Based Evaluation Technique

MRE - Mecanismo de Realocação de Energia

MRA - Mecanismo de Redução de Energia Assegurada

MCP - Mercado de Curto Prazo

MMAD - Métodos de Multicritério de Apoio à Decisão

MME - Ministério de Minas e Energia

MILP - Mixed Integer Linear Programming

MAUT - Multiattribute Utility Theory

MCDA - Multicriteria Decision Aid

NCIC - Non-Traditional Capital Investment Criteria

ONS - Operador Nacional do Sistema Elétrico

PSO - Particle Swarm Optimization

PCH - Pequenas Centrais Hidrelétricas

PLD - Preço de Liquidação de Diferenças

PROMETHEE - Preference Ranking Organisation Method for Enrichment Evaluations

PLIM - Programação Linear Inteira Mista

RC - Razão de Consistência

SAE - Santo Antônio Energia

SAESA - Santo Antônio Energia S.A.

SA - Simulated Annealing

SAMUG - Sistema de Apuração das Mudanças de Estados Operativos de Unidades Geradoras e Interligações Internacionais

SEB - Sistema Elétrico Brasileiro 
SIN - Sistema Interligado Nacional

TEO - Tarifa de Energia de Otimização

TEIF - Taxa Equivalente de Indisponibilidade Forçada

TEIFa - Taxa Equivalente de Indisponibilidade Forçada Apurada

TEIP - Taxa Equivalente de Indisponibilidade Programada

TOPSIS - Technique for Order Preference by Similarity to the Ideal Solution

UG - Unidade Geradora

EOL - Usina Eólica

UHE - Usina Hidrelétrica

UTE - Usina Térmica 
"Se podes?", disse Jesus: "Tudo é possível àquele que crê."

Marcos 9:23. 


\section{Introdução}

\section{1}

\section{Contextualização do Tema e Problemática}

O Sistema Elétrico Brasileiro (SEB) possui uma matriz elétrica formada atualmente (2021), de aproximadamente $83 \%$ de energia renovável com relação a capacidade instalada [1]. Dessa fonte, cerca de $63 \%$ é composta de Usinas Hidrelétricas (UHEs)[1].

Neste cenário foi criado o Sistema Interligado Nacional (SIN), que tem como função coordenar e controlar a geração de energia elétrica das numerosa usinas hidrelétricas (UHEs) de grande porte, espalhadas pelo extenso território nacional. O SIN tem como missão assegurar a transmissão de energia entre os subsistemas brasileiro (Sul, Sudeste/Centro-Oeste, Nordeste e a maior parte da região Norte), de forma segura e com os menores custos possíveis [2].

No Brasil, uma das principais formas de contratação de energia elétrica hoje são os leilões, nos quais os vencedores são escolhidos através do critério de menor tarifa, que irão fornecer energia no mercado de Ambiente de Contratação Regulada (ACR) [3]. No caso dos leilões de usinas hidrelétricas, os grupos econômicos que vencem o leilão para a construção de novos centros de geração, pactuam o compromisso de que a Usina Hidrelétrica (UHE) a ser construída atenda a uma série de especificações técnicas, a qual uma delas será detalhada à frente.

As usinas hidrelétricas conectadas ao SIN e despachadas centralizadamente pelo Operador Nacional do Sistema Elétrico (ONS) participam do Mecanismo de Realocação de Energia (MRE). Ele foi criado em virtude das diferenças hidrológicas entre as regiões do extenso território brasileiro, onde ao mesmo tempo, há períodos secos em uma região e úmidos em outra [4]. O MRE é um mecanismo financeiro com o objetivo de compartilhar o risco hidrológico entre geradores hidrelétricos, garantindo a otimização da operação do sistema hidrotérmico ao longo do ano [5].

Além disso, quando as geradoras assinam contratos de energia, assumem o risco da quantidade de energia que irão gerar de acordo com sua Garantia 
Física $(\mathrm{GF})^{12}$, podendo não gerar energia suficiente para atender o montante contratado. Neste caso, deverão comprar energia de outros agentes geradores com superavit de energia [7]. Em suma, o MRE realoca contabilmente o excedente de energia dos agentes de geração que geraram além de sua GF para aqueles que geraram abaixo [8].

Para garantir e incentivar um serviço de qualidade pelos geradores participantes do MRE, foi criado o Mecanismo de Redução de Energia Assegurada (MRA) [9]. O objetivo do MRA é avaliar se as usinas cumpriram em um determinado período os seus respectivos requisitos de disponibilidade de geração.

A avaliação é feita para cada usina, através de uma comparação entre os valores esperados (definidos em contrato) de interrupção programada e forçada das suas unidades geradoras (UGs), com os seus seus respectivos valores verificados ao longo do tempo. Para verificar a disponibilidade das hidrelétricas, o MRA utiliza o Fator de Disponibilidade (FID), que está descrito na Resolução Normativa $n^{\circ}$ 614/2014 (em vigor) [9].

A disponibilidade avaliada no cálculo do FID é contabilizada através de índices de indisponibilidades, são eles: Taxa Equivalente de Indisponibilidade Programada (TEIP) e Taxa Equivalente de Indisponibilidade Forçada Apurada (TEIFa). Essas taxas seguem valores de referência, denominadas de Taxa Equivalente de Indisponibilidade Forçada (TEIF) e de Indisponibilidade Programada (IP), que são definidos em contrato, como já descrito anteriormente $[9]$.

O FID é utilizado para reduzir matematicamente, ou seja, apenas para fins de penalidade de lastro para venda de energia, a GF das usinas para o compartilhamento do risco hidrológico no MRE. Ele é uma forma de verificar o desempenho das usinas, relacionando-se diretamente com as manutenções realizadas.

Em vista disso, o seu planejamento obtém destaque nas tomadas de decisões estratégicas da organização, sendo necessário ferramentas que direcionem o gestor a programar as manutenções de seus equipamentos, de forma que os desligamentos necessários impactem o menor possível nas perdas financeiras relacionadas ao FID.

Assim, com a redução da GF, o agente será impactado financeiramente, já que a usina necessitará comprar uma maior quantidade de energia de outros

${ }^{1}$ Garantia Física de uma usina corresponde à fração a ela alocada da Garantia Física do Sistema $^{2}$ e independe da sua geração real, está associada às condições hidrológicas de longo prazo da usina, assumindo um critério específico de risco do não atendimento do mercado [6].

${ }^{2}$ Garantia Física do Sistema corresponde à máxima carga que pode ser suprida a um risco de não atendimento da mesma, obtida por meio de simulações da operação, utilizando séries sintéticas de energia afluente [6]. 
geradores para atender seus requisitos contratuais. A Figura 1.1 exemplifica o impacto do FID para uma usina hidrelétrica genérica, que teve sua GF reduzida pelo FID, devido a altas horas de interrupção.

A esquerda, na Situação 1, encontra-se a usina antes da aplicação do MRA, nela é possível perceber que a geração desta usina hipotética foi menor que o estipulado no contrato de venda. Em vista disso, ocorre a aplicação do MRA na Situação 2, onde a Garantia Física apurada (GFa), sofre influência do FID. Isso quer dizer que matematicamente, a GF da usina é reduzida.

Após a redução, o MRE atua realocando energia (área em azul escuro) de outras usinas que geraram acima de sua GF, sendo valorada pela Tarifa de Energia de Otimização (TEO). Entretanto, como houve redução da GF, o agente não conseguirá atender seus contratos de venda de energia e terá que adquirir esse deficit de energia (área sombreada de vermelho) no Mercado de Curto Prazo (MCP).

A aquisição de energia no MCP é valorada pelo Preço de Liquidação de Diferenças (PLD), o qual assume valores elevados em comparação à TEO [7]. Dessa forma, estudos relacionados ao FID são de grande importância para as usinas hidrelétricas do Brasil, já que um desempenho ruim das disponibilidades pode ocasionar grandes impactos financeiros.

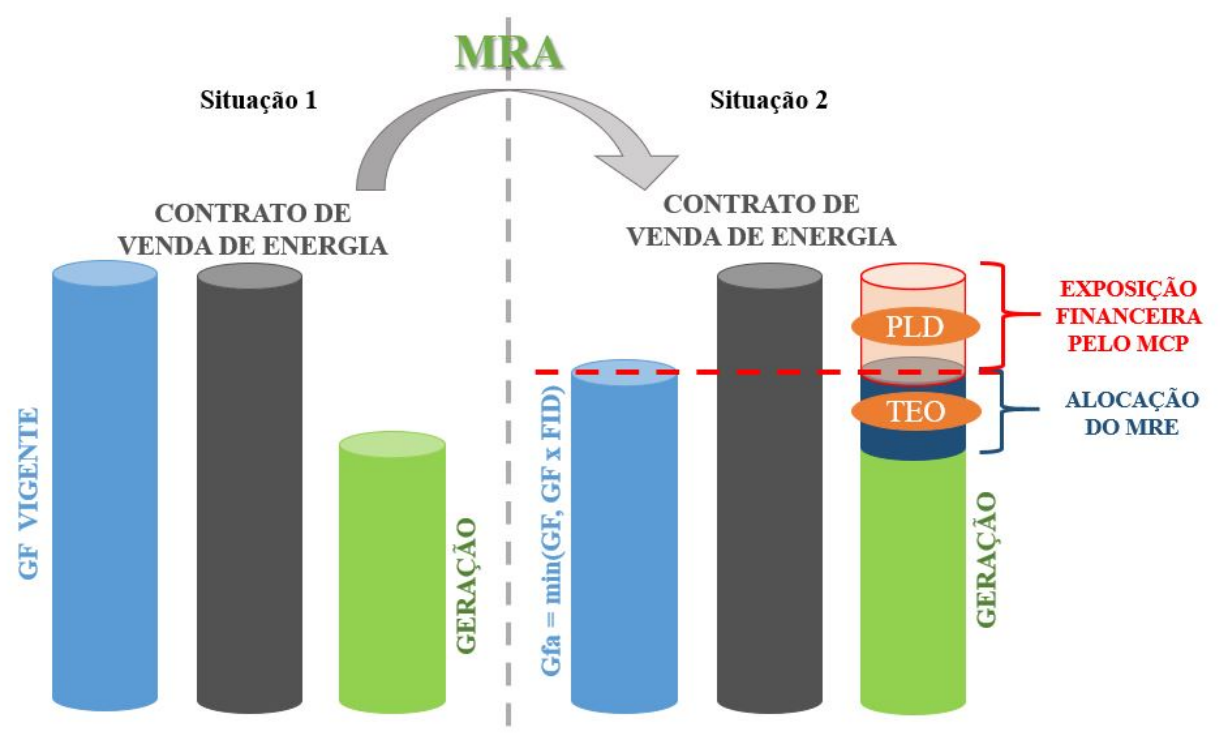

Figura 1.1: Exemplo de Impacto do FID

Fonte: Adaptado de [7]

Para mitigar esses problemas é ideal que as manutenções preventivas das usinas sejam programadas ao longo do ano de forma otimizada, minimizando as penalizações que são contabilizadas como horas de interrupções, as quais impactam negativamente nos valores de FID da usina. 
Vale ressaltar, que essas interrupções para realização de manutenções, são contabilizadas nas usinas Santo Antônio, Jirau e Belo Monte, apenas quando há impacto ao sistema, ou seja, quando impacta em uma geração abaixo do demandado pelo sistema [10]. Nas demais usinas brasileiras também é contabilizado as horas de interrupções, porém de forma diferente. As regras regulatórias com relação ao que acontece nessas três usinas, serão melhor detalhadas no decorrer deste trabalho.

Em vista disso, um dos maiores desafios das usinas hidrelétricas é encontrar o cronograma de manutenções ideal e que atenda a demanda de manutenção das instalações, principalmente das UGs. Deve-se buscar respeitar sempre as restrições de duração da manutenção, mão-de-obra disponível, periodicidade, continuidade, inflexibilidade, janela de tempo permitida, entre outras. Além disso, principalmente atender os limites das taxas de manutenção calculadas no FID, para que não sofra grandes perdas financeiras como vem ocorrido em algumas delas.

Baseado nos pontos apresentados, este trabalho propõe uma metodologia para Programação da Agenda de Manutenção de Geradores, em inglês Generator Maintenance Scheduling Problem (GMS ou GMSP). O objetivo é construir um problema de otimização para agendar ao longo do ano as manutenções preventivas necessárias para cada UG.

A modelagem proposta tem como foco minimizar as penalizações por paradas, levando em consideração restrições operativas da usina e a duração de cada manutenção desejada. Para isso, calcula-se de forma ótima, para todos os dias do ano, o estado operativo das unidades geradoras e também o dia de início das manutenções estabelecidas previamente.

\section{2}

\section{Descrição da Usina Hidrelétrica Estudada}

A usina escolhida para esboçar o estudo de caso, é a Usina Hidrelétrica Santo Antônio, objeto de concessão pelo Consórcio Madeira Energia S.A. (MESA). Ela está situada no Rio Madeira em Porto Velho, cidade do estado de Rondônia.

Esta usina iniciou suas operações em 30 de março de 2012 por meio da concessionária Santo Antônio Energia S.A. (SAESA), que é um grupo formado por empresas públicas e privadas que são líderes na implantação e operação de hidrelétricas, são elas: Furnas Centrais Elétricas S.A. (43,06\%), Caixa FIP Amazônia Energia (19,63\%), Odebrecht Energia do Brasil S.A. (18,25\%), SAAG Investimentos S.A. (10,53\%) e Cemig Geração e Transmissão S.A. (8,53\%) [11]. A Figura 1.2 ilustra esta situação. 


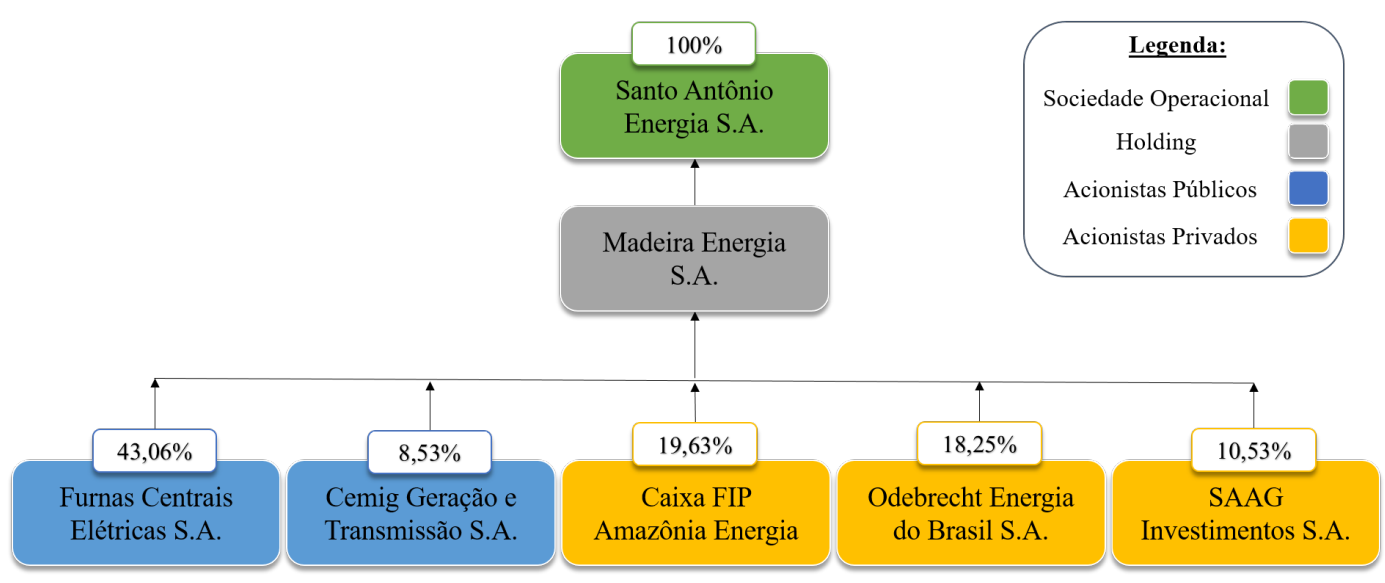

Figura 1.2: Composição Acionária da Santo Antônio Energia S.A. Fonte: Adaptado de [11] Última Atualização: 27 de Março de 2019

A Santo Antônio Energia (SAE) possui turbinas do tipo Bulbo [11]. Sua principal característica é o aproveitamento da alta vazão do Rio Madeira no período de cheia, implicando num reservatório reduzido e com pequena queda d'água, a qual ocupa uma área um pouco maior, que a ocupada no alagamento da região no período de chuva, antes da usina ser construída [11].

Esse tipo de usina é conhecido como usina fio d'água e tem o objetivo de alcançar a máxima eficiência, com o mínimo impacto socioambiental. A Santo Antônio tem potência instalada de 3.568 MW e 2.424,20 MWmed de energia assegurada, energia gerada por 50 turbinas de dois tipos, de 4 e 5 pás, uma característica importante é que as turbinas do grupo de 4 pás ficam paradas cerca de 3 meses por ano, isto ocorre durante o período de baixas vazões por restrição de queda [11].

No Edital do Leilão $n^{o}$ 005/2007, referente a contratação da UHE Santo Antônio Energia, os valores de referência da TEIF e IP definidos para a SAE foram 0,5 e $0,0 \%$, respectivamente, porém, o que tem ocorrido na prática são índices de indisponibilidade forçada e programada acima do proposto no referido edital de licitação, reduzindo a GF da usina através do FID e levando à um impacto financeiro.

Por exemplo, as penalidades aplicadas à usina devido a violação deste requisito somam cerca de $\mathrm{R} \$ 812$ milhões para a Santo Antônio em 2018 [12], portanto estudos relacionados ao FID da usina são de extrema relevância para o agente.

Sobre a comercialização de energia da Santo Antônio Energia, foi firmado em contrato que ela deveria dispor de pelo menos $70 \%$ de energia ao Ambiente de Contratação Regulado (ACR) e os outros 30\% seriam destinados ao Ambiente de Contratação Livre (ACL) [13]. 


\section{3 \\ Objetivos da Pesquisa}

Este trabalho tem como objetivo desenvolver um modelo matemático para determinar o melhor momento para realizar as manutenções das turbinas da Santo Antônio Energia. Uma vez que, nos períodos de baixa vazão, que são bem definidos na SAE, existe a flexibilidade da realização das manutenções sem ocorrer penalidades relacionadas ao Fator de Disponibilidade. Como pode ser visto no Anexo A, a penalidade ocorre somente quando o Operador Nacional do Sistema Elétrico verifica vertimento na usina e este ocorrer por responsabilidade dela [10].

A elaboração do modelo matemático para solução do problema é uma tarefa complexa, decorrente de problemas conhecidos na otimização de Scheduling. Os problemas de agendamento são muito comuns em diversos tipos de indústria e principalmente nas áreas de estratégia, buscando retornos financeiros significativos, neste sentindo, o setor de energia não é diferente.

Propõe-se também, fazer a classificação das turbinas utilizando o método de multicritério Análise Hierárquica do Processo ou, em inglês, Analytic Hierarchy Process, (AHP) com o intuito de priorizar no modelo matemático as unidades geradoras mais críticas para a realização da manutenção preventiva, com objetivo aumentar a disponibilidade dos equipamentos, evitando paradas forçadas, o qual tem consequências diretas no FID.

Será realizado também, o cálculo de alguns componentes do sistema hidrotérmico, que serão necessários para encontrar o Turbinamento Máximo de cada Unidade Geradora. Para este objetivo é preciso obter a previsão de vazão do Rio Madeira (local onde a SAE está construída) que servirá de input para o cálculo dos componentes Nível à Montante do Reservatório, Nível à Jusante do Reservatório, Queda Bruta, Queda Líquida e por fim, o Engolimento Máximo de cada turbina.

Portanto, as principais contribuições dessa dissertação e suas delimitações são:

- Elaboração de um modelo de otimização da agenda diária da manutenção preventiva das turbinas no período de um ano;

- Aplicação do método AHP para classificação de turbinas hidráulicas utilizando parâmetros de disponibilidade e manutenção;

- Planejamento da agenda da manutenção preventiva, com aproveitamento máximo de turbinamento de cada turbina em função da vazão média prevista; 
- Mitigação das penalizações regulatórias através da aplicação do GMS, considerando restrições operativas e de manutenção das unidades geradoras;

- Aumento a disponibilidade de geração hídrica, fonte renovável e de baixo custo, priorizando a manutenção nos momentos em que não há vazão afluente suficiente para operar todas as UGs;

- Estudo de caso real em uma usina hidrelétrica brasileira de grande porte.

\section{4}

\section{Justificativa}

A importância desse estudo é justificada pela gravidade do problema, ocasionando perda de receita nas usinas hidrelétricas de todo o país. Além disso, o modelo apresentado poderá ser utilizado como direcionamento para as demais usinas do mercado.

O estudo de caso tem como oportunidade, ser aplicado em uma das maiores geradoras hídricas de energia do Brasil, a Usina Hidrelétrica Santo Antônio, visto que vem apresentando um deficit significativo em sua receita, devido a aplicação do FID. Dessa forma, o estudo deste indicador é de grande importância para as geradoras, já que um desempenho ruim das disponibilidades pode ocasionar grandes impactos negativos no fluxo de caixa das usinas.

Devido a relevância do FID para as usinas, diversos trabalhos trazem o assunto como discussão. Inicialmente, destaca-se a dissertação apresentada por [14], onde o autor contribui com propostas de procedimentos mais adequados para aumentar o indicador de disponibilidade das unidades geradoras, voltadas principalmente para melhorias no planejamento da manutenção, passando a atuar como papel estratégico na empresa.

Na dissertação apresentada por [15] é proposto um modelo de sazonalização de energia assegurada de usinas hidrelétricas utilizando Algoritmos Genéticos (AG) para minimização da perda esperada e do risco com a sazonalização influenciada pela aplicação do FID.

No trabalho de [16], tem como contexto, reduzir a exposição do Mecanismo de Redução de Energia Assegurada e, portanto, sugere como melhoria, novas perspectivas de processos internos direcionados aos indicadores confiabilidade e suportabilidade e manutenabilidade que estão diretamente ligados no desempenho do FID, enfatizando a importância.

Neste contexto, finaliza-se com o estudo apresentado por [17], que se trata também da Usina Hidrelétrica Santo Antônio, cujo principal objetivo é analisar todo o processo da questão judicial promovida pela SAE, devido sua 
insatisfação com a apuração do Fator de Disponibilidade, trazendo detalhes sobre todos os conceitos envolvidos.

É importante ressaltar que a maioria dos trabalhos encontrados utilizam programação heurística ou meta-heurística para resolver os problemas de GMS. A necessidade existe porque os modelos exatos têm baixa eficiência computacional em sua aplicação. No entanto, este trabalho busca preencher essa lacuna, por meio de um modelo determinístico aplicado em um caso real, uma grande hidrelétrica, observando os aspectos regulatórios e construtivos.

\section{5 \\ Estrutura da Dissertação}

Esta dissertação está organizada em sete capítulos. No primeiro tópico, já abordado, encontra-se a questão problema, através da contextualização do tema. Encontra-se também, uma breve descrição da usina utilizada no estudo de caso e além disso, os objetivos e justificativas do trabalho.

No segundo capítulo, aborda-se os tópicos relacionados ao embasamento teórico, destacando as definições dos conceitos relacionados ao problema abordado. Nele é possível entender como funciona de forma geral, o Sistema Elétrico Brasileiro. Além disso, compreende-se também, as regras operativas que envolvem o indicador chamado de Fator de Disponibilidade, citado no texto como FID. Ainda nesta seção, alguns conceitos de manutenção preventiva, métodos multicritério de apoio à decisão e sobre o planejamento da agenda da manutenção são descritos.

No terceiro capítulo, encontra-se a metodologia e aplicação do Método de Análise Hierárquica do Processo (AHP). Neste item, é demonstrado passo a passo, como aplicar o AHP através de dados reais, utilizando uma usina hidrelétrica de grande porte como exemplo.

Na sequência é apresentado a metodologia desenvolvida para este estudo, descrevendo os procedimentos a serem executados na modelagem do problema da programação ótima da manutenção preventiva. O próximo tópico, o estudo de caso, descreve-se a sua aplicação na usina estudada.

No sexto capítulo, os resultados são apresentados e discutidos. Nesta seção, os resultados encontrados após aplicação do AHP e do desenvolvimento da agenda da manutenção, são discutidos separadamente. O intuito é trazer com detalhes os benefícios de cada aplicação.

As considerações finais da pesquisa e sugestões de continuação do estudo são apresentadas no capítulo sete. Por ultimo são listadas as referências bibliográficas. 


\section{2}

\section{Referencial Teórico}

\section{1}

\section{Sistema Elétrico Brasileiro}

O Sistema Elétrico Brasileiro (SEB) possibilita o intercâmbio de energia na maior parte do território nacional, cerca de 98\%, com exceção de algumas regiões isoladas na região Norte do país [18]. Em vista disso o Sistema Interligado Nacional é formando por redes de transmissão, permitindo a transferência de energia entre os subsistemas, levando energia a todo o país.

No decorrer dos anos o SEB passou por diversas mudanças, porém o modelo atual segue ilustrado na Figura 2.1, na qual está representada a hierarquia das principais instituições que dão corpo ao setor e abaixo suas respectivas funções [19].

- Conselho Nacional de Política Energética (CNPE): é um órgão que tem a função de prestar apoio ao Presidente da República com propostas que auxiliam nas políticas energéticas do país e principalmente assegurando o suprimento de energia nas áreas mais remotas [20].

- Ministério de Minas e Energia (MME): é o órgão do Governo Federal, responsável pelo conselho do Comitê de Monitoramento do Setor Elétrico (CMSE) e do Conselho Nacional de Política Energética (CNPE), cuja finalidade é realizar o planejamento e gestão das políticas públicas, além de monitorar a segurança do suprimento de energia e ter políticas que previnem a diferença entre a energia gerada com a demanda [20].

- Empresa de Pesquisa Energética (EPE): é uma organização a serviço do MME que tem o papel de assistir no desenvolvimento de estudos e pesquisas do setor elétrico, como por exemplo, o planejamento dos recursos energéticos e de expansão [21].

- Comitê de Monitoramento do Setor Elétrico (CMSE): é um órgão que foi criado sob o comando do MME e tem a finalidade de acompanhar e verificar a continuidade do fornecimento de energia no país e a segurança do suprimento eletroenergético [20]. 
- Agência Nacional de Energia Elétrica (ANEEL): é uma autarquia que tem o papel de regularizar e fiscalizar a geração, transmissão, distribuição e comercialização de energia elétrica, além de estabelecer tarifas e atividades que promovem as outorgas e concessões de empreendimentos de energia elétrica [18].

- Operador Nacional do Sistema Elétrico (ONS): organização sem fins lucrativos que tem como papel operar, supervisionar e controlar a geração de energia no Sistema Interligado Nacional, ela é regulamentada e fiscalizada pela ANEEL [2].

- Câmara de Comercialização de Energia Elétrica (CCEE): empresa que administra a viabilização e bem como o nome já diz, a comercialização de energia, realizando leilões de energia elétrica, por delegação da ANEEL, além de amparar a evolução do mercado energético brasileiro $[3]$.

\section{CNPE}

Conselho Nacional de Política Energética

CMSE

Comitê de

Monitoramento do Setor Elétrico
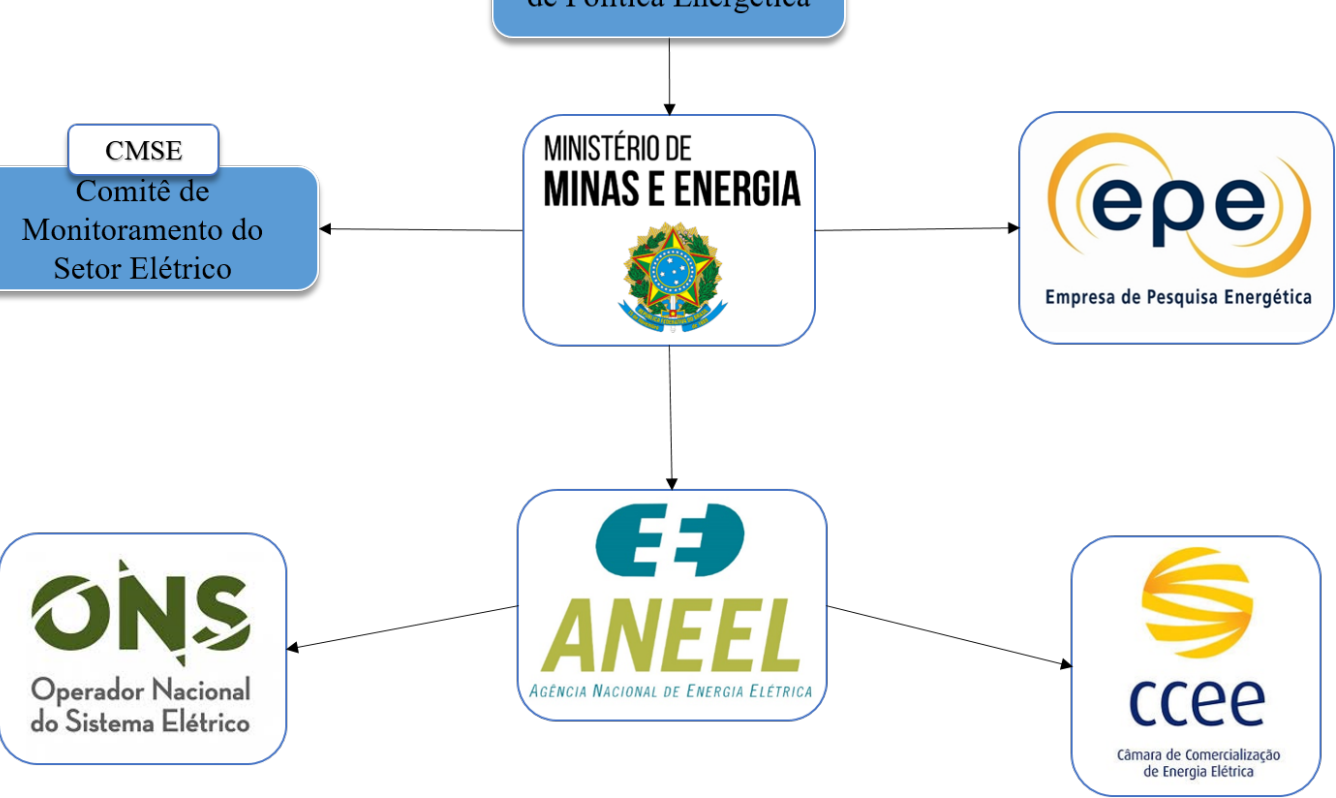

Figura 2.1: Instituições do Setor Elétrico Brasileiro Fonte: Elaboração Própria

Com relação a matriz elétrica brasileira, a atual capacidade instalada de fontes renováveis é de cerca de 83\%. Porém, o "Plano Decenal de Expansão de Energia 2030" prevê que chegue a 85\% no ano de 2030. Destaca-se ainda, que das fontes renováveis atualmente, cerca de $63 \%$ é composta de Usinas Hidrelétricas e pretende-se chegar a $64 \%$ no ano de 2030 [1]. 
Na Figura 2.2 é possível observar a projeção da Evolução da Capacidade Instalada Existente e Contratada do SIN ao longo dos anos 2020, 2025 e 2030. Ao final de dezembro de 2020, têm-se uma capacidade instalada de cerca de 172 GW [1].

De toda a capacidade instalada atualmente, aproximadamente $63 \%$ é de Usinas Hidrelétricas (UHE), 14\% de Usinas Térmicas (UTE), 11\% é de Usinas Eólicas (EOL) e Centrais Geradoras Fotovoltaicas (UFV), 8\% de Biomassa (BIO) e 4\% de Pequenas Centrais Hidrelétricas (PCH) [1].

Além disso, é possível verificar o crescimento da capacidade instalada de fontes renováveis e diminuição das não renováveis, como é o exemplo das UTEs, diminuindo aproximadamente $6 \%$.
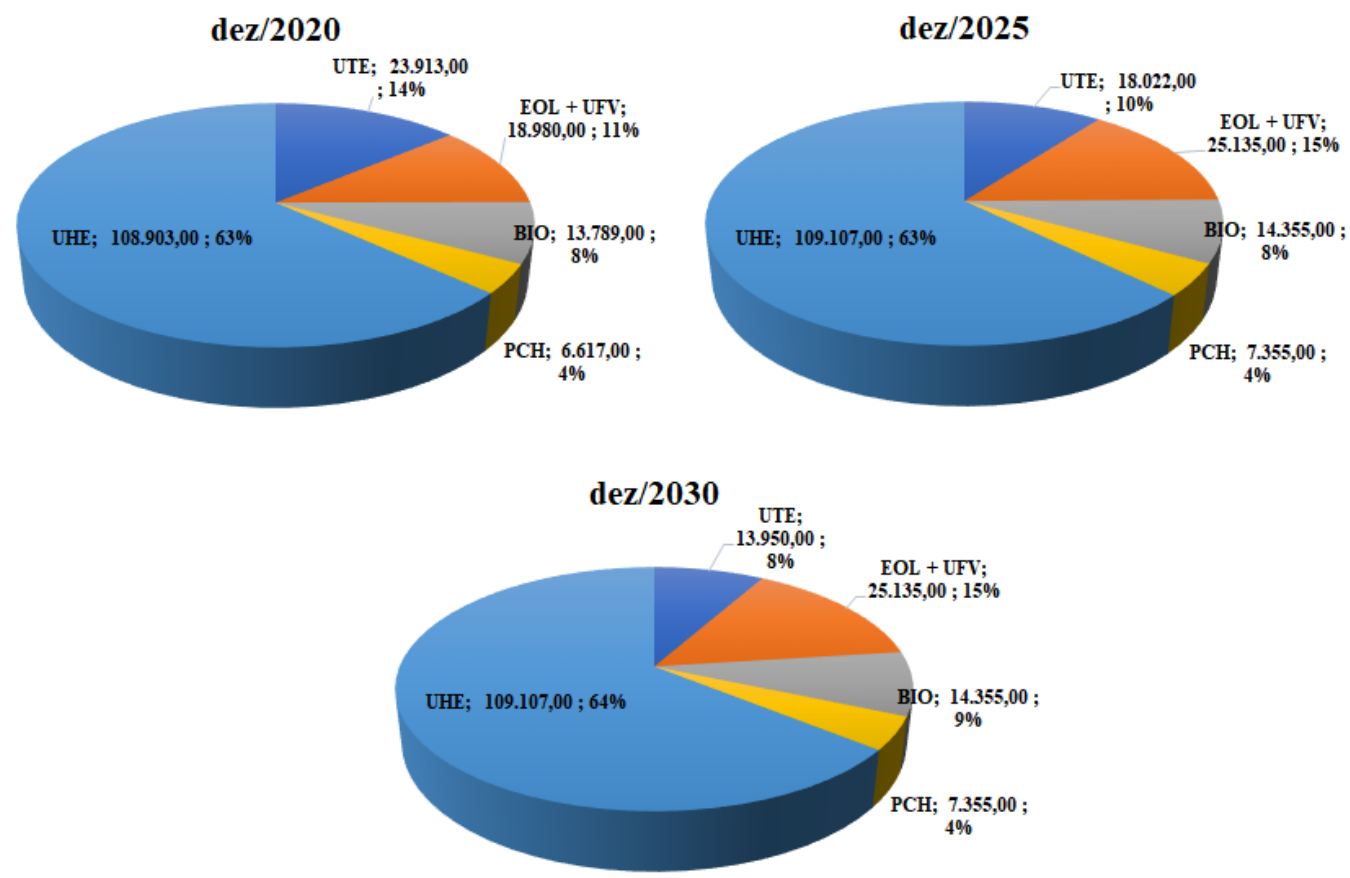

Figura 2.2: Evolução da Capacidade Instalada e Contratada do SIN Fonte: Adaptado do "Plano Decenal de Expansão de Energia 2030" [1]

Sobre este potencial de geração oriundo de fontes renováveis, ressalta-se o depoimento do secretário de Planejamento e Desenvolvimento Energético do Ministério de Minas e Energia Reive Barros (secretário na data da publicação):

O Brasil se destaca no mundo pela utilização cada vez maior de fontes renováveis, contribuindo, dessa forma, para uma redução maior da emissão de gases de efeito estufa, com valores compatíveis com os compromissos assumidos no Acordo de Paris [22]. 
Portanto, a geração e transmissão de energia elétrica brasileira tem a característica de ser um sistema hidro-termo-eólico predominantemente de usinas hidrelétricas, de grande porte e com muitos proprietários. Devido a isso o SIN tem o papel de coordenação e controle dos subsistemas Sul, Sudeste/Centro-Oeste, Nordeste e a maior parte da região Norte [2]. A sua atividade abrange realização de simulações complexas coordenadas pelo ONS, que por sua vez é regulado e fiscalizado pela ANEEL [23].

A malha de transmissão brasileira propicia a interconexão dos sistemas elétricos, proporcionando a transmissão de energia entre os subsistemas. Além disso, possibilita uma operação mais econômica e segura [2].

O mapa do Sistema Interligado Nacional pode ser visualizado na Figura 2.3. Nele é possível perceber a principal vantagem para o sistema se beneficiar de complementariedade do regime hidrológico das diferentes regiões do território nacional. Este fato está muito presente no território brasileiro devido a sua grande extensão territorial.

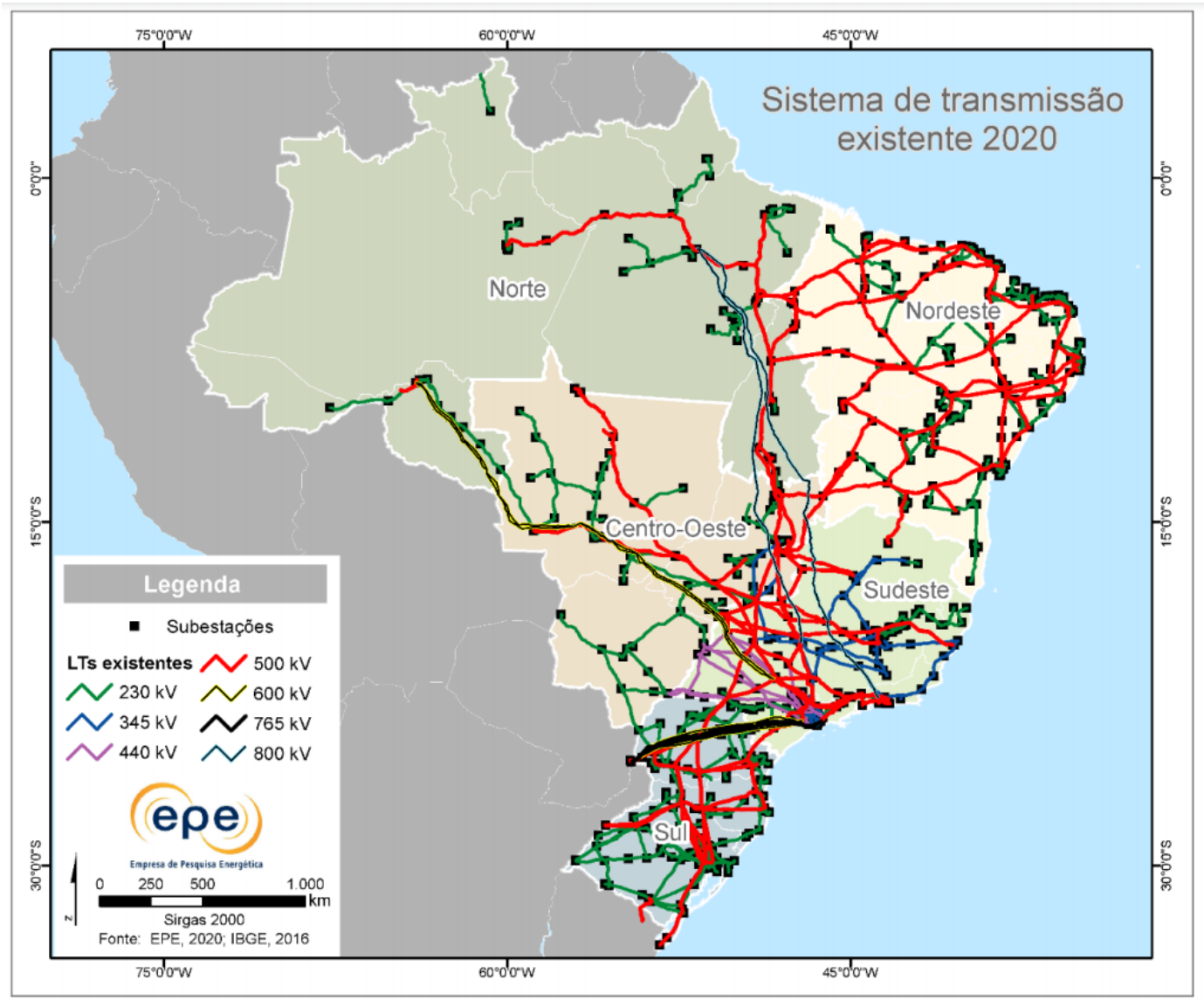

Figura 2.3: Diagrama do SIN em Operação - Horizonte 2020 Fonte: Plano Decenal de Expansão de Energia 2030 [1] 
Outra característica importante é sobre o modelo de comercialização de energia elétrica no Brasil, que atualmente pode ser realizado em dois ambientes de mercado, sendo eles o Ambiente de Contratação Regulada e o Ambiente de Contratação Livre, que acontece pela intermediação da CCEE.

- Ambiente de Contratação Regulada (ACR): ambiente no qual os preços são estipulados nos leilões de compra de energia elétrica promovidos pela CCEE, que está sob delegação da ANEEL. Os participantes são geradoras, distribuidoras e comercializadoras [3]. As comercializadoras podem negociar energia somente nos leilões de energia existente.

- Ambiente de Contratação Livre (ACL): neste ambiente participam geradoras, comercializadoras, consumidores livres e especiais e os preços são acordados livremente e estabelecidos entre o comprador e o vendedor [3].

\section{2}

\section{Fator de Disponibilidade (FID)}

O setor energético brasileiro possui diversas diretrizes que incentivam a eficiência operativa do setor. Em vista disso, existe o rigor na apuração de um indicador regulamentado pela ANEEL, chamado Fator de Disponibilidade, como já mencionado.

O FID encontra-se descrito em duas resoluções normativas da ANEEL, as Resoluções Normativas n ${ }^{o}$ 688/2003 e n n 614/2014 (em vigor). Através dessas resoluções são estabelecidas regras para o cálculo da taxa de indisponibilidade de usinas hidrelétricas e termelétricas.

A Resolução $n^{\circ}$ 688/2003 aprova as regras do mercado, que incorpora incentivo à eficiência de usinas participantes do Mecanismo de Realocação Energia (MRE) [4]. Após modificações nesta última, entra em vigor a Resolução Normativa $n^{o}$ 614/2014, que consolida as normas referentes à apuração de indisponibilidade de unidade geradora ou empreendimento de importação de energia conectados ao Sistema Interligado Nacional, estabelecendo novos critérios de apuração e de verificação [9].

O seu cálculo é resultante do efeito do Mecanismo de Redução da Energia Assegurada (MRA). No artigo $2^{\circ}$ da Resolução Normativa $n^{o}$ 614/2014, é tratado com detalhes como é aplicado ao MRA.

Na resolução é definido que o ONS deve apurar mensalmente as indisponibilidades das usinas hidrelétricas, termelétricas e empreendimentos de importação de energia elétrica despachados centralizadamente [9]. O cálculo do FID depende da potência instalada, do número de horas de desligamento, entre outros parâmetros descritos detalhadamente na resolução [9]. 
Porém, o importante é entender que as indisponibilidades avaliadas pelo ONS são apurados por meio da Taxa Equivalente de Indisponibilidade Programada (TEIP) e da Taxa Equivalente de Indisponibilidade Forçada Apurada (TEIFa). Dessa forma, para cada usina despachada centralizadamente pelo ONS, deverão ser calculados os índices TEIP e TEIFa.

Os valores são mensurados mensalmente para os 60 meses anteriores ao mês apurado (inclusive). Conforme as Equações (2-1) e (2-2).

$$
\begin{gathered}
\text { TEIP }=\frac{\sum_{j=1}^{60} \sum_{i=1}^{n} P_{i} \cdot(H D P+H E D P)_{i j}}{\sum_{j=1}^{60} \sum_{i=1}^{n} P_{i} \cdot(H P)_{i j}} \\
T E I F a=\frac{\sum_{j=1}^{60} \sum_{i=1}^{n} P_{i} \cdot(H D F+H E D F)_{i j}}{\sum_{j=1}^{60} \sum_{i=1}^{n} P_{i} \cdot(H D F+H E D F+H S+H D C E+H R D)_{i j}}
\end{gathered}
$$

Onde:

i $\quad$ índice da unidade geradora em operação comercial;

$n \quad$ Número de unidades geradoras em operação comercial;

j $\quad$ índice do mês apurado;

$P \quad$ Potência instalada da unidade geradora $i$;

HDP Número de horas de desligamento programado da unidade $i$ no mês $j$;

HEDP Número de horas de equivalentes de desligamento programado da unidade $i$ no mês $j$ (a unidade opera com potência nominal limitada, associada a uma condição programada);

HP Número de horas do período de apuração considerado no mês $j$ para a unidade $i$;

HDF Número de horas de desligamento forçado da unidade $i$ no mês $j$;

HEDF Número de horas equivalentes de desligamento forçado da unidade $i$ no mês $j$ (a unidade opera com potência nominal limitada, associada a uma condição forçada); 
HS Número de horas em serviço da unidade $i$ no mês $j$ (número de horas equivalentes em serviço somado ao número de horas em que a unidade opera sincronizada ao sistema, sem restrição de potência);

$H R D \quad$ Número de horas de reserva desligada da unidade $i$ no mês $j$ (a unidade não está em serviço por interesse sistêmico, apesar de disponível para operação);

HDCE Número de horas desligada por condições externas da unidade $i$ no mês $j$ (a unidade não está em serviço por condições externas às suas instalações).

Observando as equações acima, é possível verificar quais são os índices passíveis de alteração, otimização e planejamento, para que as taxas sejam menores. Na Equação (2-1), que indica o cálculo da TEIP, os índices envolvidos no numerador são associados as horas de manutenções programadas ou preventivas das Unidades Geradoras (UGs) e, portanto, podem ser modificadas com o devido planejamento.

Da mesma maneira, na Equação (2-2), relacionada a TEIFa, os índices do numerador, HDF e HEDF, que indicam as manutenções forçadas, conhecidas como manutenções corretivas, não são flexíveis a alterações. Porém, com o uso de ferramentas que auxiliam na gestão da manutenção, além de promover a realização de manutenções preventivas, possibilitará na diminuição de futuras paradas (manutenções corretivas).

Já os índices HP, HS, HDCE e HRD não são passíveis de modificação pelo agente pois dependem de condições externas.

Para realizar o cálculo do TEIP e TEIFa das usinas hidrelétricas, o ONS utiliza informações provenientes do Sistema de Apuração das Mudanças de Estados Operativos de Unidades Geradoras e Interligações Internacionais (SAMUG), no histórico de dados consistidos da base de dados técnica do ONS.

As mudanças de estados operativos de unidades geradoras são apuradas diariamente pelos Centros de Operação do ONS, com a participação dos agentes. Todos os eventos de mudanças de estados operativos, condição operativa e disponibilidade de unidades geradoras que operam sob despacho centralizado do ONS devem ser registrados na sua Base de Dados Técnica. Para isso, utiliza-se o sistema desenvolvido pelo ONS, chamado SAMUG.

Após o conhecimento das informações apresentadas acima, é possível executar o cálculo do FID. Isto, em função dos índices de TEIP e TEIFa apurados e dos índices referências estabelecidos em contrato de Indisponibilidade Programada (IP) e a Taxa Equivalente de Indisponibilidade Forçada (TEIF). Conforme as Equações 2-3, 2-4 e 2-5. 


$$
\begin{gathered}
I D v=(1-T E I P) \times(1-T E I F a) \\
I D=(1-I P) \times(1-T E I F) \\
F I D=\frac{I D v}{I D}
\end{gathered}
$$

Onde:

IDv Índice de Disponibilidade Verificado;

ID Índice de Disponibilidade de Referência;

IP Indisponibilidade programada;

TEIP Taxa Equivalente de Indisponibilidade Programada;

TEIF Taxa Equivalente de Indisponibilidade Forçada;

FID Fator de disponibilidade geração, valor adimensional, limitado superiormente a um.

Como citado previamente, o objetivo do MRA é reduzir matematicamente, a Garantia Física das usinas que não cumprirem os requisitos de disponibilidade, dessa forma o FID impactará diretamente na Garantia Física apurada da usina, como apresentado na Equação (2-6).

$$
G F a=\min (G F, G F \times F I D)
$$

Onde:

GFa Garantia Física apurada;

GF Garantia Física vigente (MWmed).

Portanto, caso o FID seja menor que 1, a usina avaliada terá sua Garantia Física reduzida, impactando diretamente na análise do MRE. Nesse caso, o agente será impactado financeiramente, pois a usina em questão necessitará de uma maior quantidade de energia de outros geradores para atender seus requisitos contratuais de energia assegurada [8]. 


\section{3 \\ Manutenção Preventiva}

Como visto na seção 2.2, o FID é impactado diretamente pelo desempenho das manutenções realizadas na SAE, por esse motivo a preocupação com a gestão da manutenção para tentar mitigar os efeitos negativos da aplicação desse indicador. Em vista disso, um breve referencial em torno do contexto da manutenção é apresentado nesta sub-cessão.

É importante mencionar que o conceito de manutenção vem se renovando com o decorrer do tempo, inicialmente a manutenção era vista como um mal necessário, a qual servia para consertar as máquinas e equipamentos que naturalmente quebravam. O objetivo era manter os processos produtivos em funcionamento dentro da indústria [24].

Hoje, tornou-se ponto chave no planejamento estratégico das organizações, uma vez que a função manutenção contribui significativamente para o aumento da produtividade, devendo ser considerada não apenas a ideia de conservação de máquinas e sim manter a disponibilidade do equipamento o maior tempo possível e diminuir a probabilidade de parada [25]. Portanto, a gestão da manutenção reflete na competitividade, apoiando e impulsionando a estratégia empresarial, principalmente quando se trata dos reflexos no FID.

Para a realização da gestão da manutenção é importante conhecer os tipos de manutenção existentes, que são Manutenção Corretiva, Manutenção Preventiva e Manutenção Preditiva [26].

A manutenção corretiva significa deixar as instalações continuarem a operar até que quebrem. O trabalho de manutenção é realizado somente após a quebra do equipamento ter ocorrido. Esse tipo de manutenção resulta normalmente em altos custos com trabalho extra e estoque de peças sobressalentes, parada de máquina por tempo elevado e, sobretudo, a baixa disponibilidade de produção [26].

Pode-se classificar como manutenção preventiva todo serviço de manutenção realizado em máquinas que não estejam em falha, estando com isto em condições operacionais. Ela é voltada para evitar que a falha ocorra, através de manutenções em intervalos de tempo pré-definidos, visando eliminar ou reduzir as probabilidades de falhas por manutenção (limpeza, lubrificação, substituição e verificação) das instalações em intervalos de tempo pré-planejados [26].

Já a manutenção preditiva tem como objetivo identificar o tempo correto para reparar o equipamento, evitando as desmontagens para inspeção, e utilizar o componente até o máximo de sua vida útil [24]. Ela privilegia a disponibilidade à medida que não promove a intervenção nos equipamentos, pois as medições e verificações ocorrem com o equipamento produzindo [26]. 
Atualmente, a SAE prioriza as manutenções baseadas em alguns fatores como: risco de sinistros, com longo tempo para recuperação, tempo de operação do equipamento entre as manutenções preventivas realizadas a cada 25.000 horas de operação, e sistemas que necessitam intervenções para não falhar durante o período úmido, como exemplo, os sistemas auxiliares e sistemas de vedação do eixo. Entretanto, essa priorização pode ser feita através de metodologias sofisticadas, levando em consideração diversos índices relevantes para usina.

\section{4}

\section{Métodos Multicritério de Apoio à Decisão}

O processo de tomada de decisão está presente tanto na decisões pessoais, quanto no ambiente empresarial. É um processo decisório que busca escolher uma alternativa dentre várias opções existentes e para isso existe diversas informações dessas alternativas. No contexto atual das grandes empresas, onde a competitividade é intensa, tomar decisões e/ou escolhas ficou ainda mais complexo.

Em vista disso, os Métodos de Multicritério de Apoio à Decisão (MMAD), ou em inglês, Multicriteria Decision Aid (MCDA), tem como finalidade auxiliar um tomador de decisões a fazer sua escolha através de uma modelagem computacional que envolve um problema complexo, com diversas alternativas e critérios de análise [27].

Os métodos MMAD são ferramentas extramente úteis para chegar a conclusões importantes que não podem ser encontradas de forma óbvia [28]. Hoje em dia, existem diversos métodos MMAD disponíveis para auxilio na tomada de decisão. Para selecionar o melhor método a ser aplicado nesse estudo de caso, é fundamental conhecer as principais características dos métodos mais consagrados.

Segundo [29], os métodos Multiattribute Utility Theory (MAUT), Analytic Hierarchy Process (AHP), Analytic Network Process (ANP), NonTraditional Capital Investment Criteria (NCIC), Measuring Attractiveness by a Categorical Based Evaluation Technique (MACBETH), ELimination Et Choice Translation REality (ELECTRE), Preference Ranking Organisation METHod for Enrichment Evaluations (PROMETHEE) e Technique for Order Preference by Similarity to the Ideal Solution (TOPSIS) são os mais conceituados atualmente dentre os MMAD, portanto, com referência na revisão do autor citado, as principais característica desses métodos serão descritas a seguir:

- Multiattribute Utility Theory (MAUT): este método tem similaridade com o método AHP, destacando o resultado de sua aplicação, o qual 
têm-se um conjunto de alternativas classificadas através de um ranking. Sua principal característica é que os decisores representam suas preferências através de uma função utilidade. Uma premissa desse método é a consideração da racionalidade dos decisores, onde considera-se que seus julgamentos sejam consistentes.

- Analytic Hierarchy Process (AHP): um dos métodos mais utilizados atualmente, encontrando aplicação em diversas áreas e com objetivos similares. Propõe ajudar a tomar decisões complexas em que envolvem critérios qualitativos e quantitativos. Ele foi desenvolvido por Thomas Saaty na década de 70 e se destaca com relação a utilização da lógica associada a intuição. Alia o julgamento de vários decisores através de um consenso e, portanto, encontra uma lista de alternativas com pesos, indicando a prioridade de preferência.

- Analytic Network Process (ANP): o ANP é proposto também por Saaty, sendo desenvolvido na década de 90, apresentando uma particularidade em relação ao AHP. Nesse método não é necessário independência entre os critérios, sendo utilizado em problemas quando este não pode ser estruturado através de um hierarquia. Portanto, os elementos podem ser ligados através de uma rede com subníveis ou não.

- Non-Traditional Capital Investment Criteria (NCIC): o método NCIC foi desenvolvido posteriormente ao método AHP, ele tem como objetivo analisar alternativas no universo de investimentos, eliminando as dificuldades encontradas nessa categoria, quando utilizado o AHP. Essa metodologia aborda comparações em valores monetários, permitindo a análise dos resultados com indicadores financeiros, como por exemplo o Valor Presente Líquido (VPL). Um diferencial deste modelo é que não necessariamente os resultados da análise são encontrados através de um ranking, mas mostra os benefícios das alternativas em relação aos seus custos, por exemplo.

- Measuring Attractiveness by a Categorical Based Evaluation Technique (MACBETH): diferentemente do método AHP, este método compara os critérios de forma indireta e pode até considerar alternativas fictícias na sua análise. O MACBETH geralmente é utilizado através de um software desenvolvido pelos próprios criadores e o método ainda possibilita a análise de sensibilidade dos elementos, direcionando a solucionar incoerências, quando elas ocorrerem.

- ELimination Et Choice Translation REality (ELECTRE): este método busca uma ou as alternativas de preferência satisfatória, isso quer 
dizer que os critérios da alternativa têm que estar dentro de um limite aceitável, escolhendo aquela alternativa que tem mais critérios dentro dos limites estabelecidos de aceitação. Portanto não necessariamente é a melhor alternativa, mas sim a considerada mais satisfatória. Além disso, pode-se utilizar diferentes critérios na relação com as alternativas, diferentemente do AHP, que possui o mesmo grupo de critérios para todas as possibilidades de escolha. O ELECTRE evoluiu para seis variações desde a sua criação, que podem se complementar quando desejar fazer a análise multicritério.

- Preference Ranking Organisation METHod for Enrichment Evaluations (PROMETHEE): este método tem a proposta de eliminar as lacunas encontradas na ferramenta ELECTRE e sua essência está na solução de problemas que utilizam de critérios considerados as vezes opostos um dos outros. A alternativa escolhida utiliza-se de um vetor de pesos e uma função de preferência para auxiliar na escolha. O interessante deste método é que ele produz dois rankings, considerando no segundo o equilíbrio de forças e fraquezas das alternativas. Por fim, este método tem também algumas variações, a qual algumas delas é possível considerar a estocasticidade no problema que deseja solucionar.

- Technique for Order Preference by Similarity to the Ideal Solution (TOPSIS): o método TOPSIS possui uma particularidade bastante interessante na escolha da melhor alternativa, ele analisa a distância entre as alternativas. Sua essência é escolher aquela que se aproxima mais perto da escolha ideal e se distancia ao máximo do ideal negativo. Portanto, as alternativas são ranqueadas em ordem decrescente através de uma distancia relativa entre elas e logo, é escolhida aquela alternativa "positiva ideal".

Após essa breve revisão e alinhando com os objetivos desse estudo, optouse por utilizar o método AHP (Análise Hierárquica do Processo) em detrimento dos seguintes motivos listados abaixo:

- O método AHP é bem difundido mundialmente e em vista disso, possui um estudo mais avançado na literatura, implicando na maior confiabilidade de sua aplicação;

- É uma ferramenta de simples execução, transformando problemas complexos em análises de fácil compreensão;

- É um método facilmente adaptável em diversas áreas, sendo encontrado na aplicação desde áreas de engenharia, financeira, econômica, logística e até em áreas de educação e de saúde. 
- A verificação de consistência dos critérios é um ponto positivo forte, pois além do fato de evitar incoerência na análise, induz a interação dos stakeholders envolvidos no processo, enriquecendo ainda mais o estudo do problema.

- Este método de multicritérios aproxima-se consideravelmente da realidade por considerar informações quantitativas e qualitativas, sendo tangíveis ou intangíveis.

\section{5}

\section{Planejamento de Agenda da Manutenção}

O problema da agenda da manutenção de unidades geradoras, em inglês, Generator Maintenance Scheduling Problem (GMS ou GMSP) tem sido estudado frequentemente, como pode ser visto na revisão da literatura desenvolvida por [30]. De acordo com os autores, este problema de otimização é geralmente NP-difícil e, pode ser não linear e não convexo. O trabalho enfatiza a importância do aprimoramento do cronograma de manutenção das unidades geradoras e das linhas de transmissão, cujo principal resultado é evitar paradas desnecessárias e reduzir a probabilidade de paradas forçadas que acarretam elevados custos de reparo para as usinas.

Dois trabalhos de grande destaque e que mais se aproximam deste trabalho de dissertação são os de [31] e [32]. No primeiro trabalho, os autores justificam a necessidade do planejamento do cronograma da manutenção, que ocorre principalmente pelo fato das perdas financeiras nas hidrelétricas ocasionadas quando as turbinas não estão disponíveis para operação.

O trabalho de [31] aborda um estudo de caso de uma usina hidrelétrica localizada no Canadá e propõe um modelo de programação inteira mista, que considera janelas de tempo das atividades de manutenção, as não linearidades e disjunções do problema encontrado na hidrelétrica, além das funções de produção hidráulica. Os pesquisadores optaram por simular o problema por meio de uma formulação estendida e outra pela remoção de conjuntos de desigualdades desnecessárias, obtendo na segunda, melhores resultados em relação ao tempo computacional da solução.

Já o segundo, trata-se de uma dissertação de mestrado, na qual o objetivo é modelar o cronograma dos desligamentos dos transformadores de potência de uma empresa de transmissão de energia. O autor retrata que nos ramos de empresas de transmissão existem poucas pesquisas na literatura, portanto utilizou como inspiração os problemas que diz respeito a manutenção preventiva de geradores, principal equipamento das empresas de geração de 
energia elétrica. Este problema foi modelado matematicamente como um problema de programação linear inteira mista.

Os autores de [31] dão continuidade ao seu trabalho no artigo [33]. Neste estudo os autores abordam especificamente o problema do planejamento de manutenções de unidades geradoras de usinas hidrelétricas, focados na busca da redução de custos operacionais. Os autores mostram que os impactos financeiros em sistemas hidrelétricos são difíceis de estimar devido à não linearidade da geração hidrelétrica, à incerteza das entradas de água, além da diversidade de variáveis e restrições físicas do sistema. O problema é resolvido através do algorítimo de Benders, porém os autores utilizam de sete técnicas de aceleração para o mesmo.

Entre os vários métodos que têm sido utilizados para solucionar o problema de GMS, destacam-se entre os mais recentes, o estudo de [34], no qual os autores utilizam o software General Algebraic Modeling System (GAMS) para realizar a otimização. Já o estudo de [35] utiliza o algoritmo Discrete Integer Cuckoo Search (DICS) para resolver este problema, um algoritmo baseado em meta-heurística. Os resultados deste método são comparados à técnica de Algoritmos Genéticos, em inglês Genetic Algorithms (GA), e à Otimização por Enxame de Partículas, em inglês Particle Swarm Optimization (PSO), apresentando o método DICS melhores resultados.

Quanto ao estudo de caso apresentado por [36], os autores apresentam o método que utilizaram para elaborar o cronograma de manutenção de energia hidrelétrica visando maximizar o lucro. É um estudo aplicado na Noruega, que utiliza o princípio de decomposição de Benders para programar o cronograma de manutenção da usina em um horizonte de médio prazo do planejamento do sistema hidrelétrico. Ao final, discute-se o desempenho computacional para este tipo de problema através deste estudo de caso.

Outros estudos realizados em anos anteriores são encontrados, destacamse inicialmente os trabalhos de [37] e [38], que utilizam o método metaheurístico Simulated Annealing (SA) para resolver os problemas de otimização, um modelo facilmente aplicável. Já os trabalhos de [39], comparam os resultados encontrados utilizando o modelo Genetic Algorithm (GA) com modelos híbridos de GA com SA.

O artigo desenvolvido por [40] propõe duas soluções diferentes, a primeira é através dos métodos heurísticos Ant Colony Optimization (ACO) e a segunda, também pelo método SA. Encontra-se também a tese de [41] a qual traz uma extensa explicação sobre os problemas de GMS e meta-heurísticas a serem utilizadas. Por último e não menos importante, o livro "Maintenance, modeling and optimization" dos autores [42], a qual apresentam uma revisão 
da formulação do problema e técnicas de solução.

Portanto, esta breve revisão a respeito do problema da agenda da manutenção de geradores ressalta a riqueza de estudos encontrados na literatura a respeito do assunto. Além disso, demonstra a disseminação existente quanto a este tipo de problema, largamente encontrado nas indústrias em geral e principalmente nas empresas de energia, tanto de geração, quanto de transição, evidenciando este estudo.

\section{6}

\section{Considerações Finais}

O contexto abordado nesta dissertação fica mais claro após o conhecimento das principais particularidades do Sistema Elétrico Brasileiro. Além disso, visualizar de forma numérica as características do matriz elétrica brasileira torna evidente a importância desse estudo, que está voltado para a melhoria do desempenho operacional das usinas hidrelétricas brasileiras.

Após esta introdução é possível compreender o equacionamento do indicador Fator de Disponibilidade. Fica então evidente o motivo pelo qual foi criado, que é para incentivar o melhor desempenho operacional das usinas participantes do MRE.

Como visto que o FID leva em consideração as horas computadas de manutenções programadas e forçadas, este estudo opta por direcionar estratégias no melhor planejamento das manutenções programadas/preventivas. Em vista disso, a sub-seção 2.3 trás uma breve Revisão Bibliográfica quanto a este conceito, destacando os principais ganhos com relação ao bom planejamento da manutenção preventiva.

Para escolher a ferramenta adequada que auxilie na tomada de decisão com relação ao planejamento da manutenção, alguns métodos de multicritério de apoio à decisão foram revisados. Através dos principais pontos positivos e negativos de cada método, um deles é selecionado para ser utilizado neste estudo, que é o Método de Análise Hierárquica do Processo.

Em vista desses pontos abordados é possível então dar início ao estudo realizado nesta dissertação. Lembrando que o trabalho busca trazer um modelo matemático de otimização da agenda da manutenção preventiva de turbinas de usinas hidrelétricas. 


\section{3 \\ O Método de Análise Hierárquica do Processo (AHP)}

\section{1}

\section{Contextualização}

Este capítulo tem o propósito de descrever a metodologia utilizada como ferramenta de análise de multicritério, o método de Análise Hierárquica do Processo.

O objetivo da aplicação do AHP neste estudo, é obter um ranking das turbinas da usina, buscando identificar aquelas que estão com o pior desempenho operacional. A aplicação da ferramenta irá proporcionar a classificação das UGs de forma que encontre as mais críticas, para prioriza-las na realização da manutenção preventiva.

A estratégia dessa aplicação é atuar no planejamento da manutenção, pois quando bem administrada, poderá trazer grandes benefícios para a organização. Dentre os ganhos, estão como por exemplo, o aumento da confiabilidade, da segurança e principalmente a disponibilidade dos equipamentos, além de eliminar ou reduzir as probabilidades de paradas forçadas para manutenções corretivas, fatores impactantes no FID.

Um ponto chave nesta aplicação, é o fato de utilizar diversos indicadores da manutenção, como o conjunto de critérios necessário no AHP. Além disso, estes indicadores são também fiscalizados pela ANEEL, ressaltando o grau de importância do seu monitoramento e escolha. Para esta etapa, que ficará mais clara nas sub-seções seguintes, será utilizado dados históricos dos indicadores selecionados, aumentando ainda mais, o retrato da realidade do desempenho operacional da usina.

Assim sendo, optou-se por dividir esse capítulo em mais duas sub-seções. A primeira descreve a sistemática da ferramenta, mostrando passo a passo de como aplica-la. Na seção seguinte, é demonstrado a aplicabilidade do método AHP em um caso real, utilizando dados reais da usina hidrelétrica escolhida para este trabalho. Os resultados serão discutidos no Capítulo 6. 


\section{2 \\ Metodologia}

O método de Análise Hierárquica do Processo é uma ferramenta utilizada para auxiliar os gestores no processo de tomada de decisão. Este método foi introduzido por Thomas Saaty na década de 70 [42], se tornando um dos mais consagrados na literatura. Este mérito é devido ao fato de combinar análise quantitativa de múltiplos critérios, frente à várias alternativas existentes.

Para aplicar o AHP, Saaty retrata que possivelmente, a função mais importante, é escolher quais os julgamentos serão utilizados na hierarquia [43]. Uma vez que, eles devem ser relevantes o suficiente para retratar o mais próximo possível, a realidade do problema.

Portanto, o objetivo desta metodologia é obter através de um ranking, uma alternativa de preferência ou uma sequência de alternativas, que fornecerá uma visão geral de relacionamentos complexos, capturando aspectos subjetivos e objetivos.

O método AHP pode ser representado em formato de uma hierarquia, se dividindo em três níveis pelo menos, como está representado na Figura 3.1. No topo da hierarquia encontra-se o objetivo a qual se busca alcançar, descendo um nível, tem-se o conjunto de critérios e sub-critérios (quando for necessário) selecionados para análise.

Os critérios estão todos interligados com o próximo nível, que são as alternativas selecionadas para análise [42]. Talvez a tarefa mais difícil para se utilizar esta ferramenta, seja definir quais critérios serão selecionados, pois eles devem buscar representar o mais próximo da realidade, o problema a ser resolvido [43].

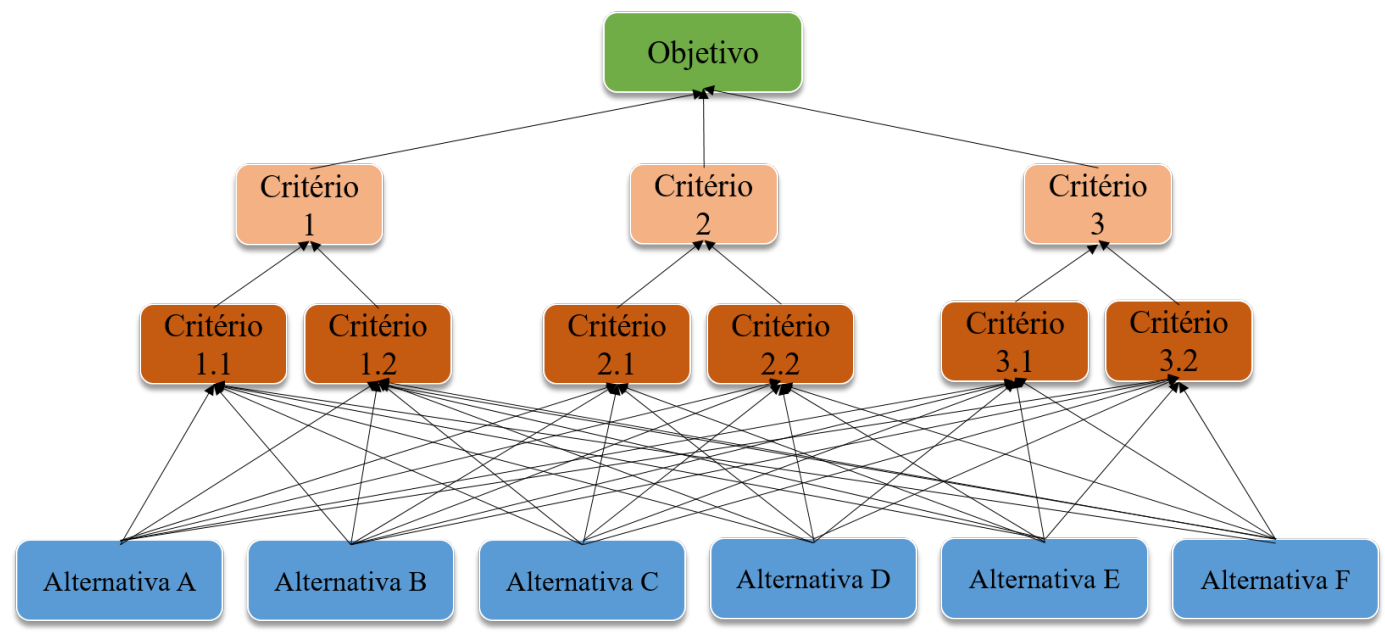

Figura 3.1: Estrutura Hierárquica Genérica

Fonte: Elaboração Própria 
Em vista disso, o objetivo desse método, pode ser encontrar uma alternativa de preferência ou também uma sequência de alternativas, gerando assim, um ranking que direcionará uma visão geral de relacionamentos complexos, além de capturar aspectos subjetivos e objetivos.

A sub-sessão a seguir, tem a finalidade de descrever o passo a passo da aplicação do Método AHP. O processo está descrito em 8 etapas adaptadas de [42] pela autora.

\section{3}

\section{Etapas do Método AHP}

- Etapa 1 - Construção da Estrutura Hierárquica:

A primeira etapa consiste em construir a hierarquia, que é formada por três níveis, ou mais, caso o nível de critérios possua sub-grupos. O objetivo da decisão encontra-se no nível mais alto da hierarquia, seguido de um segundo nível, composto pelos critérios e no último nível possui as alternativas existentes.

\section{- Etapa 2 - Elaboração da Matriz de Critérios:}

Após construída a hierarquia que representa o problema, o próximo passo é construir a matriz de critérios. Nessa fase é concedido os pesos aos critérios selecionados, buscando representar a intensidade da relação entre eles. Esses valores, sugere-se seguir a escala proposta por [42], representada na Tabela 3.1.

Tabela 3.1: Escala de Saaty [43]

\begin{tabular}{ccc}
\hline Intensidade & Definição & Explicação \\
\hline 1 & Igual importância & As duas atividades contribuem igualmente \\
para o objetivo
\end{tabular}


A matriz de critérios pode ser interpretada da seguinte forma, supondo dois critérios 'A' e 'B', quando se diz que o critério ' $\mathrm{A}$ ' tem importância grande sobre o critério 'B', é atribuído o peso 5 , logo a relação de intensidade de 'B' com 'A' deverá ser o inverso, portanto, de $1 / 5$.

Outro ponto de atenção é na diagonal principal, que deve ser preenchida com o valor 1, pois é a relação do critério com ele mesmo e portanto igual importância. Na Tabela 3.2 é possível ver um exemplo hipotético da matriz de critérios. Para os cálculos posteriores, deve ser acrescentado uma última linha na matriz, sendo preenchida com a soma do valores de critérios de sua respectiva coluna.

Tabela 3.2: Exemplo de uma Matriz de Critérios Genérica

\begin{tabular}{lcccc}
\hline & Critério A & Critério B & Critério C & Critério D \\
\hline Critério A & 1 & 5 & 4 & $1 / 9$ \\
\hline Critério B & $1 / 5$ & 1 & $1 / 2$ & $1 / 3$ \\
\hline Critério C & $1 / 4$ & 2 & 1 & $1 / 2$ \\
\hline Critério D & 9 & 3 & 2 & 1 \\
\hline
\end{tabular}

\section{- Etapa 3 - Normalização da Matriz de Critérios e Formação do Vetor de Prioridade:}

A terceira etapa consiste em realizar a normalização da matriz de critérios e encontrar o autovetor $w_{i}$, que contém a prioridade de cada critério. Considera-se uma matriz de tamanho $n \times \mathrm{x} n$ e cada elemento dessa matriz representado por $a_{i, j}$.

A normalização consiste em dividir o valor de cada elemento $\left(a_{i, j}\right)$, pela soma da coluna a qual está situado, como representado na Equação (3-1).

$$
a_{i, j}^{*}=\frac{a_{i, j}}{\sum_{i}^{n} a_{i, j}} \quad \forall j \in J
$$

Após normalizada, aplica-se a Equação (3-2), que calcula a média de cada linha, encontrando assim o autovetor $w_{i}$ que será utilizado nos próximos passos.

$$
w_{i}=\frac{\sum_{j}^{n} a_{i, j}}{n} \quad \forall i \in I
$$

- Etapa 4 - Encontrar o Desvio Máximo da Matriz de Critérios $\left(\lambda_{\max }\right)$ :

O próximo passo é encontrar o desvio máximo da matriz de critérios, representado por $\lambda_{\max }$. Para isso, segue Equação (3-3).

Primeiramente, encontra-se um novo vetor, composto de autovalores. Ele é construído através do produto da matriz de critérios 'A' (não normalizada) com o autovetor representado por $w_{i}$. 
Em seguida, realiza -se divisão do vetor formado com autovalores pelo autovetor, encontrado a parcela que pode ser chamada de vetor estimativa de $\lambda$. O $\lambda_{\max }$ será o valor médio do vetor estimativa de $\lambda$, como representado na equação [44].

$$
\lambda_{\max }=\frac{1}{n} \sum_{i=1}^{n} \frac{A \cdot w_{i}}{w_{i}}
$$

- Etapa 5 - Identificar o Índice de Consistência (IC) da Matriz de Critérios:

O quinto passo constitui-se de identificar o Índice de Consistência da matriz de critérios, como demonstrado na Equação (3-4). Novamente, $n$ representa a quantidade de critérios analisados e $\lambda_{\max }$ foi calculado na quarta etapa. O IC será necessário para verificar a consistência da matriz de critérios, tarefa que está detalha na próxima etapa.

$$
I C=\frac{\lambda_{\max }-n}{n-1}
$$

\section{- Etapa 6 - Verificação da Consistência da Matriz de Critérios:}

A avaliação dos especialistas pode conter inconsistências nos seus julgamentos, porém o ideal é que sejam as menores possíveis. Em vista disso, esse passo tem o intuito de verificar a consistência da matriz de critérios. Para isso, é calculado a Razão de Consistência (RC), definida ela Equação (3-5).

É necessário consultar o IC encontrado na etapa anterior e o Índice Randômico. O IR é um valor tabelado, encontrado na Tabela 3.3. Ela foi desenvolvida por [43] e varia de acordo com a ordem da matriz, ele afirma que uma matriz de critérios é considerada consistente se $\mathrm{RC}<0,1$.

\begin{tabular}{|c|c|c|c|c|c|c|c|c|c|c|}
\hline $\mathbf{n}$ & 1 & 2 & 3 & 4 & 5 & 6 & 7 & 8 & 9 & 10 \\
\hline $\mathrm{IR}$ & 0 & 0 & 0,52 & 0,89 & 1,11 & 1,25 & 1,35 & 1,4 & 1,45 & 1,49 \\
\hline
\end{tabular}

Tabela 3.3: Índice Randômico (IR) [43]

- Etapa 7 - Elaboração da Matriz de Alternativas versus Critérios:

Quase finalizando o processo, é preciso da matriz de alternativas versus critérios, que da mesma forma que a matriz critérios, é atribuído os pesos na matriz utilizando a Escala de Saaty [43].

Outra opção é utilizar de valores históricos das alternativas frente aos critérios. A normalização dessa matriz também deve ser feita conforme instruções vistas na terceira etapa desse método. 


\section{- Etapa 8 - Formação do Vetor Ordem de Prioridades:}

Por fim, é possível encontrar o ranking com a ordem de prioridade das alternativas. Esta classificação trará uma nova perspectiva sobre as alternativas e critérios selecionados.

Para isso, é necessário realizar o produto da matriz de alternativas normalizada versus critério, pelo autovetor.

Isto é, a multiplicação matriz encontrada Etapa 7 pelo peso de cada critério encontrado na Etapa 3. Enfim, obtém-se a ordem de prioridade desejada, finalizando o processo de multicritério AHP.

\section{4}

\section{Aplicação do Método AHP na Usina Hidrelétrica}

Como já mencionado, o método AHP é estruturado através de uma hierarquia, integrando o topo contendo o objetivo pretendido, com o conjunto de critérios. Tais critérios estão interligados ao conjunto de alternativas selecionadas.

A ferramenta irá proporcionar uma classificação de dois grupos (4 pás e 5 pás) das unidades geradoras da SAE, esta divisão foi necessária pelo fato dessas turbinas serem de características e desempenhos diferentes, portanto incomparáveis.

Vale ressaltar que o principal ganho dessa aplicação, será que após as manutenções preventivas realizadas nas turbinas consideradas piores, irá proporcionar um melhor desempenho e confiabilidade das mesmas.

O bom desempenho operacional das UGs é imprescindível, principalmente nos períodos em que a usina precisa ter ativa todas as turbinas simultaneamente, para atender o despacho do ONS. Logo, busca-se realizar as manutenções de forma programada, ou seja, antes que a falha ocorra.

Portanto, a escolha da ordem da realização das atividades de manutenção preventiva, a ser realizada durante o ano na SAE, será feita através do Método de Multicritério AHP, buscando trazer para usina, todos os benefícios que vem sendo discutido, além de proporcionar a comunidade acadêmica, uma aplicação real, clara e objetiva do método.

Cada etapa desenvolvida, está descrita detalhadamente nos tópicos abaixo, utilizando os dados reais da Usina Hidrelétrica Santo Antônio.

Etapa 1: O conjunto de alternativas é formado pelas UGs, em seus respectivos grupos, logo, pelas Turbinas de 4 pás (24 UG's) e pelas Turbinas de 5 pás (26 UG's). O conjunto de critérios selecionados são indicadores de manutenção fiscalizados pela ANEEL, ressaltando sua importância. Tais 
indicadores refletem o desempenho operacional da hidrelétrica, demonstrando o impacto que o FID sofrerá. São eles:

- TF - Taxa de Falhas: gerencia a taxa de falhas por unidade geradora no período considerado, verificando os valores limites das faixas classificadas como normal, alerta e insatisfatória.

- TDF - Taxa de Desligamento Forçado: gerencia o desempenho de unidades geradoras durante o período considerado.

- INDISPMP - Indisponibilidade para Manutenção Programada: gerenciamento da indisponibilidade para a operação devido à manutenção programada de unidades geradoras durante o período considerado.

- INDISPMF - Indisponibilidade para Manutenção Forçada: gerenciamento da indisponibilidade para manutenção forçada de unidades geradoras durante o período considerado.

- TMEF - Tempo Médio Entre Falhas: a finalidade desse indicador é mensurar as médias de tempo em funcionamento entre uma falha e outra, de itens ou equipamentos que sejam reparáveis.

- TMR - Tempo Médio de Reparo: gerenciamento do tempo médio de reparo das unidades geradoras, verificando os valores limites das faixas classificadas como normal, alerta e insatisfatória. O seu objetivo é demonstrar a média de tempo que a equipe de manutenção utiliza para colocar um equipamento em funcionamento novamente, levando em consideração desde a falha até o reparo ser considerado concluído.

- HDF + HEDF - soma do número de Horas de Desligamento Forçado e Horas Equivalentes de Desligamento Forçado: contribuem negativamente na composição da TEIFa.

Um detalhe importante, o qual requer muita atenção, é com relação a análise do significado de cada indicador escolhido como critério. A maioria dos indicadores indicam uma escala que quanto maior o seu valor registrado, pior é o desempenho do equipamento/turbina, indo ao encontro do objetivo da aplicação do Método AHP, que é encontrar as UGs com pior desempenho.

Porém, o indicador TMEF, tem uma análise inversa aos outros indicadores, sua análise apresenta que quanto maior o valor computado, melhor é o desempenho da UG. Por isso, para resolver essa diferença de escala, foi estabelecida uma função utilidade ao critério TMEF, inversa aos outros indicadores, que pode ser representada pela seguinte função matemática $f(x)=1 / x$.

Os demais indicadores permanecem com a sua função utilidade, uma constante, representada por $f(x)=x$. Onde $x$ representa a média histórica de 
cada indicador, relacionado a cada alternativa/UGs e $f(x)$ o valor utilizado para execução do Método AHP.

Portanto, a estrutura hierárquica ficou formada por três níveis. Primeiramente, o objetivo da decisão (UGs com baixo desempenho) que está no nível superior. O segundo nível é composto pelos julgamentos, que sãos os indicadores da manutenção selecionados. E o último nível com as turbinas formando as alternativas que serão avaliadas.

Na Figura 3.2 está a Hierarquia do Grupo de 4 pás e na Figura 3.3 do Grupo de 5 pás. A hierarquia está desenhada na horizontal por conveniência.

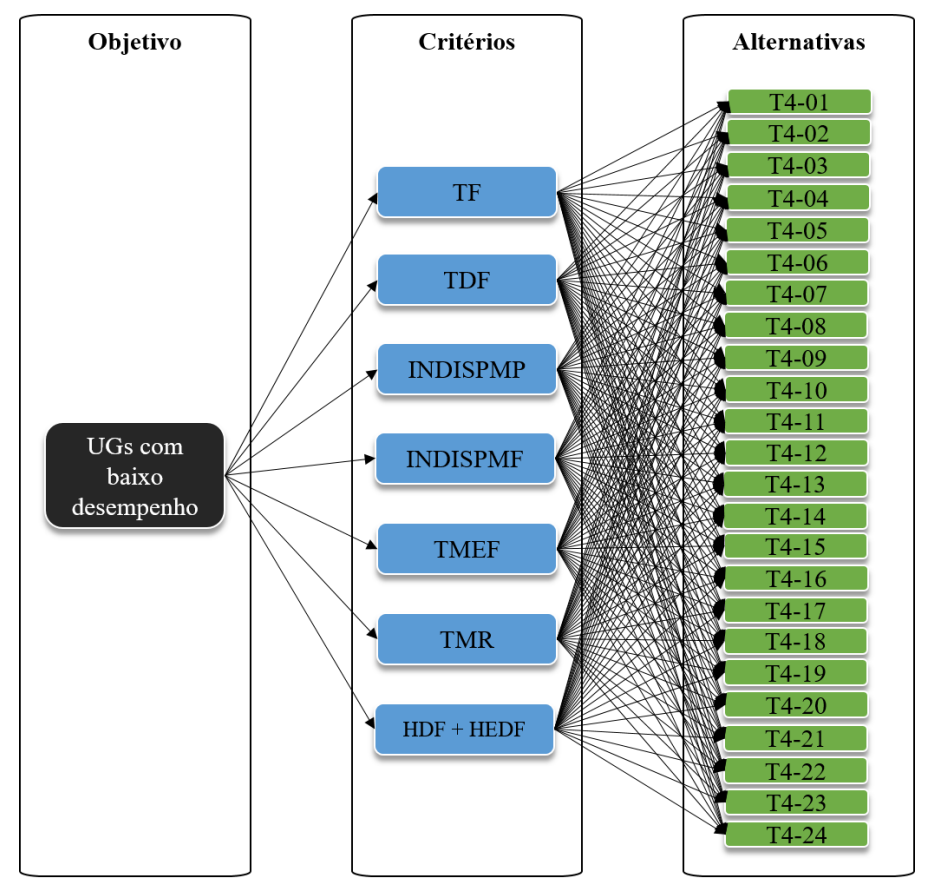

Figura 3.2: Hierarquia - Grupo de 4 pás Fonte: Elaboração Própria

Etapa 2: Nessa etapa, é concedido os pesos aos critérios, representando a força da relação entre eles. Esses pesos seguem a escala elaborada por Saaty [42], que pode ser consultada na Tabela 3.1 da sub-seção 3.3.

A matriz tem a estrutura de critérios versus critérios, onde a diagonal principal é preenchida com o valor 1, pois é a relação do critério com ele mesmo. Relembrando que a relação de um critério 'A' com 'B', é a inversa da relação de 'B' com 'A'.

A matriz de critérios elaborada, para o estudo de caso da Santo Antônio Energia, está representada na Tabela 3.4. Os pesos considerados nesta avaliação, levam em consideração o conhecimento e a experiência do gerente de operações da SAE juntamente com a sua equipe, sendo atribuído em comum acordo por eles cada peso. Esta decisão encontra-se como uma limitação encontrada no trabalho. 


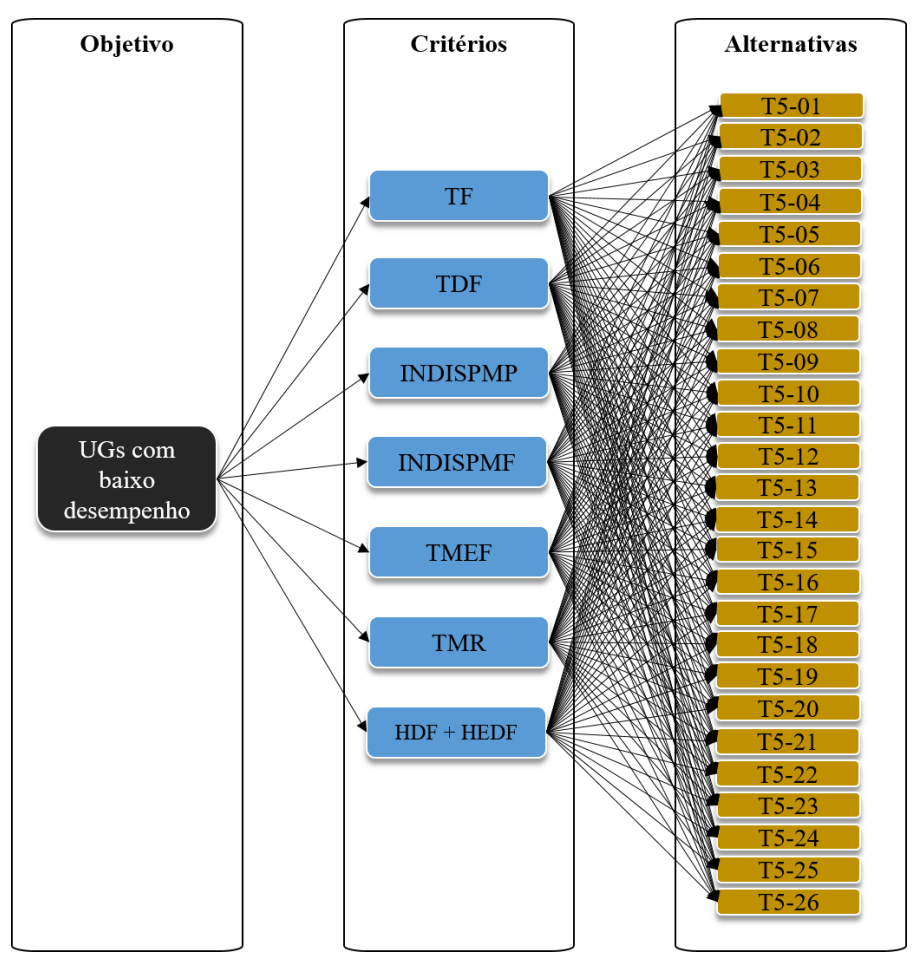

Figura 3.3: Hierarquia - Grupo de 5 pás Fonte: Elaboração Própria

Embora Saaty propõe que esta atribuição seja realizada por um grupo de especialistas [42], pressupõe-se que o gestor e sua equipe definiram os pesos, garantindo que o resultado esteja alinhado com suas expectativas (expectativas deste estudo). Portanto, definiu-se que a matriz de critérios, seja construída apenas através da perspectiva conjunta de sua equipe.

Tabela 3.4: Matriz Critérios SAE

\begin{tabular}{cccccccc}
\hline & TF & TDF & INDISPMP & INDISPMF & TMEF & TMR & $\begin{array}{c}\text { HDF + } \\
\text { HEDF }\end{array}$ \\
\hline TF & 1 & 1 & $1 / 2$ & $1 / 3$ & 2 & 4 & $1 / 5$ \\
\hline TDF & 1 & 1 & $1 / 2$ & $1 / 3$ & 2 & 4 & $1 / 5$ \\
\hline INDISPMP & 2 & 2 & 1 & $1 / 2$ & 3 & 4 & $1 / 3$ \\
\hline INDISPMF & 3 & 3 & 2 & 1 & 5 & 7 & $1 / 2$ \\
\hline TMEF & $1 / 2$ & $1 / 2$ & $1 / 3$ & $1 / 5$ & 1 & 2 & $1 / 7$ \\
\hline TMR & $1 / 4$ & $1 / 4$ & $1 / 5$ & $1 / 7$ & $1 / 2$ & 1 & $1 / 9$ \\
\hline HDF + HEDF & 5 & 5 & 3 & 2 & 7 & 9 & 1 \\
\hline
\end{tabular}

Etapa 3: Após a elaboração da matriz de critérios, ela dever ser normalizada, conforme Equação (3-1). Consiste em dividir o valor de cada elemento, pela soma da coluna a qual está situado, formando a matriz de critérios normalizada. Em seguida, calcula-se a média de cada linha, como demonstrado na Equação (3-2). Após isto, encontra-se o autovetor, visualizado na Tabela 3.5. Este vetor contém o percentual de prioridade de cada critério .

Etapas 4, 5 e 6: A avaliação do gestor ainda pode conter inconsistências nos seus julgamentos, embora o ideal é que sejam as menores possíveis. 
Tabela 3.5: Peso de cada Critério SAE - autovetor

\begin{tabular}{ccc}
\hline İndice & Autovetor $\left(w_{i}\right)$ & Prioridade (\%) \\
\hline TF & 0,0863 & $8,63 \%$ \\
\hline TDF & 0,0863 & $8,63 \%$ \\
\hline INDISPMP & 0,1381 & $13,81 \%$ \\
\hline INDISPMF & 0,2327 & $23,27 \%$ \\
\hline TMEF & 0,0483 & $4,83 \%$ \\
\hline TMR & 0,0284 & $2,84 \%$ \\
\hline HDF + HEDF & 0,3800 & $38,00 \%$ \\
\hline
\end{tabular}

Portanto, é verificando se as atribuições têm coerência através do calculo da Razão de Consistência, sendo demonstrada na Equação (3-7).

Para chegar ao valor da $\mathrm{RC}$, primeiro, encontra-se o vetor composto de autovalores, que é formado através da multiplicação da matriz de critérios não normalizada com o autovetor. Em seguida, encontra-se o vetor estimativa de $\lambda$, formado através do divisão do vetor com autovalores pelo vetor chamado autovetor. O $\lambda_{\max }$ será o valor médio do vetor estimativa de $\lambda$, como demonstrado na Equação (3-3). Os valores deste estudo de caso estão apresentados na Tabela 3.6.

Tabela 3.6: Vetor com Autovalores e Estimativa de $\lambda$

\begin{tabular}{cc}
\hline$A \cdot w_{i}$ & Estimativa de $\lambda$ \\
\hline 0,6053 & 7,0132 \\
\hline 0,6053 & 7,0132 \\
\hline 0,9847 & 7,1298 \\
\hline 1,6567 & 7,1210 \\
\hline 0,3382 & 7,0090 \\
\hline 0,1988 & 6,9996 \\
\hline 2,7160 & 7,1477 \\
\hline$\lambda_{\max }$ & $\mathbf{7 , 0 6 1 9}$ \\
\hline
\end{tabular}

Além disso, falta calcular o Índice de Consistência da Matriz de Critérios, cálculo demonstrado na Equação (3-6). Neste caso, $n=7$ representando os sete critérios selecionados e $\lambda_{\max }=7,0619$.

O Índice Randômico, como dito anteriormente, é um valor tabelado, e varia de acordo com a ordem da matriz, que pode ser consultado na Tabela 3.3. Recordando que Saaty afirma, que uma matriz de critérios é considerada consistente, se $\mathrm{RC}<0,1$ [43]. Para sete critérios, têm-se $I R=1,35$.

$$
\begin{aligned}
& I C=\frac{\lambda_{\max }-n}{n-1}=\frac{7,0619-7}{7-1}=0,0103 \\
& R C=\frac{I C}{I R}=\frac{0,0103}{1,35}=0,0076=0,76 \%
\end{aligned}
$$

Conforme Equação (3-7), o Índice Randômico encontrado é de 0,76\%, portanto, a matriz de critérios é considerada consistente. 
Etapa 7: Da mesma forma que a matriz critérios, é atribuído os pesos na matriz alternativas frente aos critérios. Neste estudo, optou-se por utilizar médias históricas dos indicadores apresentados, uma vez que eles representam o desempenho operacional da usina. Lembrando que a matriz de alternativas, também deve ser normalizada. Foi construída 2 matrizes, representado o Grupo de UGs de 4 pás e o de 5 pás, sendo representado na Tabela 3.7 a matriz de alternativas do Grupo de 4 pás e na Tabela 3.8 a matriz de alternativas do Grupo de 5 pás.

Tabela 3.7: Matriz Alternativas SAE - Grupo de 4 pás

\begin{tabular}{cccccccc}
\hline UG & TF & TDF & INDISPMP & INDISPMF & TMEF & TMR & $\begin{array}{c}\text { HDF + } \\
\text { HEDF }\end{array}$ \\
\hline T4-01 & 0.059 & 0.088 & 0.050 & 0.001 & 0.008 & 0.475 & 6.943 \\
T4-02 & 0.085 & 0.143 & 0.004 & 0.001 & 0.005 & 0.277 & 14.761 \\
T4-03 & 0.213 & 0.242 & 0.000 & 0.001 & 0.002 & 1.019 & 10.631 \\
T4-04 & 0.271 & 0.424 & 0.009 & 0.012 & 0.002 & 2.977 & 16.187 \\
T4-05 & 0.166 & 0.195 & 0.054 & 0.001 & 0.003 & 0.423 & 18.660 \\
T4-06 & 0.134 & 0.163 & 0.009 & 0.000 & 0.004 & 0.209 & 17.018 \\
T4-07 & 0.256 & 0.286 & 0.000 & 0.000 & 0.005 & 0.267 & 18.903 \\
T4-08 & 0.072 & 0.131 & 0.071 & 0.001 & 0.001 & 0.676 & 21.234 \\
T4-09 & 0.341 & 0.409 & 0.001 & 0.006 & 0.006 & 1.484 & 27.994 \\
T4-10 & 0.265 & 0.297 & 0.026 & 0.001 & 0.001 & 0.224 & 11.210 \\
T4-11 & 0.065 & 0.065 & 0.006 & 0.000 & 0.001 & 0.004 & 10.217 \\
T4-12 & 0.222 & 0.289 & 0.000 & 0.000 & 0.002 & 0.121 & 16.598 \\
T4-13 & 0.068 & 0.156 & 0.014 & 0.000 & 0.003 & 0.184 & 24.037 \\
T4-14 & 0.097 & 0.198 & 0.000 & 0.001 & 0.001 & 0.488 & 26.409 \\
T4-15 & 0.174 & 0.233 & 0.000 & 0.001 & 1.669 & 0.388 & 23.653 \\
T4-16 & 0.290 & 0.355 & 0.001 & 0.001 & 0.003 & 0.181 & 29.911 \\
T4-17 & 0.192 & 0.305 & 0.000 & 0.001 & 0.003 & 0.761 & 10.523 \\
T4-18 & 0.712 & 0.772 & 0.069 & 0.001 & 0.003 & 0.632 & 8.188 \\
T4-19 & 0.155 & 0.269 & 0.000 & 0.001 & 0.002 & 0.375 & 10.316 \\
T4-20 & 0.256 & 0.355 & 0.021 & 0.001 & 0.002 & 0.384 & 15.591 \\
T4-21 & 0.345 & 0.447 & 0.001 & 0.001 & 0.004 & 0.358 & 26.343 \\
T4-22 & 0.149 & 0.229 & 0.013 & 0.000 & 0.005 & 0.354 & 25.758 \\
T4-23 & 0.212 & 0.241 & 0.007 & 0.000 & 0.004 & 0.359 & 45.742 \\
T4-24 & 0.165 & 0.290 & 0.018 & 0.002 & 0.002 & 1.211 & 12.377 \\
\hline
\end{tabular}


Tabela 3.8: Matriz Alternativas SAE - Grupo de 5 pás

\begin{tabular}{cccccccc}
\hline UG & TF & TDF & INDISPMP & INDISPMF & TMEF & TMR & $\begin{array}{c}\text { HDF + } \\
\text { HEDF }\end{array}$ \\
\hline T5-01 & 0.141 & 0.291 & 0.012 & 0.000 & 0.023 & 0.149 & 23.568 \\
$\mathbf{T 5 - 0 2}$ & 0.204 & 0.303 & 0.009 & 0.000 & 0.002 & 0.147 & 5.471 \\
$\mathbf{T 5 - 0 3}$ & 0.447 & 0.534 & 0.066 & 0.000 & 0.003 & 0.226 & 5.683 \\
$\mathbf{T 5 - 0 4}$ & 0.127 & 0.227 & 0.013 & 0.000 & 0.002 & 0.153 & 16.656 \\
$\mathbf{T 5 - 0 5}$ & 0.603 & 0.726 & 0.020 & 0.001 & 0.003 & 0.356 & 20.811 \\
$\mathbf{T 5 - 0 6}$ & 0.352 & 0.543 & 0.013 & 0.001 & 0.002 & 0.631 & 29.222 \\
$\mathbf{T 5 - 0 7}$ & 0.259 & 0.748 & 0.036 & 0.011 & 0.002 & 2.204 & 40.910 \\
$\mathbf{T 5 - 0 8}$ & 0.777 & 1.104 & 0.038 & 0.060 & 0.003 & 31.781 & 79.944 \\
$\mathbf{T 5 - 0 9}$ & 0.412 & 0.720 & 0.026 & 0.001 & 0.002 & 0.387 & 33.606 \\
$\mathbf{T 5 - 1 0}$ & 0.320 & 0.568 & 0.005 & 0.000 & 0.002 & 0.308 & 35.037 \\
$\mathbf{T 5 - 1 1}$ & 0.294 & 0.420 & 0.007 & 0.000 & 0.003 & 0.307 & 16.998 \\
$\mathbf{T 5 - 1 2}$ & 0.209 & 0.266 & 0.016 & 0.001 & 0.002 & 0.425 & 24.173 \\
$\mathbf{T 5 - 1 3}$ & 0.236 & 0.352 & 0.001 & 0.000 & 0.002 & 0.309 & 14.499 \\
$\mathbf{T 5 - 1 4}$ & 0.282 & 0.311 & 0.014 & 0.000 & 0.003 & 0.071 & 7.659 \\
$\mathbf{T 5 - 1 5}$ & 0.191 & 0.251 & 0.001 & 0.001 & 0.002 & 0.507 & 4.980 \\
$\mathbf{T 5 - 1 6}$ & 0.115 & 0.246 & 0.009 & 0.005 & 0.002 & 3.549 & 8.489 \\
$\mathbf{T 5 - 1 7}$ & 0.150 & 0.210 & 0.001 & 0.001 & 0.002 & 0.554 & 5.265 \\
$\mathbf{T 5 - 1 8}$ & 0.208 & 0.298 & 0.001 & 0.021 & 0.003 & 15.267 & 21.102 \\
$\mathbf{T 5 - 1 9}$ & 0.241 & 0.316 & 0.002 & 0.001 & 0.002 & 0.425 & 4.146 \\
$\mathbf{T 5 - 2 0}$ & 0.236 & 0.592 & 0.020 & 0.003 & 0.003 & 1.877 & 4.632 \\
$\mathbf{T 5 - 2 1}$ & 0.287 & 0.349 & 0.016 & 0.001 & 0.002 & 0.478 & 4.162 \\
$\mathbf{T 5 - 2 2}$ & 0.200 & 0.259 & 0.006 & 0.001 & 0.002 & 0.233 & 8.099 \\
$\mathbf{T 5 - 2 3}$ & 0.125 & 0.196 & 0.039 & 0.001 & 0.002 & 0.674 & 14.533 \\
$\mathbf{T 5 - 2 4}$ & 0.223 & 0.286 & 0.005 & 0.120 & 0.003 & 86.725 & 97.751 \\
$\mathbf{T 5 - 2 5}$ & 0.276 & 0.411 & 0.004 & 0.001 & 0.004 & 0.711 & 33.497 \\
$\mathbf{T 5 - 2 6}$ & 0.391 & 0.569 & 0.035 & 0.031 & 0.002 & 21.883 & 63.413 \\
\hline
\end{tabular}

Etapa 8: Enfim, a última etapa da metodologia, que consiste em realizar o produto da matriz de alternativas normalizada versus critério, pelo peso de cada critério. Assim, obtém-se o vetor prioridade de cada grupo, demonstrado na Tabela 3.9.

Tabela 3.9: Matriz Prioridade SAE - Grupo de 4 e 5 pás

\begin{tabular}{|c|c|c|c|c|c|c|c|}
\hline \multicolumn{4}{|c|}{ Grupo de 4 pás } & \multicolumn{4}{|c|}{ Grupo de 5 pás } \\
\hline UG & Prior. & UG & Prior. & UG & Prior. & UG & Prior. \\
\hline T4-04 & $11,89 \%$ & T4-01 & $3,29 \%$ & T5-24 & $19,69 \%$ & T5-01 & $2,36 \%$ \\
\hline T4-09 & $8,20 \%$ & T4-10 & $3,27 \%$ & T5-08 & $14,07 \%$ & T5-20 & $2,29 \%$ \\
\hline T4-15 & $7,80 \%$ & T4-14 & $3,23 \%$ & T5-26 & $9,09 \%$ & T5-11 & $2,16 \%$ \\
\hline T4-18 & $6,30 \%$ & T4-13 & $3,11 \%$ & T5-07 & $5,59 \%$ & T5-04 & $1,98 \%$ \\
\hline T4-08 & $5,60 \%$ & T4-03 & $2,79 \%$ & T5-09 & $4,13 \%$ & T5-16 & $1,73 \%$ \\
\hline T4-23 & $5,25 \%$ & T4-07 & $2,75 \%$ & T5-18 & $3,84 \%$ & T5-13 & $1,60 \%$ \\
\hline T4-05 & $4,68 \%$ & T4-17 & $2,53 \%$ & T5-03 & $3,68 \%$ & T5-21 & $1,60 \%$ \\
\hline T4-16 & $4,02 \%$ & T4-06 & $2,48 \%$ & T5-06 & $3,48 \%$ & T5-14 & $1,53 \%$ \\
\hline T4-21 & $3,95 \%$ & T4-12 & $2,40 \%$ & T5-10 & $3,34 \%$ & T5-02 & $1,44 \%$ \\
\hline T4-24 & $3,84 \%$ & T4-02 & $2,20 \%$ & T5-05 & $3,30 \%$ & T5-22 & $1,38 \%$ \\
\hline T4-22 & $3,65 \%$ & T4-19 & $2,01 \%$ & T5-25 & $3,01 \%$ & T5-15 & $1,30 \%$ \\
\hline T4-20 & $3,48 \%$ & T4-11 & $1,29 \%$ & T5-23 & $3,00 \%$ & T5-19 & $1,03 \%$ \\
\hline & & & & T5-12 & $2,54 \%$ & T5-17 & $0,85 \%$ \\
\hline
\end{tabular}




\section{4}

\section{Modelagem Matemática Proposta}

\section{1}

\section{Visão Geral do Modelo}

Conforme previamente discutido, o objetivo principal do trabalho é encontrar uma agenda de manutenção ótima, para as unidades geradoras de uma usina hidrelétrica. O intuito é reduzir as penalizações ocasionadas por desligamentos programados, em períodos inadequados.

As penalizações ocorrem quando o Operador Nacional do Sistema Elétrico, demanda a geração de energia da UHE e as turbinas estão indisponíveis para operação. Isto ocorre devido programação inadequada das manutenções, tanto preventivas, quanto corretivas, e então o agente é penalizado, pois está afetando todo o Sistema Interligado Nacional.

Além disso, a nova agenda deverá atender todas as manutenções necessárias de cada unidade geradora, de forma a prevenir possíveis panes e interrupções indesejáveis. A proposta é elaborar um cronograma da manutenção anual, através de uma modelagem matemática que direcione os gestores no planejamento diário de operações.

Em vista disso, esta dissertação tem como objetivo, desenvolver um modelo matemático para determinar o momento ideal de realização das manutenções das unidades geradoras. Uma vez que, nos períodos de baixa vazão, que são bem definidos na Santo Antônio Energia, existe a flexibilidade da realização das manutenções, sem ocorrer penalidades relacionadas ao FID.

A agenda é elaborada todo mês de dezembro contemplando todos os meses do ano seguinte. Neste estudo de caso trata-se do planejamento para o ano de 2021.

Para atender o objetivo principal deste trabalho, existem dois objetivos intermediários. O primeiro, uma etapa crucial para agenda da manutenção, compõe-se da classificação das unidades geradoras, utilizando o método de multicritério Análise Hierárquica do Processo. Sua finalidade é de direcionar no modelo matemático, a priorização da manutenção preventiva das turbinas consideradas mais críticas.

Através de uma outra perspectiva, o intuito poderá ser também, buscar 
priorizar a operação daquelas turbinas consideradas com melhor desempenho, ou seja, que encontram-se no final do ranking do AHP. Por esse motivo, uma sessão dedicada somente à explicação e aplicação dessa ferramenta, que encontra-se descrita no Capítulo 3.

Já o segundo objetivo, trata-se de encontrar o Turbinamento Máximo de cada Unidade Geradora. A finalidade dessa informação, é fazer com que o modelo encontre o aproveitamento máximo de cada UG, e para isso, o cálculo de alguns componentes relacionados ao sistema hidrotérmico, são necessários. Os componentes são Nível Montante e Jusante do reservatório, Queda Bruta e Líquida e por último, o Engolimento Máximo de cada turbina.

Estes dois objetivos, juntamente com a informação de duração do período de manutenção preventiva de cada turbina formam os inputs necessários para o problema. A Figura 4.1 traz uma visão global de todos os processos necessários para obter o output denominado "Agenda da Manutenção".
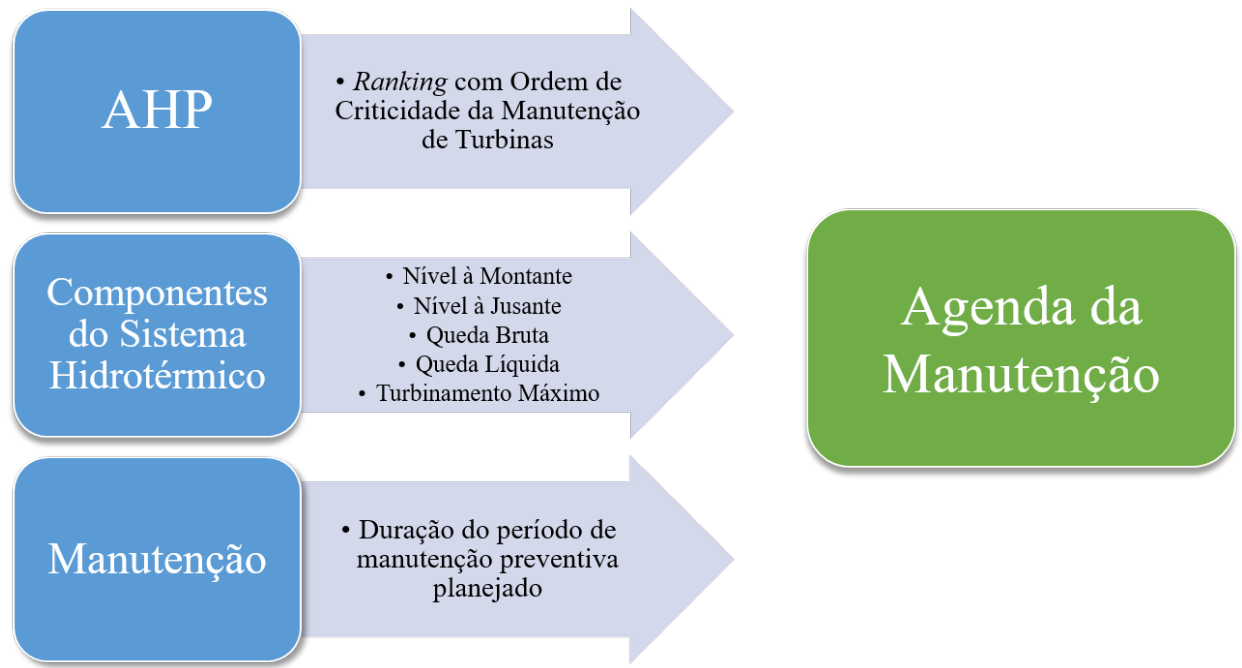

Figura 4.1: Visão Geral do Modelo Fonte: Elaboração Própria

Como mencionado, a usina é penalizada, somente quando ocorre vertimento por motivo de responsabilidade da usina. Com o intuito de melhor esclarecer estas regras de penalizações, a Figura 4.2 apresenta um fluxograma, que demonstra o efeito da penalização por indisponibilidades, especificamente para as usinas na região Norte do Brasil.

Em resumo, quando a usina possui UGs inoperantes, em virtude de planejamento operacional interno, e ocorrer o vertimento de água, então há penalização. A contabilização será proporcional ao número de horas desligadas neste período, podendo ser horas de manutenção programada ou forçada, computadas respectivamente pelos índices HDP e HDF. 
Além disso, mesmo com todas as turbinas operantes, a usina ainda é passível de penalização no seguinte caso, se ocorrer vertimento e alguma UG não estiver operando na sua capacidade máxima, por motivos de responsabilidade da usina. Neste caso a penalização será proporcional à diferença de potencial máximo operativo, com o real ocorrido e contabilizada durante o período de tempo que este fato ocorreu. Neste caso, as horas são contabilizados nos indicadores HEDP e HEDF.

Portanto, como pode ser visto na Figura 4.2, havendo vertimento, porém não sendo ocasionado por responsabilidade da usina, não haverá penalização. Caso ocorra vertimento e este seja ocasionado por critério operativo da usina, ela será penalizada.

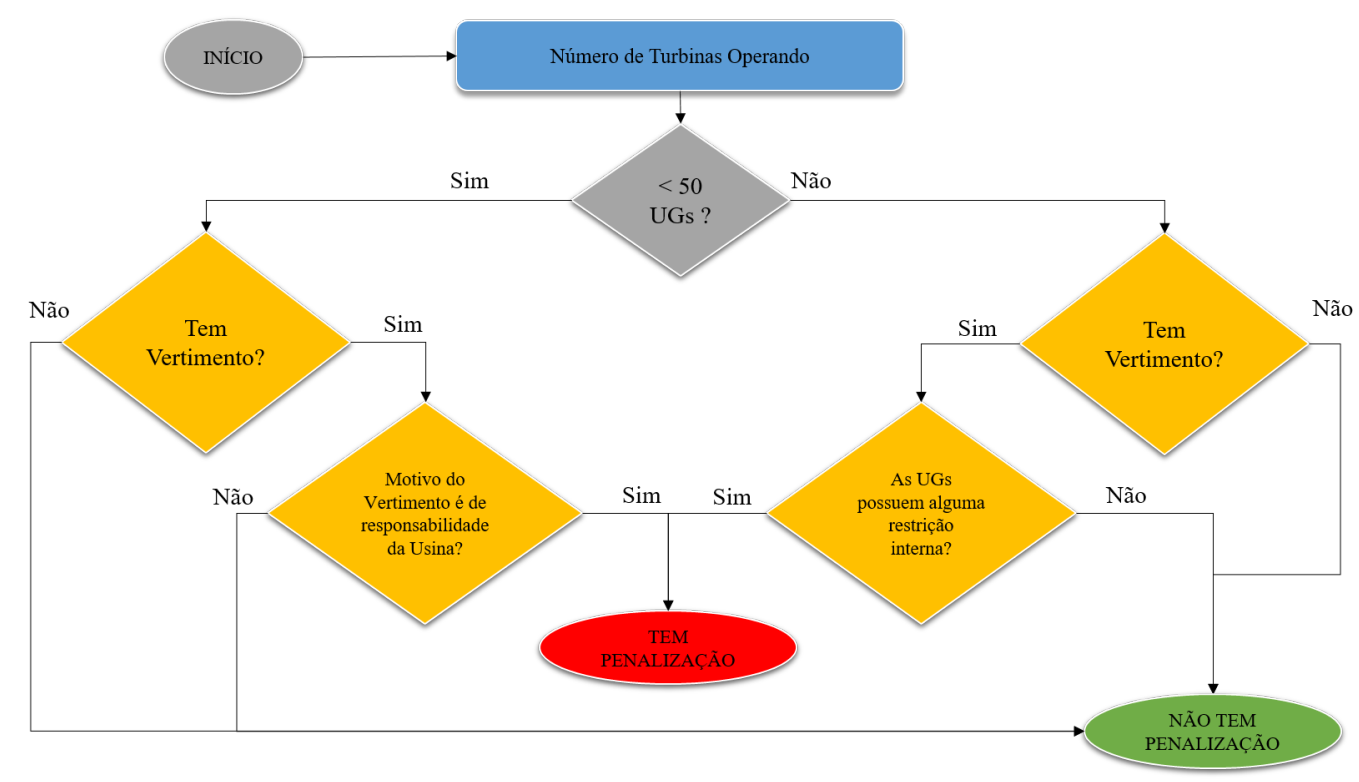

Figura 4.2: Fluxograma de Regras de Penalização para SAE Fonte: Elaboração Própria

Dessa forma, o objetivo é agendar todas as manutenções preventivas em um horizonte anual, de forma a evitar vertimento de água provocado pela usina, reduzindo as penalizações. Consequentemente irá reduzir o impacto do FID e a exposição da usina no mercado de curto prazo.

\section{2}

\section{Ordem de Prioridade para Realização da Manutenção Preventiva}

Como já mencionado, o objetivo da aplicação do AHP, é direcionar o modelo matemático na escolha da ordem de prioridade para realização da manutenção preventiva das turbinas.

O Referencial Teórico quanto a sua metodologia e aplicação, estão descritos no Capítulo 3. A etapas de seu desenvolvimento, podem ser revistas de forma resumida e estruturada na Figura 4.3. 


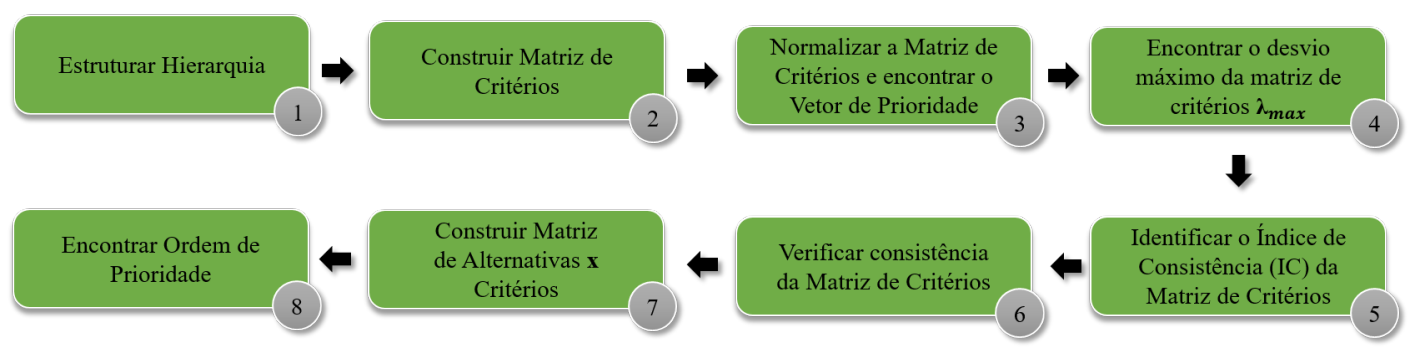

Figura 4.3: Etapas do AHP

Fonte: Elaboração Própria

\section{3}

\section{Componentes do Sistema Hidrotérmico: Engolimento Máximo}

Considerando a formulação do problema, que será apresentado no próximo item, alguns componentes relacionados ao sistema hidrotérmico precisam ser conhecidos. Esses componentes serão utilizados para o cálculo do parâmetro Turbinamento Máximo de cada Unidade Geradora, que está sendo utilizado na restrição (4-8) do problema. A Figura 4.4 ilustra estes componentes, através da visão lateral da barragem de uma usina hidrelétrica. A variáveis vistas na figura, estão descritas na modelagem matemática.

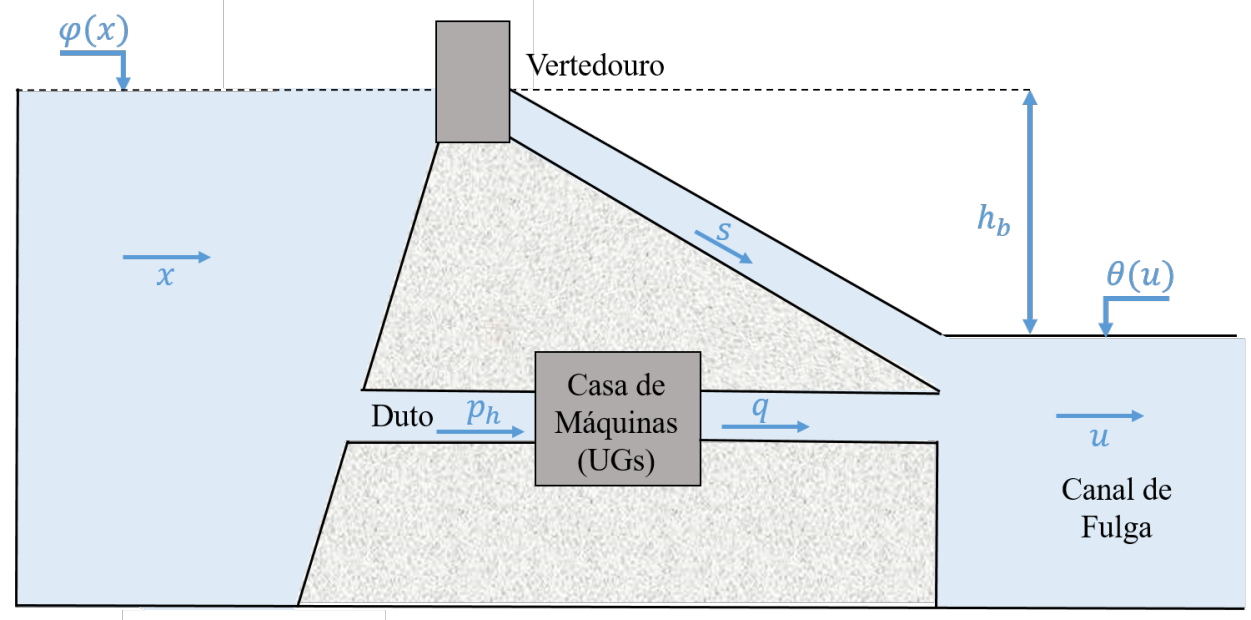

Figura 4.4: Componentes de uma Usina Hidrelétrica Fonte: Elaboração Própria

Os cálculos necessários para encontrar o Turbinamento Máximo de cada UG estão apresentados em 5 passos descritos a seguir:

Passo 1: Encontrar o Nível à Montante diário do reservatório em $m$, representado por $\varphi(x)_{d}$. É um polinômio não linear de $4^{o}$ grau, conhecido como Polinômio Nível Montante x Volume. A Equação (4-1) apresenta este polinômio, onde $x$ é o volume no reservatório em $m^{3}$ no dia $d$ e $a, b, c, d, e$ são os coeficientes do Polinômio Nível Montante x Volume [45]. Em alguns casos 
o nível da montante é encontrado através de regras operativas específicas de cada usina.

$$
\varphi(x)_{d}=a+b \cdot x_{d}+c \cdot x_{d}^{2}+d \cdot x_{d}^{3}+e \cdot x_{d}^{4}
$$

Passo 2: Encontrar o Nível à Jusante diário do reservatório em $m$, representado por $\theta(u)_{d}$ e chamado também de Nível do Canal de Fuga. Para o seu cálculo é utilizado também um Polinômio de $4^{o}$ grau (Equação (4-2)), no qual é necessário os coeficientes $(a, b, c, d, e)$ do Polinômio Nível Jusante x Vazão. Os coeficientes são dados disponibilizados pela usina e é preciso conhecer a vazão defluente (vazão turbinada + vazão vertida), que está representada por $u$ em $\mathrm{m}^{3} / \mathrm{s}$ [45].

$$
\theta(u)_{d}=a+b \cdot u_{d}+c \cdot u_{d}^{2}+d \cdot u_{d}^{3}+e \cdot u_{d}^{4}
$$

Passo 3: Encontrar o valor da Queda Bruta diária $(m)$, representada por $h b_{d}$. Seu valor é encontrado a partir da diferença das alturas do Nível à Montante e do Canal de Fuga do reservatório, cálculo representado na Equação $(4-3)$.

$$
h b_{d}=\varphi(x)_{d}-\theta(u)_{d}
$$

Passo 4: Encontrar o valor da Queda Líquida diária $(m)$, sendo definida pela diferença entre a altura de queda bruta e a perda hidráulica, representada por $h l_{d}$ em (4-5) [46]. A perda hidráulica $p h_{d}$, que geralmente está associada ao atrito da água e as canalizações do canal de adução, pode ser representada conforme Equação (4-4), onde $k$ é uma constante que expressa a característica da comporta em $s^{2} / m^{5}[47]$.

$$
\begin{gathered}
p h_{d}=k \cdot q_{d}^{2} \\
h l_{d}=h b_{d}-p h_{d}
\end{gathered}
$$

Passo 5: Engolimento Máximo diário $\left(\bar{q}_{d}\right)$ de cada UG, vide Equação (4-6). Consiste em encontrar a vazão máxima associada a maior potência de geração, esta última, em função da altura de queda líquida $h l_{d}$ [45]. Utiliza-se então, a função chamada de Função de Rendimento de uma Unidade Geradora ou de "Curva Colina", devido ao seu formato, para consultar os valores. Ela irá fornecer as informações necessárias para encontrar o Turbinamento Máximo de cada UG, dada uma queda líquida fixa e a respectiva potência da unidade geradora.

$$
\bar{q}_{d}=\bar{q}\left(h l_{d}\right)_{d}
$$

Para exemplificar, uma Curva Colina pode ser vista na Figura 4.5, representada na forma de curvas de nível. Pode-se notar, que dada uma altura 
de queda líquida e variando a vazão turbinada, que a potência atrelada ao rendimento também varia.

Neste caso o rendimento está variando de um valor mínimo (Ponto A), passando por um valor máximo (Ponto B) e chegando a um valor intermediário (Ponto $\mathrm{C}$ ), quando a vazão turbinada atinge o seu máximo.

O ponto chave nesta análise, é com relação a potência do conjunto turbina/gerador. Observa-se que a potência varia de $80 \mathrm{MW}$ até aproximadamente 115 MW, apenas aumentando o turbinamento da UG. Neste caso, 115 MW está associado ao engolimento máximo com um altura de queda líquida "constante". A curvatura notada através do Ponto A ao C é em virtude da interdependência entre os três eixos, por isso essa diferença de 2 metros entre os dois pontos.

Em vista disso, busca-se neste modelo, o Engolimento Máximo de cada Unidade Geradora. Uma vez que, trará o maior potencial de geração que uma turbina consegue gerar, com as condições hidrológicas disponíveis.

Portanto, além de atender o SIN com mais energia, a usina obtém uma receita maior com a venda dessa de energia e ainda está utilizando o maior potencial de geração da UG. Neste caso, evitará penalização no FID por queda de potência, representada pelos índices HEDP e HEDF. Logo, indo mais uma vez, ao encontro do objetivo deste estudo, que é reduzir o impacto do FID, na usina estudada.

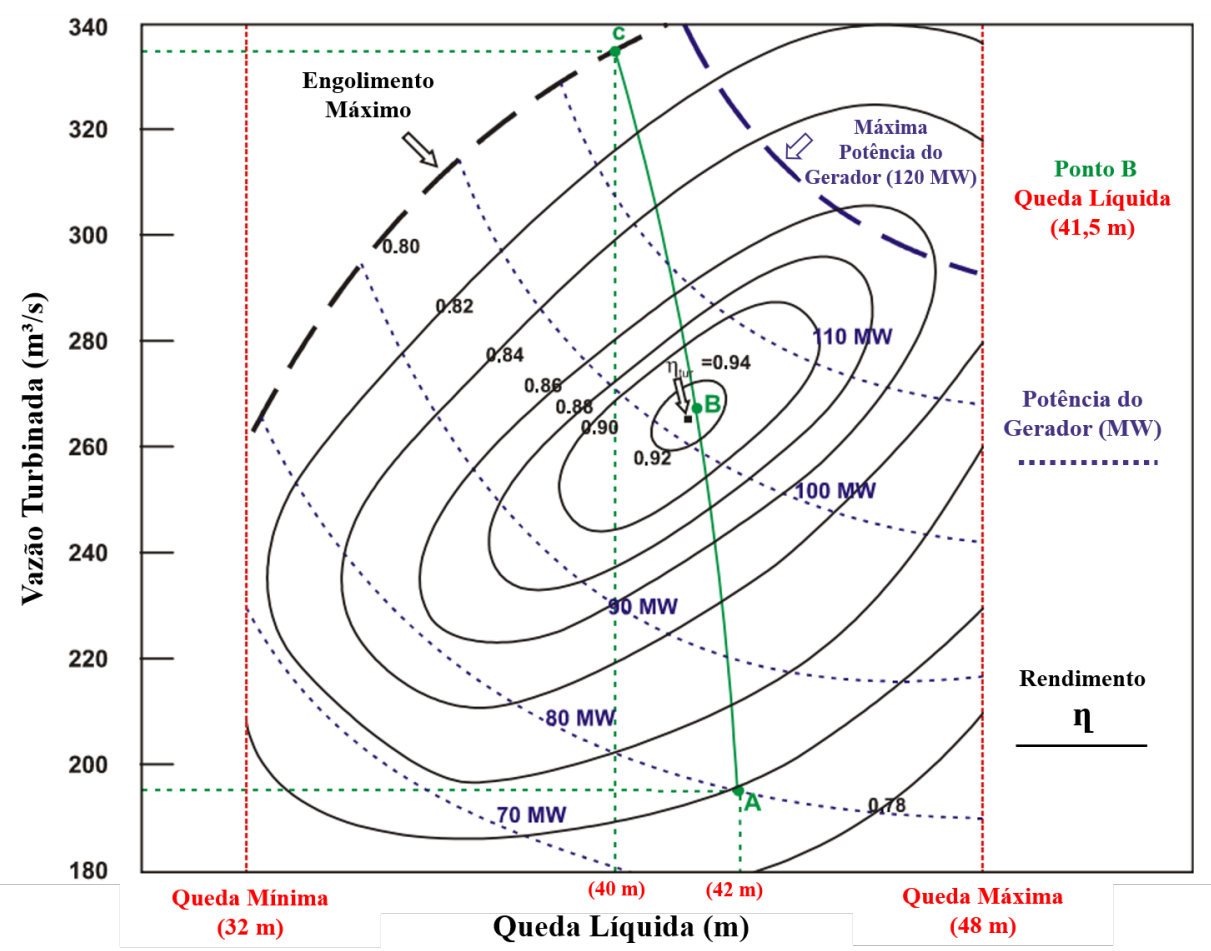

Figura 4.5: Curva Colina Genérica

Fonte: Adaptada [45] 


\section{4}

\section{Modelo Matemático Proposto para a Agenda da Manutenção}

O modelo matemático desenvolvido tem como finalidade otimizar o planejamento da agenda da manutenção de unidades geradoras de uma usina hidrelétrica. O problema envolve variáveis binárias e reais, além de restrições ligadas a tempo e espaço, categorizando-se portanto, em um problema de Programação Linear Inteira-Mista, conhecido em inglês por Mixed Integer Linear Programming (MILP).

O objetivo é otimizar o planejamento da operação e o início da manutenção de cada turbina, representada pelo sub-índice $t$. Além disso, respeitar as restrições do problema, visando minimizar a vazão vertida e consequentemente, reduzir o impacto financeiro ocasionado pelo FID à usina hidrelétrica.

A agenda de manutenção e operação otimizada é feita em base diária, onde cada dia é representado pelo sub-índice $d$. Portanto, a modelagem consiste em minimizar o somatório diário do volume de água vertido. Assim, a metodologia proposta para o problema de programação de manutenção de unidades geradoras é formulada por (4-7)-(4-11).

$$
\min Z=\sum_{d=1}^{D} s_{d}
$$

Sujeito à:

$$
\begin{gathered}
q_{d}=\sum_{g=1}^{G} x_{g, d} \cdot \bar{q}_{g, d} \quad \forall d \in D \\
q_{d}+s_{d}=u_{d} \quad \forall d \in D \\
\sum_{d=1}^{M_{g}-1} y_{g, d}=P_{g} \quad \forall g \in G \\
\left(y_{g, d}=0\right) \vee\left(\sum_{s=0}^{M_{g}-1} x_{g, d+s}=0\right) \quad \forall g \in G, \\
d=1,2,3, \ldots, D-M_{g}+1 \\
\sum_{d=1}^{D} y_{g, d} \leq N \quad \forall g \in G \\
x_{g, d}, y_{g, d} \in[0,1] \cap \mathbb{Z} \\
q_{d}, s_{d} \geq 0
\end{gathered}
$$

Onde:

G Número de unidades geradoras;

$D \quad$ Número de dias; 
$s_{d} \quad$ Vazão vertida pela usina no dia $d\left(\mathrm{~m}^{3} / \mathrm{s}\right)$;

$q_{d} \quad$ Vazão turbinada pela usina no dia $d\left(\mathrm{~m}^{3} / \mathrm{s}\right)$;

$\bar{q}_{g, d} \quad$ Turbinamento máximo da unidade $g$ no dia $d\left(\mathrm{~m}^{3} / \mathrm{s}\right)$;

$u_{d} \quad$ Vazão afluente prevista para o dia $d\left(\mathrm{~m}^{3} / \mathrm{s}\right)$;

$x_{g, d}$ Estado de operação da unidade $g$ em $d$ dias, onde $x_{g, d}=0$ representa inoperante e $x_{g, d}=1$, operante;

$y_{g, d} \quad$ Dia em que incia a manutenção da turbina $g$, onde $y_{g, d}=1$, representa o dia $d$ que a turbina entrou em manutenção;

$M_{g} \quad$ Duração da manutenção da turbina $g$;

$P_{g} \quad$ Número de períodos de manutenção da turbina $g$;

$N \quad$ Máximo de períodos simultâneas de manutenção.

Neste problema, a função objetivo, representada por (4-7), busca minimizar o volume de água vertida na usina, pois quando este ocorre, a hidrelétrica sofre perdas financeiras significativas. Esse processo engloba buscar utilizar o máximo possível de água defluente no rio através do turbinamento (geração de energia) das turbinas disponíveis. O planejamento da manutenção ocorre em intervalos de tempo diários de cada unidade geradora. Esta função objetivo está sujeita as seguintes restrições:

- Restrição de Vazão Turbinada: apresentada em (4-9), cada unidade geradora, quando disponível (estado indicado pela variável $x_{g, d}=1$ ) irá sempre turbinar o seu potencial máximo, resultando a vazão total de turbinamento diário de toda a usina, conforme (4-8). A vazão defluente, que é a vazão turbinada somada a vazão vertida, deve ser sempre igual a vazão afluente do rio para todos os dias do período planejado.

- Restrição de Períodos de Manutenção: o número de manutenções realizadas de cada turbina, deve ser igual ao número de manutenções planejadas desta turbina, representado em (4-10).

- Restrição Duração da Manutenção e Continuidade: todas as unidades geradoras devem ser desligadas durante o período de tempo correspondente a duração de sua manutenção $\left(M_{g}\right)$. Além disso, quando a manutenção é inciada, ela deve ocorrer continuamente (sem interrupções), até que o período planejado seja atendido, ou seja, a manutenção não pode ser abortada ou dada como concluída antes do programado. Estas duas premissas serão atendidas em uma única restrição, expressa em 
(4-11). Esta restrição é uma Restrição Disjuntiva, que diz ou $y_{g, d}=0$ ou a soma $\sum_{s=0}^{M_{g}-1} x_{g, d+s}=0$, mas não simultaneamente. Esta restrição é aplicada para todas as turbinas declaradas no problema.

- Restrição de Limite de Manutenções Iniciando Simultaneamente: indicada por (4-12), indica que a soma dos inícios $y_{g, d}$ no dia $d$ é limitada por um escalar. A restrição é importante de forma a representar limitações da equipe de manutenção da usina hidrelétrica.

- Restrições de Canalização: por fim, as restrições de canalização limitam as variáveis do problema. Para as variáveis binárias, $x_{g, d}$ e $y_{g, d}$, está indicado em (4-13) e para o volume vertido $s_{d}$, em (4-14).

Restrições Disjuntivas dessa natureza são frequentemente encontradas em problemas de programação de agenda da manutenção, pois são aplicáveis quando o problema apresenta regiões viáveis disjuntas. No problema apresentado, a restrição disjuntiva pode ser substituída por um conjunto de desigualdades lineares, usando o auxílio do Big-M (um número extremamente grande), sendo representada em (4-15). O Big-M está representado pelo 'M' aparecendo no lado direito dessa restrição, a qual neste caso é igual à duração de cada período de manutenção $M_{g}$, da respectiva unidade $g$. Portanto, atende a restrição de duração da manutenção e de continuidade ao mesmo tempo.

$$
\begin{array}{r}
\sum_{s=0}^{M_{g}-1} x_{g, d+s} \leq M_{g} \cdot\left(1-y_{g, d}\right) \quad \forall g \in G, \\
d=1,2,3, \ldots, D-M_{g}+1
\end{array}
$$

A otimização considera que as turbinas em operação irão turbinar o seu máximo disponível no dia, dessa forma, a dimensão do problema é reduzida, já que o volume turbinado de cada UG não é uma variável, mas sim, um parâmetro previamente calculado.

Entretanto, de forma a respeitar a restrição apresentada em (4-9), de vazão turbinada, pode ocorrer vertimento desnecessário. Isto acontece, pois na Equação (4-8), o turbinamento de cada UG, será sempre seu máximo.

Exemplificando, o modelo deixará uma turbina inoperante por não ter água o suficiente para operar na sua capacidade máxima e então alocando essa água na parcela da vazão vertida $s_{d}$. Nesse caso, é feita uma melhoria no resultado ótimo obtido pela otimização em (4-7) - (4-14), a fim de contornar esta situação e atingir o fluxo mínimo derramado, de acordo com o fluxograma mostrado na Figura 4.6.

Com o resultado obtido na otimização proposta, inicia-se o processo de ajuste. Primeiramente, para cada dia $d$, caso haja vertimento com turbinas disponíveis, procura-se uma unidade geradora $g$ não operante no dia e sem 


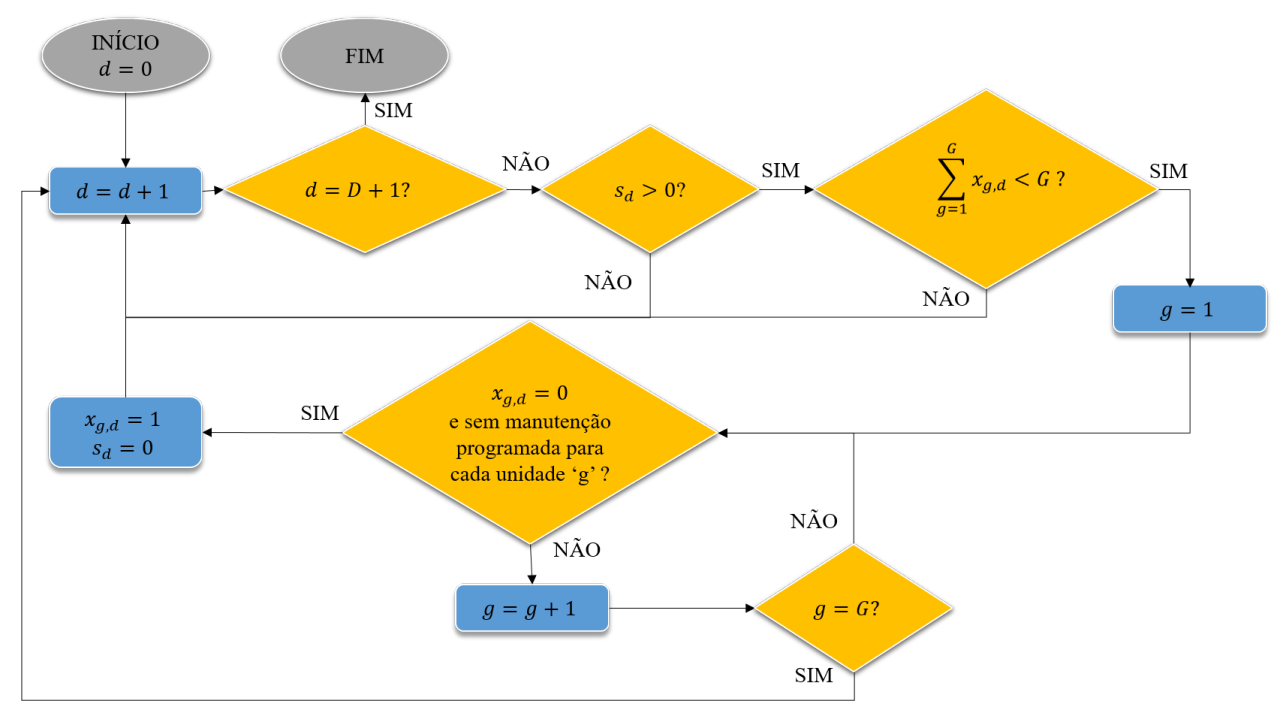

Figura 4.6: Fluxograma para ajuste pós-otimização Fonte: Elaboração Própria

manutenção, ou seja, totalmente disponível, sem afetar o resultado previamente encontrado. Neste caso, essa unidade geradora opera abaixo de sua capacidade, turbinando apenas, o que estava sendo vertido. O processo é aplicado para todos os dias, reduzindo o vertimento da usina e evitando penalizações.

O fluxograma apresentado na Figura 4.7, resume todo o processo proposto neste trabalho para a obtenção de um cronograma de manutenção.

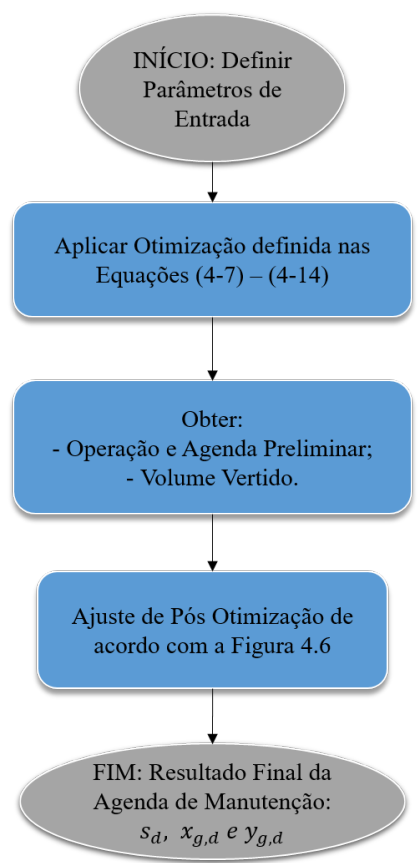

Figura 4.7: Fluxograma Geral da Metodologia Proposta Fonte: Elaboração Própria

Em resumo, a consideração da capacidade máxima e o ajuste feito após a otimização afetam o resultado ideal encontrado inicialmente sem alterar a 
viabilidade da solução. Porém, dada a dimensão do problema e sabendo que o objetivo é minimizar o derramamento, o resultado ajustado encontrado é adequado ao objetivo principal, pois leva a uma operação de derramamento reduzida, evitando penalidades regulamentares.

Ainda sobre o ajuste, propõe-se nesta etapa a utilização do ranking encontrado na aplicação do AHP. Para isso, optou-se por utilizar a classificação da forma inversa, ou seja, buscando aquelas unidades geradoras consideradas com melhor desempenho. Sua aplicação ocorre da seguinte forma, no loop onde busca-se a unidade geradora totalmente disponível, o modelo é direcionado a selecionar aquela última turbina do ranking e disponível. Isto faz com que o modelo deixe "livre" para escolha de manutenção, aquelas turbinas consideradas com pior desempenho.

Para melhor esclarecer a aplicação do AHP, traz-se novamente o Fluxograma de Ajuste, representado na Figura 4.8. Porém, indicando como é considerado a participação do ranking com ordem de prioridade das turbinas. Note que, para selecionar as turbinas de trás para frente na classificação, uma índice auxiliar, chamado de $g_{\text {melhor }}$ é criado, ele segue as mesma característica do índice $g$.

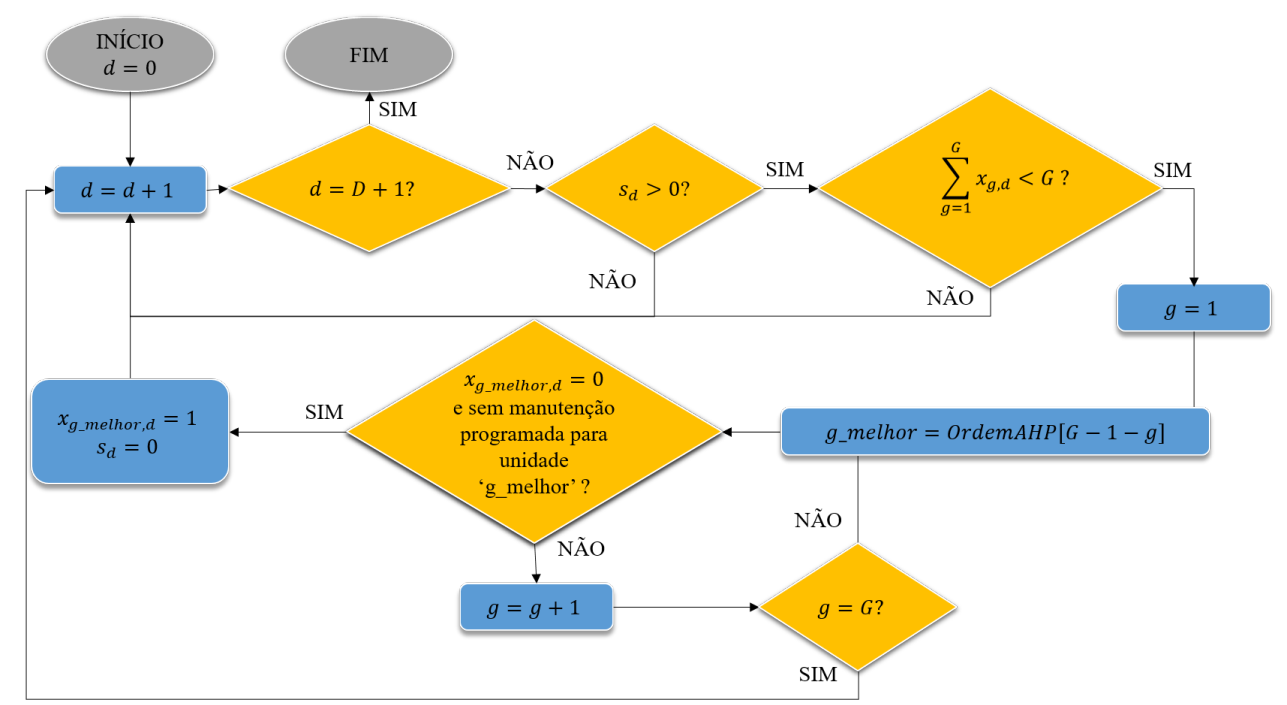

Figura 4.8: Fluxograma para ajuste pós-otimização Modificado Fonte: Elaboração Própria

O fato de optar por utilizar a priorização das turbinas apenas neste momento, faz com o que o modelo otimize da melhor forma a distribuição do cronograma de manutenções, buscando sempre evitar o vertimento, principal objetivo deste trabalho. 


\section{5}

\section{Estudo de Caso}

\section{1}

\section{Informações Gerais}

Este estudo, tem como contexto a Usina Hidrelétrica Santo Antônio. Trata-se de uma usina de grande porte, com modalidade fio d'água, isso quer dizer, o seu reservatório não possui capacidade regularização ou armazenamento.

A hidrelétrica, que está situada no Rio Madeira em Porto Velho, Rondônia, entrou em operação em 30 de março de 2012, mas atingiu geração plena, com todas as turbinas em operação comercial, em janeiro de 2017. A usina tem capacidade de 3.568 MW de potência instalada e 2.424,20 MW médios de garantia física, sendo considerada a quarta maior geradora hídrica do país [2]. A SAE possui 50 turbinas do tipo Bulbo, dividas em dois grupos, 24 turbinas de 4 pás (T4 1-24), com potência média de 69,59 MW e 26 turbinas de 5 pás (T5 1-26), com potência média de 73,29 MW.

A motivação do estudo é em virtude das perdas financeiras que a SAE vem sofrendo, o qual pode ser reduzido com o planejamento ótimo. da manutenção. A duração excessiva e mal programada da manutenção impacta diretamente o FID. Neste sentido, o objetivo do estudo se torna ainda mais necessário, quando é observado o FID da Santo Antônio Energia no período pós-2014, período em que todas as 50 turbinas entraram em operação.

A Figura 5.1 apresenta uma comparação entre o Índice de Disponibilidade Verificado (IDv) e o Índice de Disponibilidade de Referência (ID), entre Janeiro de 2015 e Dezembro de 2019. Logo, como o IDv é inferior ao ID em todos os meses, o FID da Santo Antônio Energia durante todo o período analisado, é menor que 1, impactando negativamente nas finanças da hidrelétrica.

Conforme a Resolução Normativa $n^{o}$ 614/2014, o FID do mês é calculado através dos índices nos últimos 60 meses anteriores ao mês analisado, portanto os valores altos de TEIFa e TEIP, ainda influenciarão nos próximos meses. Entretanto, à medida que alterações forem sendo feitas, principalmente na melhoria dos resultados da TEIP, será observado uma melhora no FID e consequentemente no seu custo mensal. 


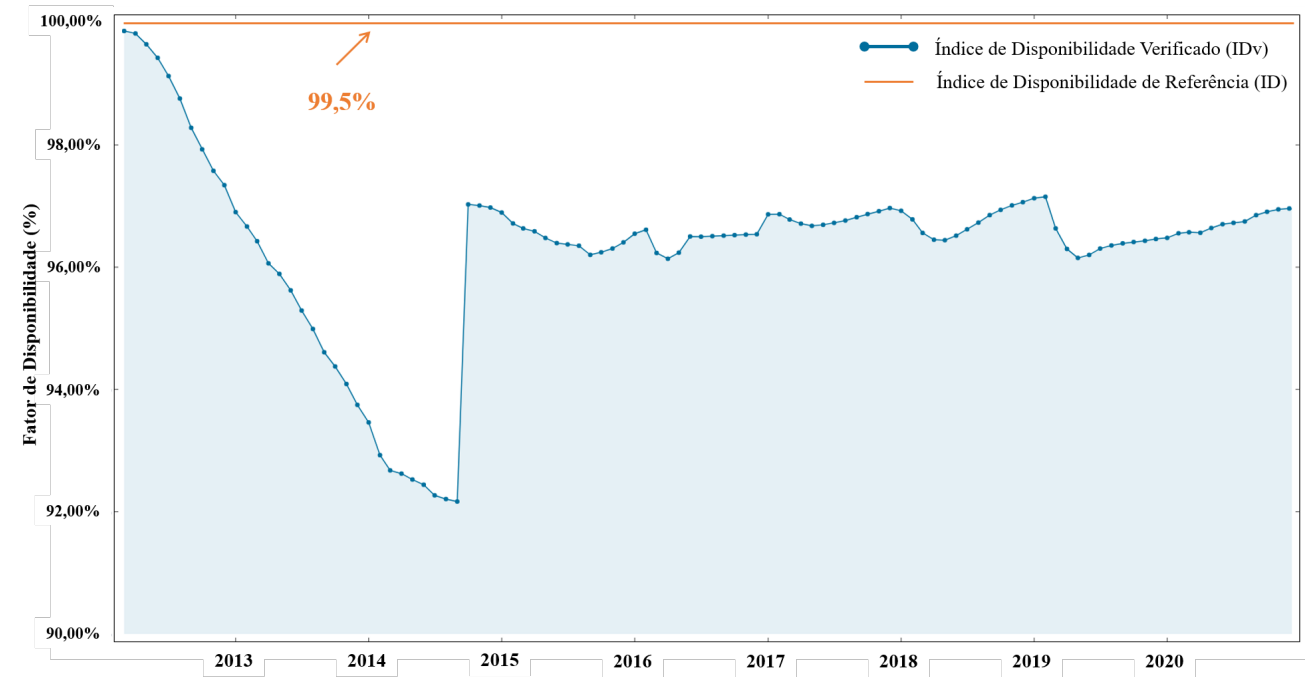

Figura 5.1: FID da Santo Antônio Energia - 2012/2020

Fonte: Dados da Usina Hidrelétrica Santo Antônio

\section{2}

\section{Dados Operacionais}

A vazão afluente da SAE é um dado relevante a ser analisado para o planejamento de manutenções das UGs, visto que, é interessante alocar as manutenções nos períodos de baixa vazão da usina, evitando vertimento.

No caso da Santo Antônio, esta sazonalidade é bem definida, característica do Rio Madeira, local onde a usina está localizada, como pode ser visto na Figura 5.2. Ela apresenta a vazão afluente média da usina, equivalente a vazão defluente, já que trata-se de uma usina a fio d'água.

Para este estudo foi utilizada a base histórica compreendida entre os anos 1968 à 2019 encontrados na base de dados interna da Santo Antônio Energia.

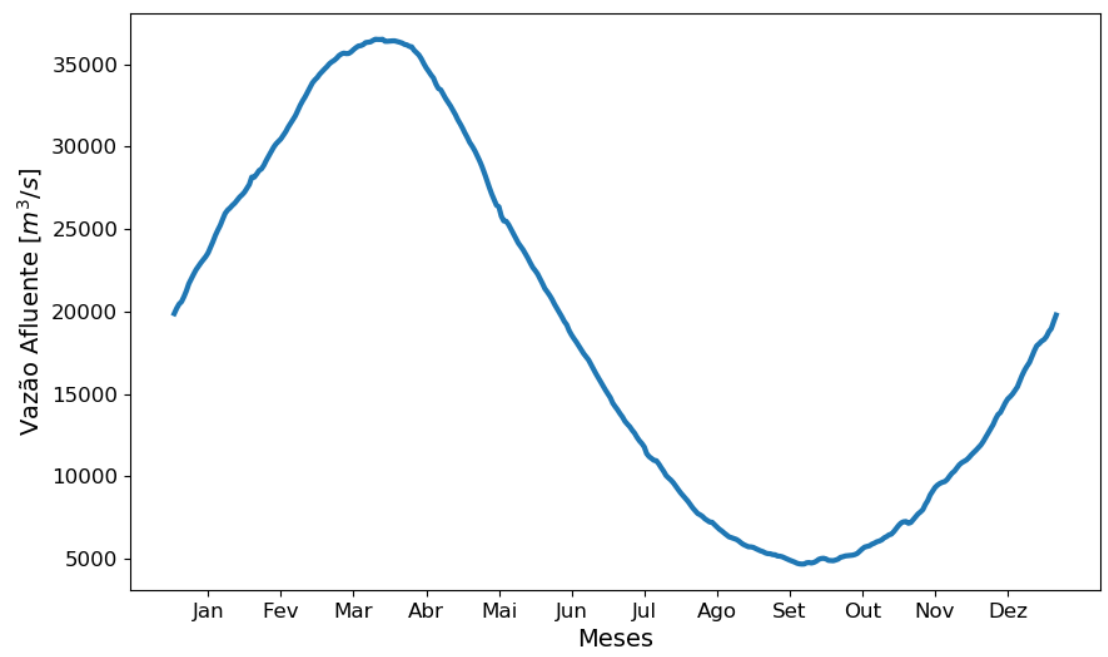

Figura 5.2: Vazão Afluente - Usina Hidrelétrica de Santo Antônio Fonte: Dados da Usina Hidrelétrica Santo Antônio 
É importante relembrar, que as Horas de Desligamento Programado, não são computadas no cálculo do FID quando não há vertimento, ou seja, quando a operação das UGs desligadas, não forem necessárias para o SIN.

Observando a Figura 5.3, ela representa a média do indicador HDP de 2017 à 2019. Nota-se que nos períodos de baixa vazão (entre julho e dezembro) o valor do indicador é baixo ou até nulo. Exemplificando que, as horas de manutenções programadas, não foram contabilizadas no indicador HDP, diferentemente do período de alta vazão, período onde mais UGs devem estar em operação, para turbinar toda a vazão disponível.

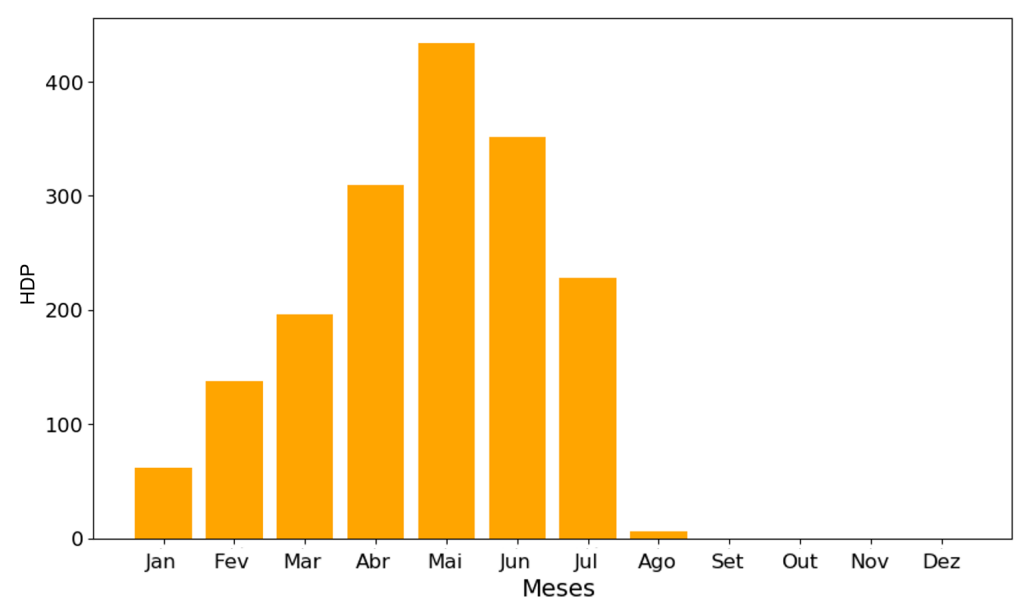

Figura 5.3: Média do Indicador HDP

Fonte: Dados da Usina Hidrelétrica Santo Antônio

Uma nota de esclarecimento, o mês de julho, pertencente ao período de baixa vazão, porém o valor do indicador HDP se mostrou elevado, isso ocorreu devido ao planejamento inadequado de manutenções preventivas ou problemas repentinos que causaram a necessidade de manutenções corretivas. Reforçando mais uma vez, o objetivo do modelo proposto, que é justamente minimizar a ocorrência desses desligamentos durante o ano, com um cronograma ótimo de manutenções.

Devido as características diferentes entre os dois grupos de unidades geradoras, turbinas de 4 e 5 pás, cada grupo possui uma vazão turbinada máxima calculada de acordo com a metodologia apresentada na Seção 4.3. Dessa forma, a Figura 5.4 apresenta as curvas de turbinamento máximo para cada grupo.

Nota-se que, as turbinas de 4 pás são incapazes de operar com determinada vazão afluente, chamando a atenção para alocar as manutenções dessas turbinas, para este período específico. 


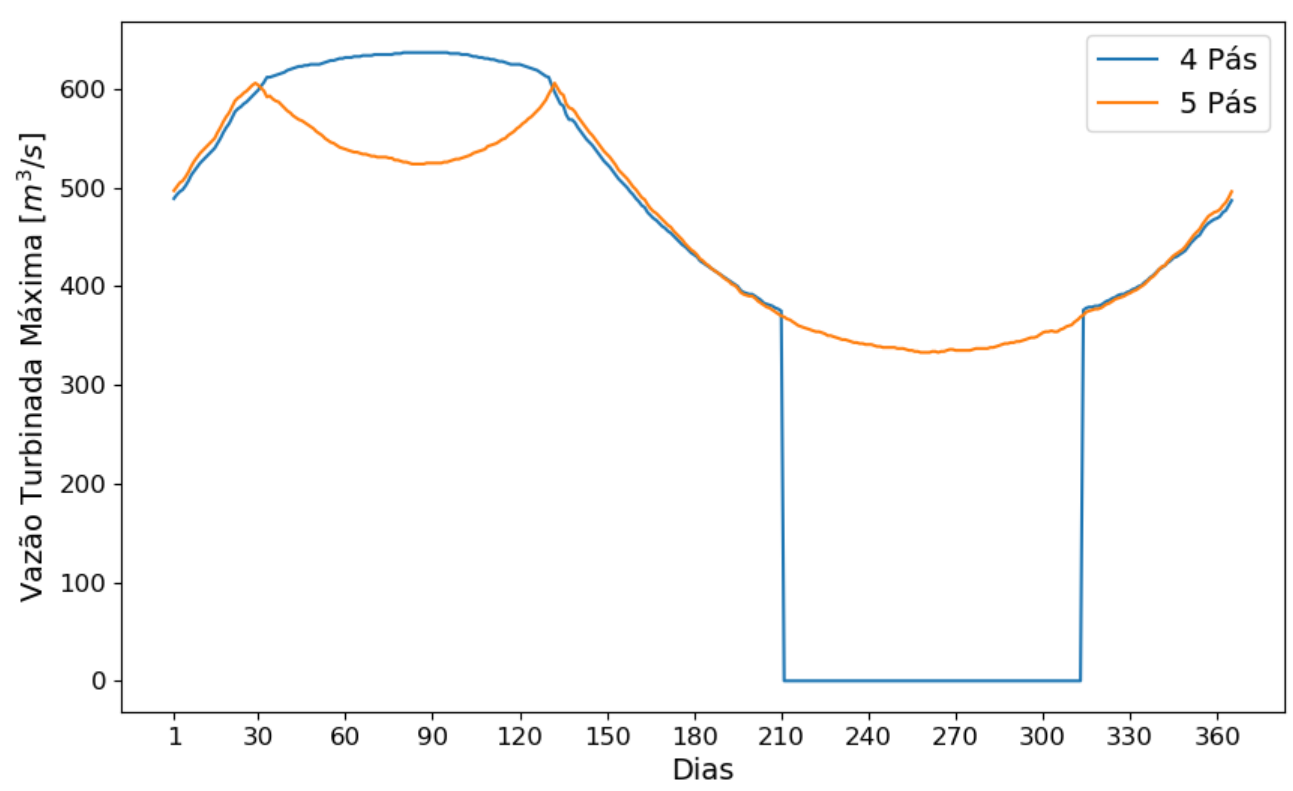

Figura 5.4: Vazão Turbinada Máxima por UG - 4 e 5 pás

\section{3}

\section{Dados de Manutenção}

A escala de manutenção a ser atendida pela SAE, trata-se de cronograma diversificado e extenso, onde algumas turbinas têm apenas um tipo de manutenção a ser realizada e outras, sete tipos de manutenções diferentes.

Afim de minimizar o esforço computacional para a solução, visto que o problema possui 50 unidades geradoras, as manutenções foram então agrupadas por turbina. Para isto, um estudo prévio foi realizado, buscando analisar a viabilidade desta opção de planejamento, sendo a mesma aceita. Portanto, a Duração da Manutenção (DM) em dias, planejado para o ano de 2021, está apresentada na Tabela 5.1.

Tabela 5.1: Duração da Manutenção em Dias

\begin{tabular}{cccc||cccc}
\hline UG & DM & UG & DM & UG & DM & UG & DM \\
\hline T4-01 & 96 & T4-13 & 2 & T5-01 & 130 & $\mathbf{T 5 - 1 4}$ & 38 \\
T4-02 & 58 & T4-14 & 63 & T5-02 & 67 & $\mathbf{T 5 - 1 5}$ & 206 \\
T4-03 & 29 & $\mathbf{T 4 - 1 5}$ & 57 & $\mathbf{T 5 - 0 3}$ & 159 & $\mathbf{T 5 - 1 6}$ & 26 \\
T4-04 & 124 & $\mathbf{T 4 - 1 6}$ & 112 & $\mathbf{T 5 - 0 4}$ & 25 & $\mathbf{T 5 - 1 7}$ & 36 \\
T4-05 & 67 & $\mathbf{T 4 - 1 7}$ & 54 & $\mathbf{T 5 - 0 5}$ & 60 & $\mathbf{T 5 - 1 8}$ & 58 \\
T4-06 & 142 & $\mathbf{T 4 - 1 8}$ & 44 & $\mathbf{T 5 - 0 6}$ & 173 & $\mathbf{T 5 - 1 9}$ & 110 \\
$\mathbf{T 4 - 0 7}$ & 73 & $\mathbf{T 4 - 1 9}$ & 95 & $\mathbf{T 5 - 0 7}$ & 59 & $\mathbf{T 5 - 2 0}$ & 28 \\
T4-08 & 56 & $\mathbf{T 4 - 2 0}$ & 116 & $\mathbf{T 5 - 0 8}$ & 161 & $\mathbf{T 5 - 2 1}$ & 60 \\
T4-09 & 71 & $\mathbf{T 4 - 2 1}$ & 22 & $\mathbf{T 5 - 0 9}$ & 61 & $\mathbf{T 5 - 2 2}$ & 45 \\
$\mathbf{T 4 - 1 0}$ & 2 & $\mathbf{T 4 - 2 2}$ & 36 & $\mathbf{T 5 - 1 0}$ & 89 & $\mathbf{T 5 - 2 3}$ & 141 \\
T4-11 & 33 & $\mathbf{T 4 - 2 3}$ & 57 & $\mathbf{T 5 - 1 1}$ & 156 & $\mathbf{T 5 - 2 4}$ & 78 \\
T4-12 & 90 & $\mathbf{T 4 - 2 4}$ & 50 & $\mathbf{T 5 - 1 2}$ & 43 & $\mathbf{T 5 - 2 5}$ & 181 \\
& & & & $\mathbf{T 5 - 1 3}$ & 63 & $\mathbf{T 5 - 2 6}$ & 145 \\
\hline
\end{tabular}




\section{4}

\section{Ordem de Prioridade para Realização da Manutenção Preventiva}

A ordem de prioridade a ser seguida no modelo matemático, para realizar a manutenção preventiva, pode ser vista na Seção 3.4. Porém, para construir a agenda, a ordem precisa ser continua, englobando um ranking com todas as 50 turbinas.

Em vista disso, montou-se um novo ranking, seguindo o percentual de priorização de cada turbina, encontrado na Etapa 8 do AHP. Relembrando que estes dois grupos de turbinas, 4 e 5 pás, não são comparáveis entre si com relação ao desempenho operacional, por isso a separação na análise do AHP. Destacando que, esta separação será fundamental na análise dos resultados apresentada no Capítulo 6.

Logo, para o estudo de caso, a ordem de prioridade encontrada e a ser seguida, encontra-se na Tabela 5.2. A direita de cada turbina está o percentual de prioridade encontrado. Lembrando que, no modelo matemático está sendo utilizada a ordem inversa encontrada no ranking, selecionando as turbinas com melhor desempenho.

Tabela 5.2: Ordem de Prioridade Geral

\begin{tabular}{cc|cc|cc|cc}
\hline UG & \% & UG & \% & UG & \% & UG & \% \\
\hline T5-24 & $19,77 \%$ & T4-21 & $3,97 \%$ & $\mathbf{T 5 - 2 5}$ & $3,02 \%$ & $\mathbf{T 4 - 1 9}$ & $2,02 \%$ \\
T5-08 & $14,09 \%$ & $\mathbf{T 5 - 1 8}$ & $3,86 \%$ & $\mathbf{T 5 - 2 3}$ & $2,97 \%$ & $\mathbf{T 5 - 0 4}$ & $1,98 \%$ \\
T4-04 & $11,93 \%$ & $\mathbf{T 4 - 2 4}$ & $3,84 \%$ & $\mathbf{T 4 - 0 3}$ & $2,81 \%$ & $\mathbf{T 5 - 1 6}$ & $1,73 \%$ \\
T5-26 & $9,10 \%$ & $\mathbf{T 4 - 2 2}$ & $3,65 \%$ & $\mathbf{T 4 - 0 7}$ & $2,76 \%$ & $\mathbf{T 5 - 1 3}$ & $1,61 \%$ \\
T4-09 & $8,23 \%$ & $\mathbf{T 5 - 0 3}$ & $3,62 \%$ & $\mathbf{T 4 - 1 7}$ & $2,54 \%$ & $\mathbf{T 5 - 2 1}$ & $1,59 \%$ \\
$\mathbf{T 4 - 1 5}$ & $7,84 \%$ & $\mathbf{T 5 - 0 6}$ & $3,48 \%$ & $\mathbf{T 5 - 1 2}$ & $2,53 \%$ & $\mathbf{T 5 - 1 4}$ & $1,52 \%$ \\
$\mathbf{T 4 - 1 8}$ & $6,25 \%$ & $\mathbf{T 4 - 2 0}$ & $3,47 \%$ & $\mathbf{T 4 - 0 6}$ & $2,48 \%$ & $\mathbf{T 5 - 0 2}$ & $1,43 \%$ \\
$\mathbf{T 5 - 0 7}$ & $5,57 \%$ & $\mathbf{T 5 - 1 0}$ & $3,35 \%$ & $\mathbf{T 4 - 1 2}$ & $2,41 \%$ & $\mathbf{T 5 - 2 2}$ & $1,38 \%$ \\
$\mathbf{T 4 - 0 8}$ & $5,54 \%$ & $\mathbf{T 5 - 0 5}$ & $3,30 \%$ & $\mathbf{T 5 - 0 1}$ & $2,36 \%$ & $\mathbf{T 5 - 1 5}$ & $1,30 \%$ \\
T4-23 & $5,26 \%$ & $\mathbf{T 4 - 1 0}$ & $3,26 \%$ & $\mathbf{T 5 - 2 0}$ & $2,28 \%$ & $\mathbf{T 4 - 1 1}$ & $1,29 \%$ \\
T4-05 & $4,63 \%$ & $\mathbf{T 4 - 1 4}$ & $3,25 \%$ & $\mathbf{T 4 - 0 2}$ & $2,20 \%$ & $\mathbf{T 5 - 1 9}$ & $1,04 \%$ \\
$\mathbf{T 5 - 0 9}$ & $4,12 \%$ & $\mathbf{T 4 - 0 1}$ & $3,24 \%$ & $\mathbf{T 5 - 1 1}$ & $2,17 \%$ & $\mathbf{T 5 - 1 7}$ & $0,86 \%$ \\
$\mathbf{T 4 - 1 6}$ & $4,04 \%$ & $\mathbf{T 4 - 1 3}$ & $3,10 \%$ & & & & \\
\hline
\end{tabular}

Vale ressaltar que por questões de sigilo, em todo o trabalho as designações atribuídas para as unidades geradoras não são as mesmas utilizadas pela Santo Antônio Energia. 


\section{6 \\ Resultados e Discussões}

\section{1}

\section{Resultados Obtidos com a Aplicação do Método AHP}

A análise utilizando o Método de Multicritério AHP fornece uma classificação das turbinas com baixo desempenho de forma mais refinada e sofisticada, ao contrário da análise simples, que analisa apenas um critério.

Portanto, os resultados obtidos e apresentados na Tabela 3.9, que pode ser revista no Capítulo 3, apresentam resultados interessantes. Dentro do Grupo de UGs de 4 pás, as turbinas 04; 09; 15; 18; 08; 23; 05 e 16 estão no topo, apresentando o pior desempenho nesta sequência, representado juntas, mais de $50 \%$ na ordem de prioridade. Destaque-se ainda, a turbina T4-04, liderando a prioridade no seu grupo.

Já no Grupo de UGs de 5 pás, as unidades 24 e 08 possuem grande importância, através do método AHP, encontra-se que elas representam 1/3 da prioridade do seu respectivo grupo. Este fato reforça a necessidade de direcionar manutenções preventivas para essas UGs.

Partindo para uma outra perspectiva, pode ser observado através da Figura 6.1, que se o gestor avalia apenas um critério, os resultados com relação a ordem de prioridade, seriam diferentes. Por exemplo, considerando o Grupo de 4 pás, analisando a média de HDF + HEDF, a primeira alternativa escolhida para priorizar a manutenção seria a turbina T4-23, entretanto, no método AHP, essa alternativa encontra-se na $6^{a}$ posição.

A mesma divergência ocorre para outros índices, se escolhido o critério TF, a primeira opção seria a T4-18, pelo índice INDISPMP, seria a turbina T4-08, da mesma forma a decisão para os demais critérios. Portanto, conclui-se que se avaliados individualmente, podem gerar uma decisão que não atenda de uma forma global a todas as necessidades do decisor.

Com relação a classificação encontrada no Grupo de 5 pás, comparando o método AHP com o critério HDF + HEDF, as duas primeiras posições apresentam semelhança nas duas análises, reforçando a priorização da manutenção preventiva destas turbinas, T5-24 e T5-08. Após elas, orienta-se seguir a sequência encontrada no ranking do AHP. 


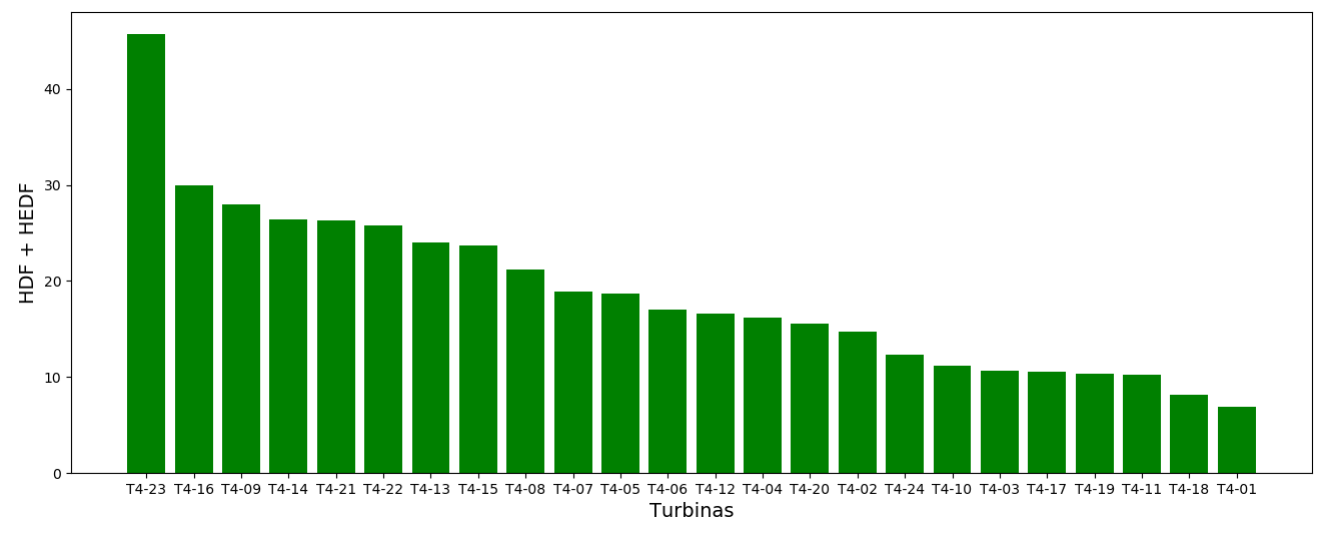

Figura 6.1: HDF + HEDF - Grupo de 4 pás

No entanto, comparando também com a análise individual de outros critérios, algumas divergências são notadas. A turbina T5-24 por exemplo, na primeira colocação do método AHP, se analisado apenas o critério TF, demonstrado na Figura 6.2, encontraria-se na $16^{a}$ posição e se fosse o critério TDF, estaria na $19^{a}$ posição de priorização.

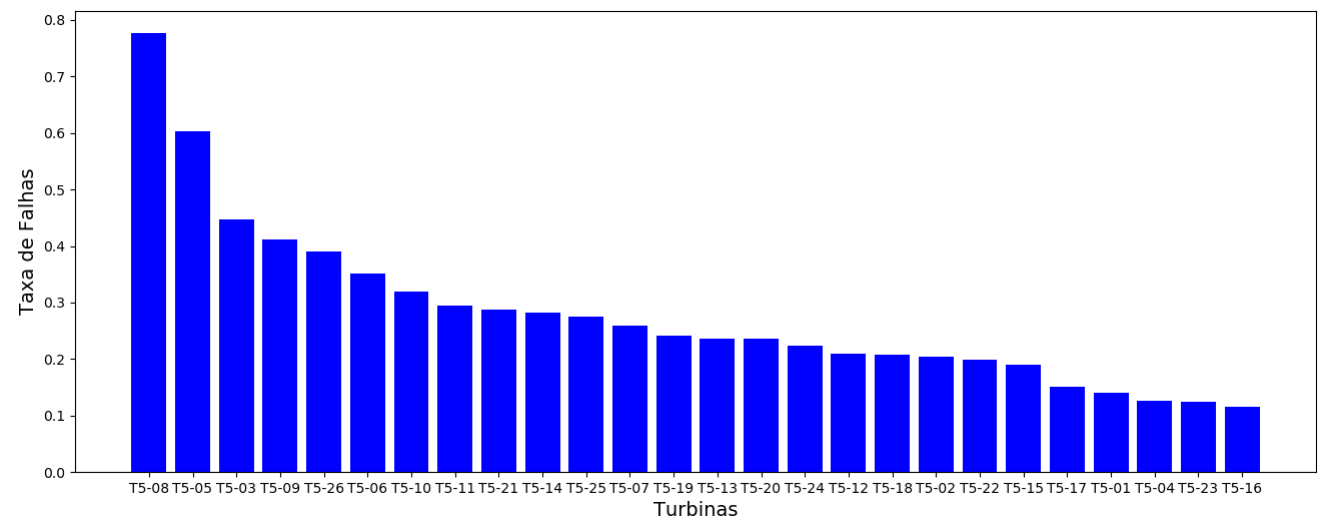

Figura 6.2: TF - Grupo de 5 pás

Em vista disso, a análise de apenas um índice pode levar à uma decisão equivocada, dessa forma, para considerar todos os parâmetros disponíveis de forma global, a aplicação do método AHP se mostra extremamente necessária, resultando em uma classificação mais realista das UGs, Além disso, auxilia de forma mais eficiente a usina, na prioridade da realização de manutenções programadas.

\section{2}

\section{Resultados Obtidos com a Modelagem Matemática Proposta}

Com os dados apresentados no Estudo de Caso, o problema consiste em 3.6866 variáveis binárias, 366 variáveis reais e 15.084 restrições. O modelo de otimização proposto foi desenvolvido em Python, utilizando o solver Gurobi e simulado em um computador com a seguinte configuração: processador Intel ${ }^{\circledR}$ 
Core $^{\mathrm{TM}}$ i5-3210M, com $2.50 \mathrm{GHz}, 12 \mathrm{~GB}$ de RAM e sistema operacional Windows. A simulação foi realizada em aproximadamente 20 minutos.

Primeiramente, a Figura 6.3 mostra o volume turbinado total pela usina ao longo do ano. Pode-se observar, que somente no período de alta vazão houve vertimento, entretanto, observando a Figura 6.4, quando houve vertimento, todas as unidades geradoras estavam em plena operação, ou seja, a usina não possui capacidade de turbinar toda a vazão afluente. Dessa forma, como explicado pela Figura 4.2, não haverá penalização para a usina devido à paradas por manutenção, pois duas situações ocorreram:

1. Toda vazão afluente foi turbinada pelas UGs, vertimento nulo: sem penalização;

2. Vertimento positivo, entretanto, todas UGs operando e sem limitações: sem penalização.

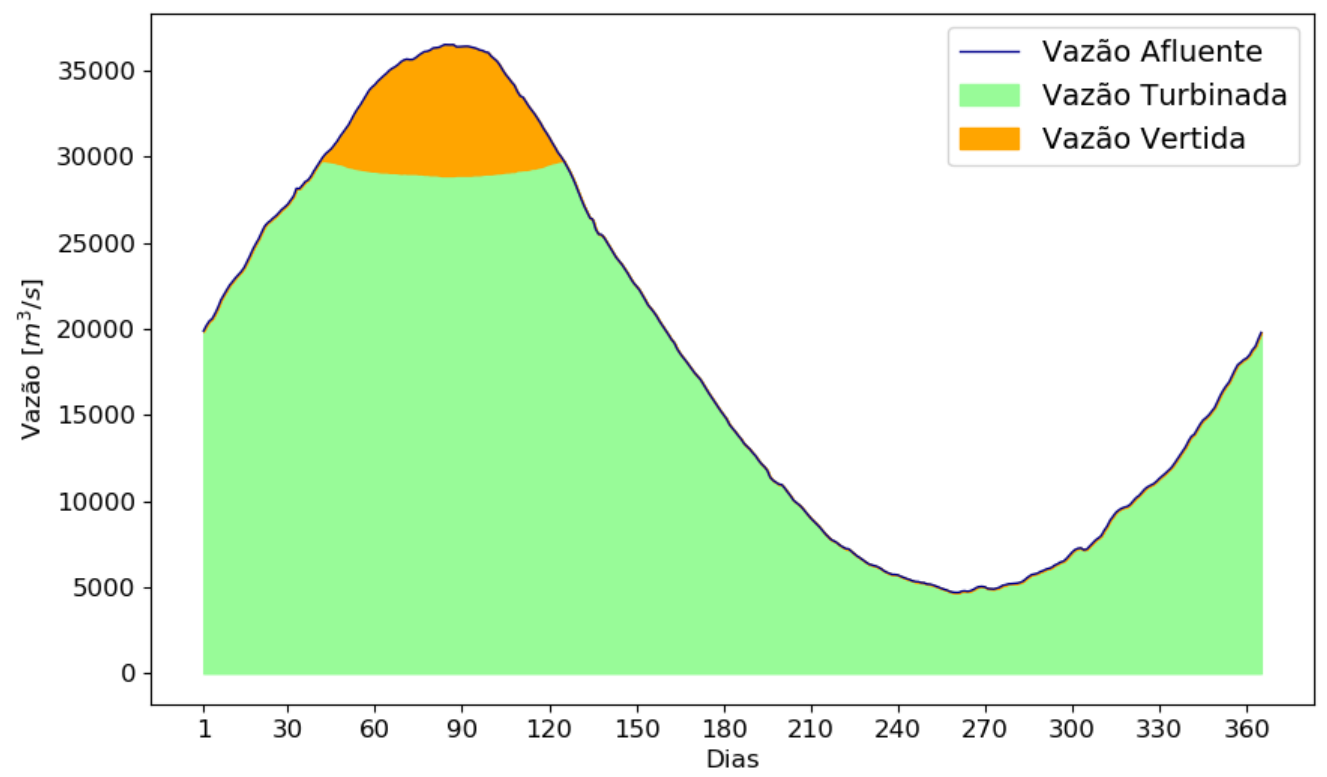

Figura 6.3: Volume Turbinado e Vertido ao Longo do Ano

Dessa forma, pode-se afirmar que o agendamento das manutenções otimizado foi satisfatório, respeitando todas as manutenções necessárias, sendo possível operar devidamente ao longo do ano, evitando assim, penalizações indesejadas.

A Figura 6.5 apresenta o número de UGs em operação (verde), manutenção (laranja) e inativas (azul) ao longo do ano. Como esperado, há um maior número de unidades ativas nos períodos de alta vazão, chegando a ter todas as 50 UGs ativas. Em seguida, esse número reduz à medida que a vazão afluente diminui e portanto as manutenções são iniciadas. 


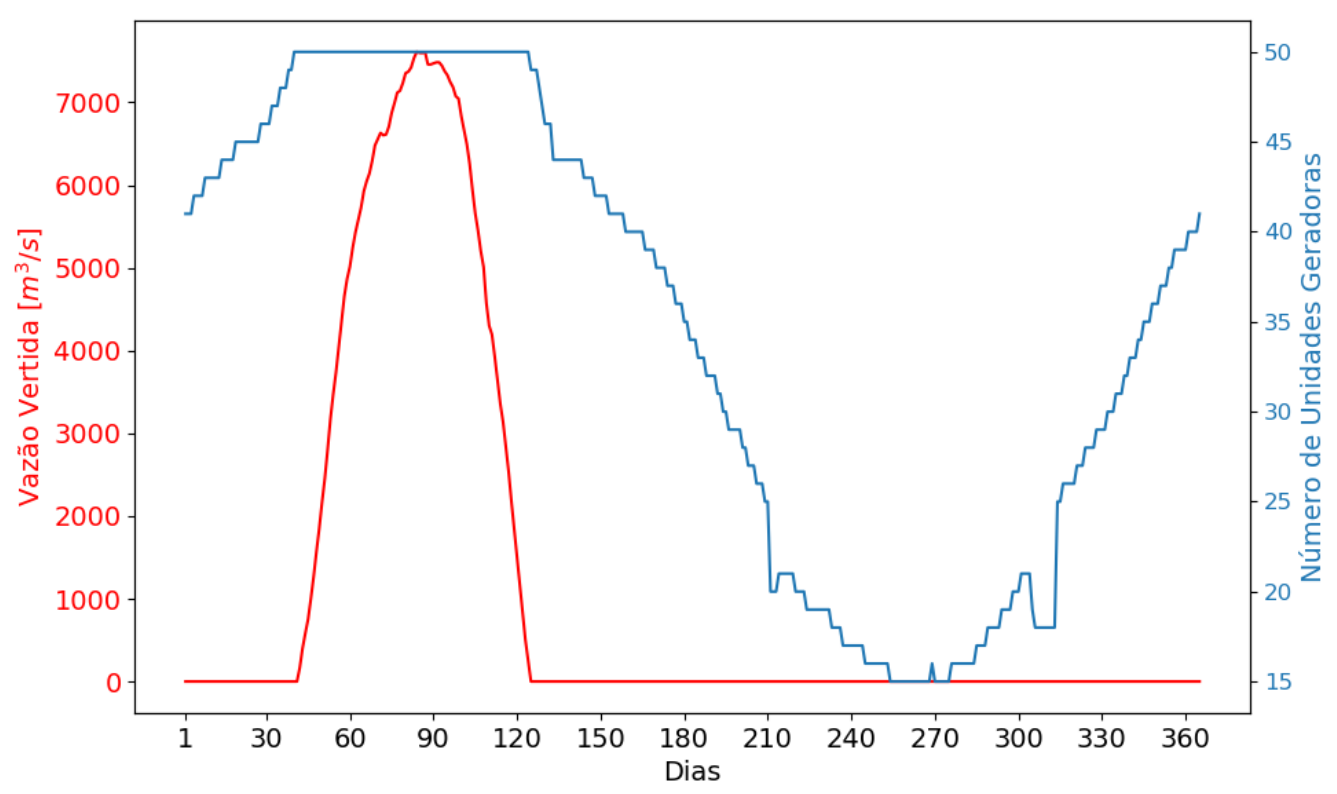

Figura 6.4: Vertimento e Número de UGs em Operação

Além disso, nenhuma manutenção começa no início do ano, pois devido à restrição de continuidade, ao iniciar a manutenção, a UG só deverá ficar disponível novamente, após o fim da atividade de manutenção. Portanto, de forma a evitar penalização por vertimento no período de alta vazão, as manutenções só iniciam após esse período.

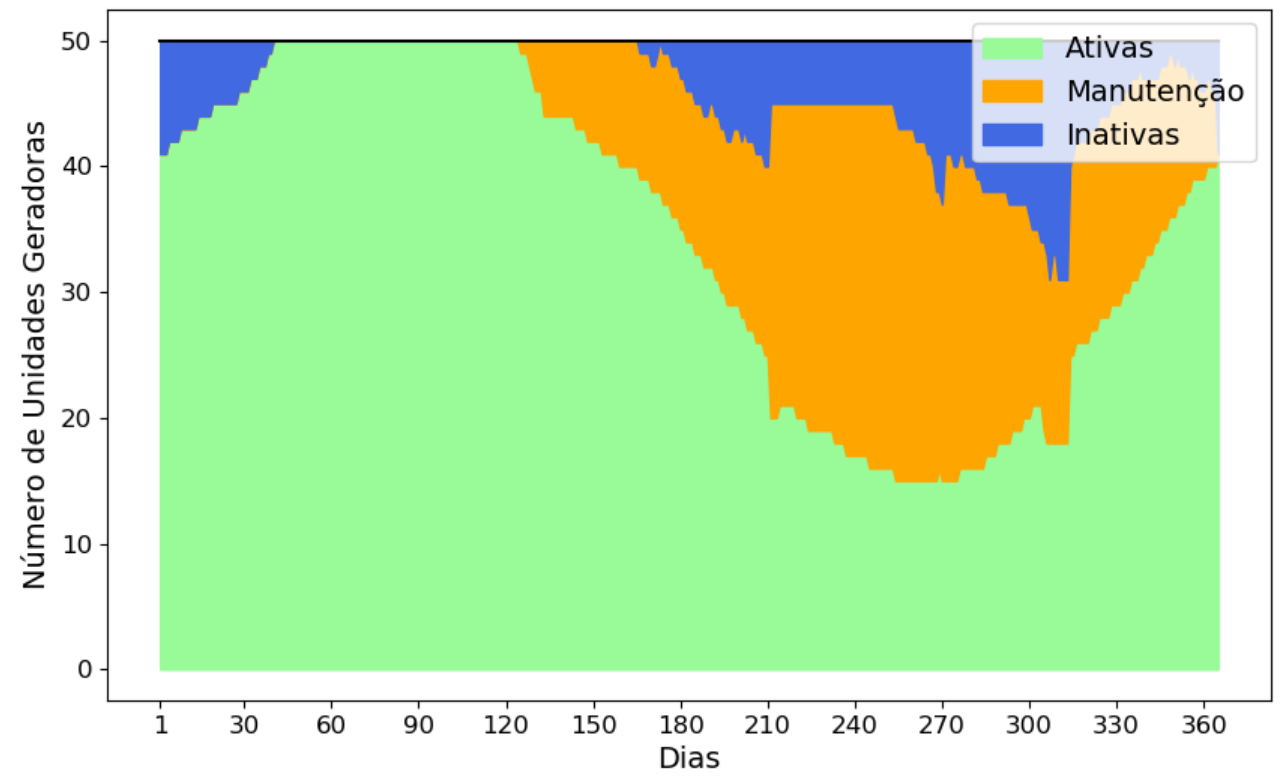

Figura 6.5: Número de UGs em Operação, Manutenção e Paradas

Já a Figura 6.6, apresenta o número de manutenções realizadas em cada dia, pode-se observar que o pico de manutenções simultâneas ocorre no período de baixa vazão. 


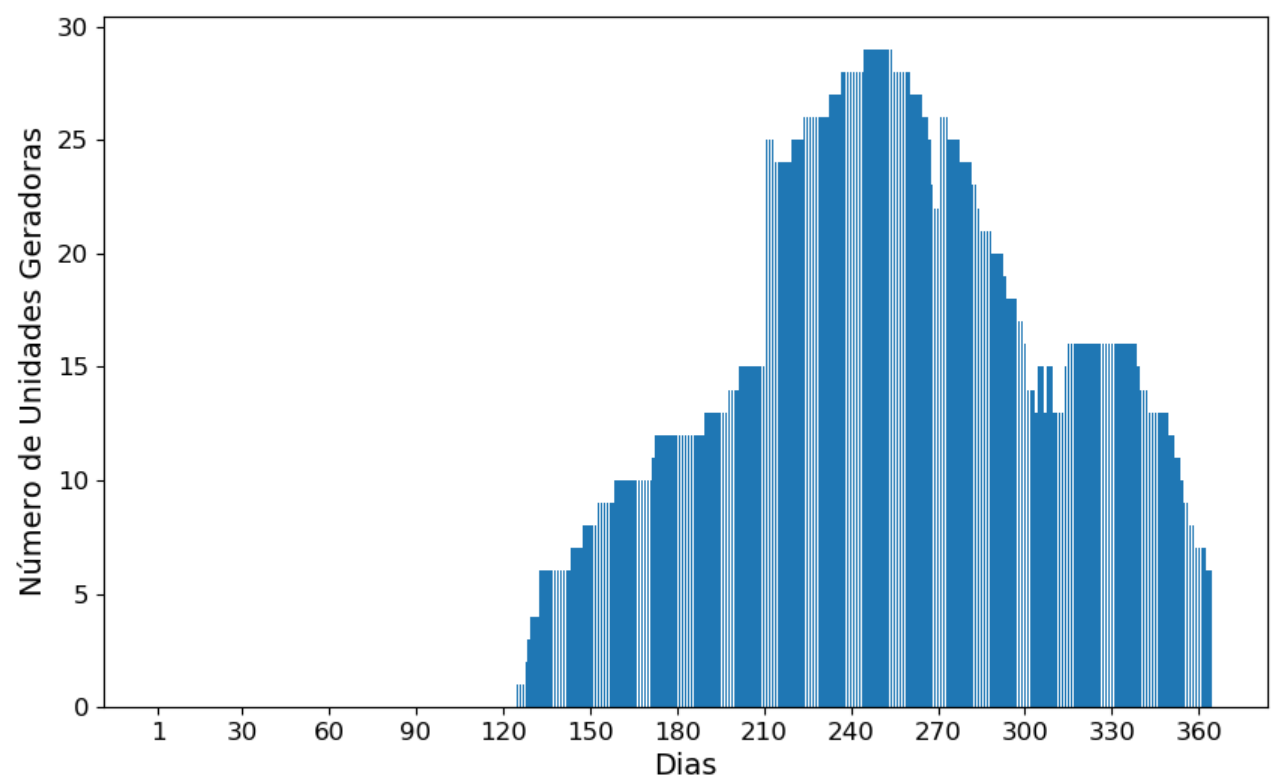

Figura 6.6: UGs em Manutenção

Por fim, de forma a complementar a análise dos resultados, a Figura 6.7 apresenta o calendário geral das manutenções, mostrando o dia de início e duração para a manutenção realizada em cada UG. Como mostrado anteriormente, as manutenções se iniciam após o período de alta vazão, de forma a reduzir as penalizações por vertimento.

Além disso, outro destaque na Figura 6.7, é o início de boa parte das manutenções das UGs de 4 pás (UG 1 a 24), que iniciam no dia 211, justamente quando essas UGs não conseguem turbinar. Isto ocorre devido às restrições operativas de queda, ocasionada pela baixa vazão, conforme a curva apresentada na Figura 5.4.

Por último e não menos importante, a agenda da manutenção seguiu parcialmente a ordem de priorização do AHP, como demonstrado nas regras de aplicação na metodologia. As manutenções das turbinas então, seguiram a melhor ordem que priorize o não vertimento de água na usina, porém, sempre que possível, seguiam a ordem do ranking encontrado.

Observa-se por exemplo, como já mencionado, que as turbinas de 4 pás iniciaram a realização da manutenção no período em que não estavam em condições de operar. Neste caso, todas as turbinas deste grupo, iniciaram a manutenção ao mesmo tempo, não seguindo a ordem encontrado no AHP.

Esta abordagem foi identificada como necessária no decorrer do estudo, uma vez que priorizar fidedignamente o ranking, infringiria o principal mérito deste estudo, que é evitar a penalização sofrida na usina pelo FID. Lembrando que, este cenário ocorre quando há vertimento de água na usina por responsabilidade da opções operacionais da hidrelétrica. 


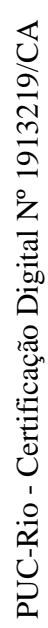

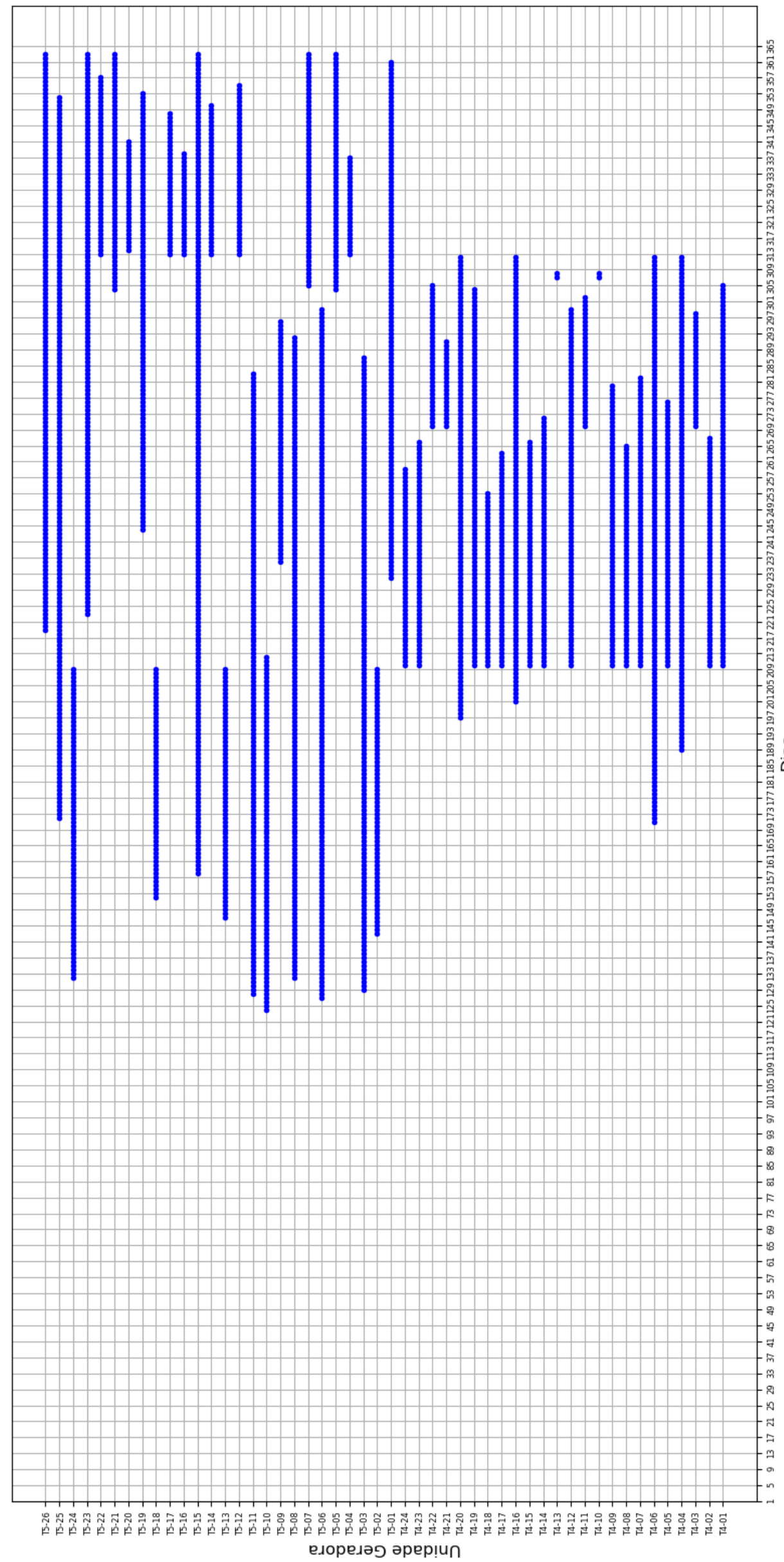

Figura 6.7: Calendário Final de Manutenção 


\section{7}

\section{Conclusões e Sugestões de Trabalhos Futuros}

Neste trabalho, o método de apoio a decisão multicritério AHP foi aplicado com objetivo de classificar as turbinas de uma usina hidrelétrica. O intuito foi auxilia-la no planejamento do cronograma das manutenções programadas, priorizando as piores turbinas indicadas pelo AHP a realizarem suas manutenções primeiro. Mas, em vista de priorizar o não vertimento de água na usina, optou-se por utilizar de forma parcial o ranking do AHP, trazendo ainda resultados significativos.

Para aplicação do método, as alternativas são as UGs, separadas em seus grupos de acordo com o número de pás. Já os critérios são as médias históricas dos índices de indisponibilidade e manutenção de cada unidade. Este índices, refletem o impacto direto e indireto das manutenções no cálculo do FID, o que resulta em grandes perdas financeiras para as usinas, de acordo com a Resolução Normativa no 614/2014.

Dessa forma, a aplicação do AHP permite obter uma classificação global das turbinas presentes na usina, levando em consideração os diversos índices relevantes das máquinas e seus respectivos pesos. Sendo assim foi possível encontrar a ordem prioridade para as UGs de 4 e 5 pás, determinando um ranking informando as turbinas com desempenhos piores e melhores.

É importante ressaltar, que as premissas do modelo AHP, podem e devem ser alteradas de acordo com as necessidades do gestor e/ou sempre que houver necessidade de reavaliação das prioridades das turbinas. Sugerese principalmente, utilizar outros indicadores mensurados na usina, como por exemplo, indicadores de custo e ainda alterar os pesos de cada critério, para um melhor retrato da realidade da usina, seguindo como sugestão para trabalhos futuros.

Considera-se que a avaliação da matriz de critérios realizada apenas por um especialista foi satisfatória, uma vez que a avaliação foi feita por um gestor da manutenção em diálogo com sua equipe, portanto, buscando atender os objetivos da usina através da experiência destes colaboradores. No entanto, entende-se ainda, que a análise compreendida por gestores de outras áreas trará questionamentos e benefícios significativos nesta etapa do modelo, sugerindo também como ponto de melhoria para futuros trabalhos. 
A principal contribuição desta etapa é a obtenção da classificação das turbinas utilizando dados reais da Santo Antônio Energia, a qual é de grande importância para o agente. O método AHP fornece significativo auxílio para quais unidades devem ser priorizadas para operação no modelo matemático, buscando deixar livres, aquelas com pior desempenho, para que recebam a manutenção preventiva assim que possível. Logo, o objetivo é evitar paradas forçadas, que impactam diretamente no FID, levando a grandes prejuízos financeiros.

O trabalho em geral, apresentou um modelo de otimização MILP (Programação Linear Inteira-Mista), para solucionar o problema de agendamento da manutenção de unidades geradoras de usinas hidrelétricas. A agenda otimizada é realizada em base diária com horizonte anual.

O modelo proposto considerou aspectos regulatórios, bem como restrições operativas e de duração e limitação da manutenção. Teve como objetivo, minimizar vertimento de água por parte da usina, visando a redução de penalizações financeiras, conforme apresentado neste estudo.

A principal motivação para o trabalho é evidenciada na Usina Hidrelétrica Santo Antônio, a qual é uma usina de grande porte e conectada no sistema elétrico brasileiro, conforme apresentado. Dessa forma, a otimização proposta foi aplicada utilizando dados reais da usina, demostrando sua aplicabilidade em problemas de grandes dimensões.

Com os resultados obtidos, as manutenções necessárias foram agendadas ao longo do ano, respeitando suas respectivas durações. Além disso, a otimização eliminou qualquer penalização, já que houve apenas vertimento no período de alta vazão, onde a usina opera com toda sua capacidade, portanto, não sendo penalizada.

Como sugestões de trabalhos futuros, propõe-se realizar testes do modelo com outros métodos de otimização, como por exemplo, através de metaheurísticas, algumas delas até foram citadas neste estudo. Além do mais, sugere-se também, expandir o universo de variáveis com relação ao número de manutenções de cada UG.

Neste estudo, agrupou-se todos os tipos de manutenções de uma mesma turbina, porém, recomenda-se identificar no modelo, os diversos tipos de manutenções, retratando de forma mais fidedigna, a realidade da usina. Esta sugestão, reforça ainda mais, a busca de métodos meta-heurísticos de solução, uma vez que o esforço computacional será maior.

Outro aspecto importante é com relação a vazão média utilizada neste estudo, sugere-se para trabalhos futuros a geração de cenários sintéticos de afluência. Cada vez mais, novas técnicas de previsão têm sido utilizadas 
e portanto, obtendo melhores resultados de previsões, tornando assim, o planejamento de operações mais eficiente.

O modelo matemático proposto é capaz de receber como parâmetro de entrada possíveis manutenções corretivas. Nesse caso, os dias com desligamentos forçados esperados terão um número limitado de UGs disponíveis para operação. Porém, vale ressaltar, que novos estudos principalmente sobre o contexto de projeções de cenários de paradas forçadas são sugeridos.

Em suma, ressalta-se a importância de levar em consideração a estocasticidade do problema. Levando em consideração por exemplo, possíveis cenários de afluência e manutenções forçadas.

Sendo assim, pode-se afirmar que o modelo proposto foi aplicado de forma satisfatória, sendo validado em um caso real. Além disso, atendeu o objetivo de reduzir penalizações regulatórias, aliás, de grande relevância para outras usinas hidrelétricas brasileiras, principalmente de grande porte. 


\section{Referências bibliográficas}

[1] EPE. Plano decenal de expansão de energia, 2021. Disponível em: https://www.epe.gov.br/sites-pt/publicacoes-dados-abertos/ publicacoes/PublicacoesArquivos/publicacao-490/topico-564/ Minuta_do_Plano_Decenal_de_Expansao_de_Energia_2030__PDE_ 2030.pdf.

[2] ONS. Site oficial da ons. http://www.ons.org.br, 2020. Acessado em novembro de 2020 .

[3] CCEE. Site oficial da câmara de comercialização de energia elétrica. http://www.ccee.org.br, 2020. Acessado em novembro de 2020.

[4] ANEEL. Resolução normativa $n^{o} 688 / 2003$, de 24 de dezembro de 2003, 2003. Disponível em: http://www2.aneel.gov.br/cedoc/ res2003688.pdf.

[5] DE SOUZA, F. C.; LEGEY, L. F. L.. Brazilian electricity market structure and risk management tools. In: 2008 IEEE POWER AND ENERGY SOCIETY GENERAL MEETING-CONVERSION AND DELIVERY OF ELECTRICAL ENERGY IN THE 21ST CENTURY, p. 1-8. IEEE, 2008.

[6] CCEE. Regras de Comercialização - Garantia Física. Câmara de Comercialização de Energia, 2020. Disponível em:https://www.ccee.org. br/. Acessado em novembro de 2020.

[7] BRANDÃO, L. E. T.. Risk control models for Brazilian hydropower investments: A proposal. PhD thesis, PUC-Rio, 2018.

[8] CCEE. Regras de Comercialização - Mecanismo de Realocação de Energia. Câmara de Comercialização de Energia, 2020. Disponível em: https://www. ccee.org.br/. Acessado em novembro de 2020.

[9] BRASIL. Resolução Normativa $\mathbf{n}^{\circ} \mathbf{6 1 4} / \mathbf{2 0 1 4}$, de 3 de Junho de 2014. Agência Nacional de Energia Elétrica, 2014. Consolida as normas referentes à apuração de indisponibilidade de unidade geradora ou empreendimento de importação de energia conectados ao Sistema Interligado Nacional - SIN, estabelece novos critérios de apuração e de verificação de lastro e dá 
outras providências. Disponível em: http://www2.aneel.gov.br/cedoc/ ren2014614.pdf.

[10] ANEEL. Ofício $\mathbf{n}^{o}$ 218/2011 - SRG/ANEEL. Agência Nacional de Energia Elétrica, 2011. Assunto: Mecanismo de Redução de Energia Assegurada para a UHE Santo Antônio, Jirau e Belo Monte.

[11] SAE. Site oficial da hidrelétrica santo antônio energia. http://www.santoantonioenergia.com.br, 2020. Acessado em janeiro de 2021.

[12] NASCIMENTO, L.. Santo antônio energia questiona cobrança de $\mathbf{r} \$ \mathbf{8 1 2}$ milhões. https:// agenciabrasil.ebc.com.br/economia/noticia/2018-04/ santo-antonio-energia-questiona-cobranca-de-r-812-milhoes, 2020. Acessado em novembro de 2020.

[13] ANEEL. Leilão $\mathbf{n}^{o}$ 05/2007 - processo n. 48500.003833/2007-01. Agência Nacional de Energia Elétrica- ANEEL, SGAN Quadra 603 - Módulo J, Brasília/DF - CEP 70.830-030. 10 de dezembro de 2007., 2007.

[14] ARANTES, A. C.. Mecanismo de redução de energia assegurada e o seu impacto no planejamento e organização da engenharia de manutenção da geração. 2010.

[15] SOKEI, C. T.. Modelo de sazonalização da energia assegurada de usinas hidrelétricas utilizando algoritmos genéticos. $\mathrm{PhD}$ thesis, Universidade de São Paulo, 2008.

[16] FREITAS FILHO, Í. T. D. C.; OTHERS. Estratégia para gestão de ativos e minimização de riscos operacionais em sistema de geração hidroelétrica. 2014.

[17] SOUZA, L. B. E.. Judicialização no setor elétrico: desafios de gestão de projetos de geração hidrelétrica - estudo de caso da uhe santo antônio. 2019.

[18] ANEEL. Site oficial da agência nacional de energia elétrica. http://www.aneel.gov.br, 2020. Acessado em novembro de 2020.

[19] CCEE. Visão geral das operações na ccee. http://www.ufjf.br/ andre_marcato/files/2010/06/Visao_Geral_das_Operacoes_CCEE_ 2010 .pdf, 2010.

[20] MME. Site oficial do ministério de minas e energia. http://www.mme.gov.br, 2020. acessado em novembro de 2020. 
[21] EPE. Site oficial da empresa de pesquisa energética. http://www.epe.gov.br, 2020. Acessado em novembro de 2020.

[22] DO BRASIL, G.. Fontes de energia renováveis representam $83 \%$ da matriz elétrica brasileira. https://https://www.gov. $\mathrm{br} / \mathrm{pt}$-br/noticias/energia-minerais-e-combustiveis/2020/01/ fontes-de-energia-renovaveis-representam-83-da-matriz-eletrica-brasileira, 2020. Acessado em novembro de 2020.

[23] ANA. Site oficial da agência nacional de águas. http://www.ana.gov.br, 2020. Acessado em novembro de 2020.

[24] VIANA, H. R. G.. PCM-Planejamento e Controle da manutenção. Qualitymark Editora Ltda, 2002.

[25] CONTADOR, J. C.. Gestão de operações: a engenharia de produção a serviço da modernização da empresa. Editora Blucher, 2010.

[26] KARDEC, A.; NASCIF, J.. Manutenção-função estratégica. Qualitymark Editora Ltda, 2012.

[27] COSTA, H. G.. Auxílio multicritério à decisão: método ahp. Rio de Janeiro: Abepro, 2006.

[28] LEE, G. K.; CHAN, E. H.. The analytic hierarchy process (ahp) approach for assessment of urban renewal proposals. Social indicators research, 89(1):155-168, 2008.

[29] AYALA, N. F.; FRANK, A. G.. Métodos de análise multicriterial: uma revisão das forças e fraquezas. Semana de Engenharia de Produção Sul Americana (13.: 2013 jun. 9-11: Gramado, RS). Anais.. [recurso eletrônico]. Porto Alegre: FEEng, 2013., 2013.

[30] FROGER, A.; GENDREAU, M.; MENDOZA, J. E.; PINSON, E. ; ROUSSEAU, L.-M.. Maintenance scheduling in the electricity industry: A literature review. European Journal of Operational Research, 251(3):695-706, 2016.

[31] RODRIGUEZ, J. A.; ANJOS, M. F.; CÔTÉ, P. ; DESAULNIERS, G.. Milp formulations for generator maintenance scheduling in hydropower systems. IEEE Transactions on Power Systems, 33(6):6171-6180, 2018. 
[32] DUCHARME, C.. Modelagem e Otimização do Programa de Manutenção de Transformadores de Potência. PhD thesis, Universidade Federal do Rio de Janeiro, 2012.

[33] RODRÍGueZ, J. A.; ANJOS, M. F.; CÔTÉ, P. ; DESAULNIERS, G.. Accelerating benders decomposition for short-term hydropower maintenance scheduling. European Journal of Operational Research, 289(1):240-253, 2020.

[34] SADEGHIAN, O.; MORADZADEH, A.; MOHAMMADI-IVATLOO, B.; ABAPOUR, M. ; GARCIA MARQUEZ, F. P.. Generation units maintenance in combined heat and power integrated systems using the mixed integer quadratic programming approach. Energies, 13(11):2840, 2020.

[35] LAKSHMINARAYANAN, S.; KAUR, D.. Optimal maintenance scheduling of generator units using discrete integer cuckoo search optimization algorithm. Swarm and Evolutionary Computation, 42:8998, 2018.

[36] HELSETH, A.; FODSTAD, M. ; MO, B.. Optimal hydropower maintenance scheduling in liberalized markets. IEEE Transactions on Power Systems, 33(6):6989-6998, 2018.

[37] SARAIVA, J. T.; PEREIRA, M. L.; MENDES, V. T. ; SOUSA, J. C.. A simulated annealing based approach to solve the generator maintenance scheduling problem. Electric Power Systems Research, 81(7):1283-1291, 2011.

[38] SCHLÜNZ, E.; VAN VUUREN, J.. An investigation into the effectiveness of simulated annealing as a solution approach for the generator maintenance scheduling problem. International Journal of Electrical Power \& Energy Systems, 53:166-174, 2013.

[39] MOHANTA, D. K.; SADHU, P. K. ; CHAKRABARTI, R.. Deterministic and stochastic approach for safety and reliability optimization of captive power plant maintenance scheduling using ga/sa-based hybrid techniques: A comparison of results. Reliability Engineering \& System Safety, 92(2):187-199, 2007.

[40] FATTAHI, M.; MAHOOTCHI, M.; MOSADEGH, H. ; FALLAHI, F.. A new approach for maintenance scheduling of generating units 
in electrical power systems based on their operational hours. Computers \& Operations Research, 50:61-79, 2014.

[41] ALMAKHLAFI, A.. The Generator Maintenance Scheduling Problem: Benchmarks, Local Search and Metaheuristics. PhD thesis, The University of Manchester (United Kingdom), 2016.

[42] BEN-DAYA, M.; DUFFUAA, S. O. ; RAOUF, A.. Maintenance, modeling and optimization. Springer Science \& Business Media, 2012.

[42] SAATY, T. L.. What is the analytic hierarchy process? In: MATHEMATICAL MODELS FOR DECISION SUPPORT, p. 109-121. Springer, 1988.

[43] SAATY, T. L.; VARGAS, L. G.. Models, methods, concepts \& applications of the analytic hierarchy process, volumen 175. Springer Science \& Business Media, 2012.

[44] E SILVA, D. M. R.. Aplicação do Método AHP para Avaliação de Projetos Industriais. PhD thesis, PUC-Rio, 2007.

[45] FINARDI, E.; DA SILVA, E.. Unit commitment of single hydroelectric plant. Electric Power Systems Research, 75(2-3):116-123, 2005.

[46] OHISHI, T.; SANTOS, E.; ARCE, A.; KADOWAKI, M.; CICOGNA, M. ; SOARES, S.. Comparison of two heuristic approaches to hydro unit commitment. In: 2005 IEEE RUSSIA POWER TECH, p. 1-7. IEEE, 2005.

[47] ARCE, A.; OHISHI, T. ; SOARES, S.. Optimal dispatch of generating units of the itaipú hydroelectric plant. IEEE Transactions on power systems, 17(1):154-158, 2002. 
A

\section{Ofício $n^{o}$ 218/2011 - SRG/ANEEL}

Ofício que trata-se do esclarecimento quanto as regras de penalização das Usinas Hidrelétricas Santo Antônio Energia, Jirau e Belo Monte.

\section{Documento Cópia - SICnet}

$\boldsymbol{E} \Rightarrow$ ANEEL

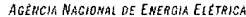

Oficio $n^{0} 218 / 2011-$ SRG/ANEEL

Brasília, 25 de agosto de 2011 .

\section{Ao Senhor}

RONALDO SCHUCK

Diretor de Operação

Operador Nacional do Sistema Elétrico - ONS

Rio de Janeiro - RJ

Assunto: Mecanismo de Redução de Energia Assegurada para a UHE Santo Antônio, Jirau e Belo Monte.

Senhor Diretor

Faz parte do edital do leilão da UHE Santo Antônio, Jirau e Belo Monte, em função do elevado número de unidades geradoras, a regra em que as manutenções programadas das unidades geradoras não serão computadas para fins do Mecanismo de Redução de Energia Assegurada - MRA quando essas manutenções ocorrerem no periodo em que as unidades geradoras não forem necessárias para o Sistema Interligado Nacional - SIN, ou seja, quando não houver vazão suficiente para operação.

2. Desta forma, essas usinas deverão informar ao ONS suas manutenções programadas que deverão ser contabilizadas, independente do período, porém não devem ser computadas para fins de cálculo do MRA quando ocorrer a situação descrita no parágrafo anterior. Para isto, na informação de indisponibilidade programada apurada que ONS encaminha à Câmara de Comercialização de Energia Elétrica - CCEE para realizar o referido cálculo, só deverão constar as indisponibilidades programadas apuradas quando a unidade geradora for necessária à operaçäo do SIN.

3. Por fim, esclarecemos que essa regra do edital não se aplica as indisponibilidades forçadas

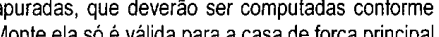

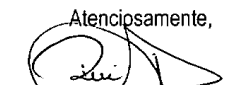

RULGUHEHERME ALTTERI SILVA

Superintendente de Regulação dos Serviços de Geração

C.c.: Ricardo Barbi Costa - Santo Antônio Energia

Victor Paranhos - Energia Sustentável do Brasi

Luiz Fernando Rufato - Norte Energia 